Special Collect. QH83 F56 


\section{区he 晒. 现. Hill}

Echai colicifibrary

$\therefore$

QH83

F56

P̈arth Caralina State

Cillegp

\section{This book must not be taken from the Library building.}

09 , Re HOZ

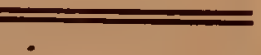


E N C H I R I D I O N

H I S T O R I A E

NATURALI

INSERVIENS,

$$
\text { Quo. }
$$

TERMINI ET DELINEATIONES

$$
\text { AVIUM, PISCIUM, }
$$

\section{AVIUM, PISCIUM,}

INSECTORUM et PLANTARUM

- ADUMBRATIONES

INTELIIGENDAS ET CONCINNANDAS,

SECUNDUNI

METHODUM SYSTEMATIS LINNAEANI CONTINENTUR,

EDITORE

IO. REINHOLDO FORSTER,

LL. MED. ET PHILOS, D. ET LL. AA. M,

In tenui labor.

VIRGII.

$H$ A L A E,

PROSTAT APUD HEMMERDE ET SCHWETSCHKE, MDCCIXIXVIII. 


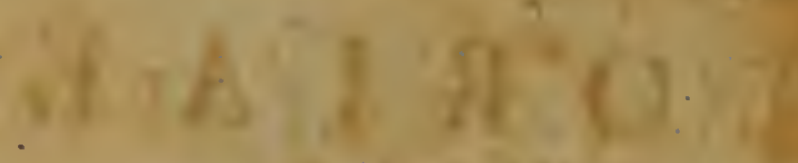
- dersy u'thr

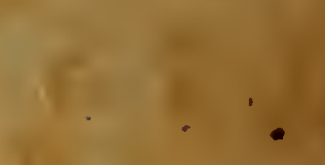

$+$

.

$\cdot$

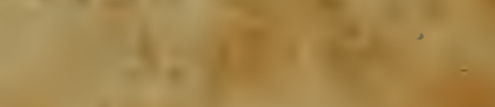

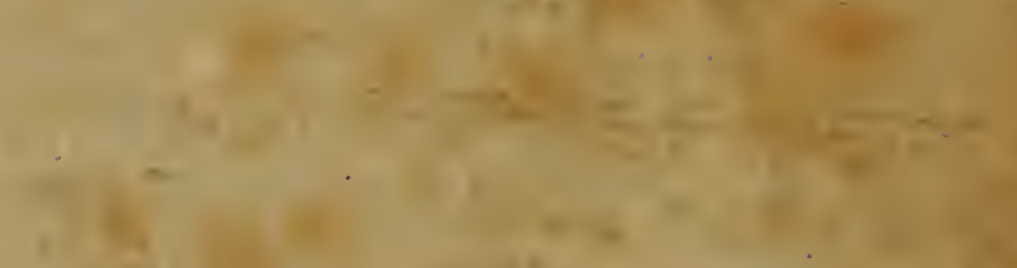

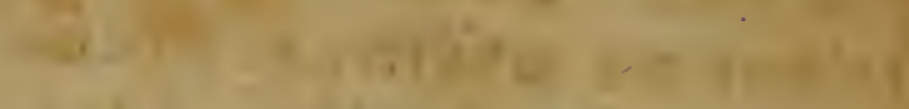

(n)

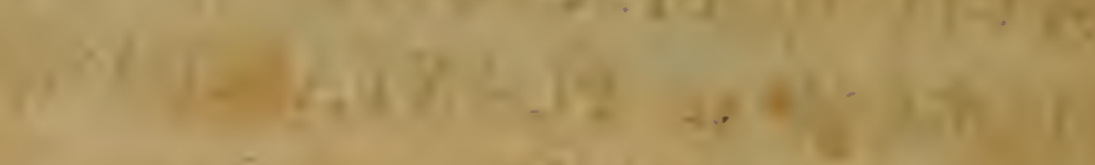

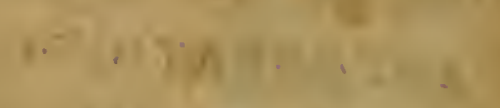

$+$

(1)

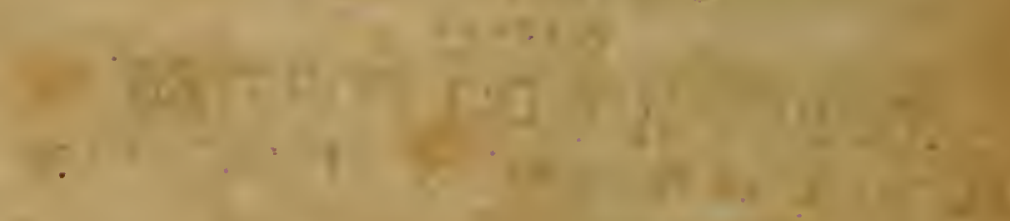

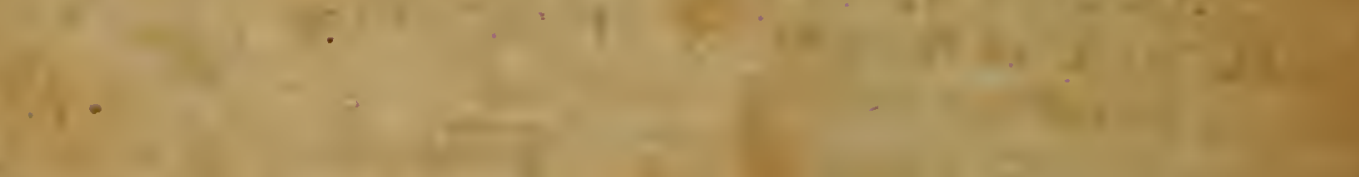

-

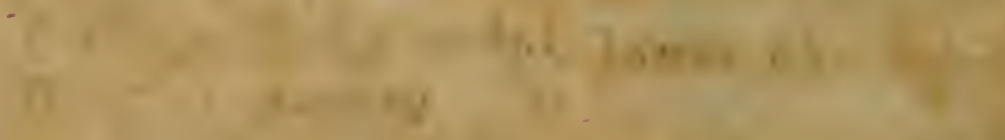

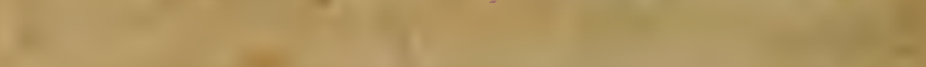

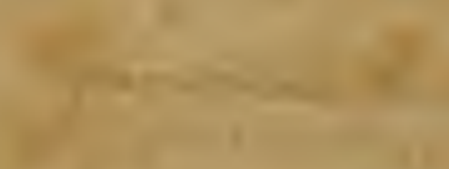

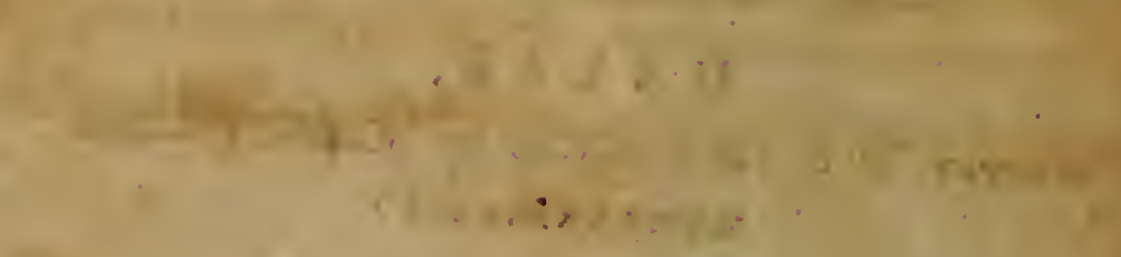

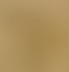


JO. REINHOLD. FORSTER

\title{
GEORGIO FORSTERO
}

\author{
DILECTISSIMO FILIO SÜO
}

XAIPEIN KAI EYIPATTEIN.

Cis quidem, dulcifime Fili, quanta cura Te a parvulo educaverim. Ego vero ea, quae fum heic dicturus, non exprobrandi caufa commemorabo; verum ut plures fciant, quantum Tu mihi, quantum et ego T IB I debeam: incidimus enim in tempora iniqua, in quibus virtus, pietas, religio in ore omnium quidem verfatur, verum vix unus et alter haec primaria vitae humanae et focietatis vincula, quae toties vulgus ore crepat, re ec faćtis exprimere curat: fimulata fpecie virtutis id plerique ftudent confequi, ut potentiam

$$
x^{2}
$$

D. H. HILL LIBRARY

North Carolina State Collega 
et nummos nancifcantur, et ut bonos viros opprimant, qui impotenti regno novorum hominum magno animo refiftunt; et prol re publica, virtutis cultu et optimarum litterarum feveriori fudio promovendis, omnes intendunt lacertos.

Poftquam vix primas voces, quae infantes difcere folent, enunciare didiciffes, illico innato impetu curiofitatis impulfus, prima naturae nos ambientis objecta noffe cupiebas; ideo nomina florum, avium, pifcium, infectorum $\mathrm{T}_{\text {I }}$ I obvia, a me curiofe exquirère, praeterea de efca animalium, de ufu rerum obviarum quaeftiunculas mihi proponere folebas; quibus tum temporis quid reponerem nefciebam. Ne igitur haec a $\mathrm{Nu}$ mine non fruftra humanis animis contributa curiofitas periret in aetatula $T \cup \Lambda$, illico pedes propinquum Gedanum petii, et emto Linnaeano Syftemate, editionis undecimae, et Ludwigii Definitionibus generum plantarum, 
rum, (qui uterque liber anno $\mathbf{7} 760$. prodiit) ingenti animi contentione, naturae ftudium fum amplexus, ne T I i r deeffem. Quascunque vicinia Gedani plantas et aves et animalia praebebat, earum nomina et naturam ex hoc Linnaei libello et aliis quos mihi paraveram et $a b$ amicis poftmodum hinc inde ad legendum corraferam, didici. Haec omnia rurfus $T_{E}$ docui fumma cura, et maximopere gaudebam, quod meis a $\mathrm{TE}_{\mathrm{E}}$ eblanditis refponfionibus indies naturae miracula magis cognita Tіві effent, quodque tantos in hiftoria naturae et reliquae eruditionis primis. rudimentis profectus feciffes.

Tandem decimo aetatis Tu $\mathrm{E}$ anno exacto, mecum iter in Roffiam fufcepifti. In hoc itinere quotidie, prout forte res novae fe offerebant, inter confabulationes fedulo TIBI naturam explicui; nec me laboris poenituit, expertus enim id fum, quod puer decennis, fine ullo auxilio, folus plantas ad

$$
x_{3} \text { Lin- }
$$


Linnaeanas defcriptiones jam probe noffes; adeo ut prae gaudio vix mihi a lacrymis temperare potuerim. Dein in Arglia, quam Anni 1766. autumno petii, linguae Anglicae familiarem ufum et elegantiam et praeterea natirae cognitionem magis certam et variam, cum mathematum et phyfices rudimentis didicifti: fimul et me juvafti in tradendis elementis linguae gallicae, et in Anglicum fermonem transfundendis operibus difcipulorum Li NNAEr, videlicet Kalmii, Osbeckii, Toreenii et Loeflingii; denique et itinera Bougainvillii, Bofjuii, Grangerii et Riedefclii junctis viribus Anglica lingua publicavimus.

His et aliis laboribus praeparatus, mecum iter cum Amico noftro Соок Iо, ad mare notium cum utilitate fufcipere poteras. In hocitinere, varia, novaque naturae miracula non folum vidimus, verum et verbis et graphio delineavimus. In plantis imprimis adumbrandis adjutore uf fuimus amico opti- 
mo Sparrmanno, cujus labores in ordinem redigere, fimul et plantas delineare T U I fuit officii : mea denique provincia erat hos labores hinc inde curatius infpicere, et pau. ciffimis in locis corrigere; animalia omnia defcribere; mores, ritus, cerimonias, cultum religiofum, vićtum, amictum, agriculturam, commercia, artes, arma, bellicum apparatum, politiam, et linguam gentium nobis obviarum curiofe inveftigare: praeterea quotidianas aëris mutationes, ventos, caloris incrementa et decrementa, et quaecunque notatu digna funt, litteris confignare. Inter otiuin navigátionis, hoc Enchiridion praeterea congeffi. Haee imprimis uno triennio funt facta. Circiter quingentae enim novae plantae, et trecenta animalia funt magna cura adumbrata. Quilibet cordatus mirabitur, tot labores $a b$ uno homine et juvene qui nondum vigefimum adtigerat annum, et unico focio laboris potuiffe perfici. Lubens igitur fateor, $T_{E}$ virili animo, in hoc flore aetatis, in quo adolefcen$x_{4}$ tes 
tes animum folent explere venatu, equitatione, ludis, comeffationibus, amore; nihil horum egiffe; verum me ftrenue adjuviffe in fuftentanda familia et educanda numerofa fobole, et poithabitis commodis TuIs, meas res TI I I cordi effe re et factis comprobaffe.

Has virtutes, hanc pietatem fingularem, Numinis fummi provida cura remunerandam duxit. Sunt TI I honores parti, quos vix in fera aetate, curriculo litterario pene decurfo, Viri in litteris primarii parare fibi quivere. Exiftimatione et fama uteris profperrima, quod non ultimum beneficium eft, in his iniquiflimis temporibus, in quibus vera eruditio vilior alga aeftimatur: nec deeft fpes et rem familiarem TUA M talem brevi fore, cujus. $T$ \& non poeniteat. Videbunt nunc aequi Judices, quantum $T u$ mihi, quantum et ego T IB I debeam: noftrumque mutuum amorem et pietatem ex praecordiis ipfis profectas.

Quum. 
Quum jam id quod animo propofueram publice heic dixerim, ad eas rationes me converto, quae me impulerunt ut $\mathrm{T}_{\text {I }}$ в I praefertim hocce infcriberem Enchiridion. Scis equidem, cariffime Fili, quod jam ante plures annos $\mathrm{T}_{\text {IB I }}$ propofueris, ejusmodi opellam Mammalium et alias Amphibiorum, Termium, imprimis Teftaceorum, denique Lapidum et Metallorum infervituras ftudio promovendo elaborare: et quum $\mathbf{T}_{\mathbf{E}}$ de propofito publicandi hoc Enchiridion certiorem feciffem, $T_{E}$ denuo mihi voluntatem TU А M declaraffe, de elaborandis iis, quae ad fupplendum hoc Enchiridion univerfae Hiftoriae naturalis reliqua funt. Quo igitur magis $\mathrm{T}_{\mathrm{E}}$ ad praeftandam haric operam inpellerem, TIB I hunc meum libellum, quem bene nofti et cujus utilitatem ipfe ante plures annos expertus es, volens lubensque trado. Nec amplius $T_{E}$ moror, quum jam nimis longae hae fint litterae; probe enim nofti, quanto $T_{E}$ amore fim amplexus a par- 
fugaces, in mortuo fpecimine evanefcerent. Ad has difficultates acceldebat, quod nos ipfi, cibis feilicet minime vel parum nutrientibus per menfes aliquot in nave comeftis, minus validi effernus, et vires nos penitus deficerent. Adeo ut dum in terram efcenderemus, urgente nos mentis ardore, quam longiffmis excurfionibus infulas terrasque perveftigare cuperemus; tamen vires corporis primo impetu exhauftáe, recufarent animi vigorem fequi; nos itaque per avia et devia fub fole fervido errantes, cibo parco, vel nullo fublevati, et potu aquae-quogue non raro deficiente, coacti fuinnus umbram quaerere arbufculae vel tugurii, ut laffa membra humi ftrata reficeremus quiete. Verum nec tunc quidem quietem capere nobis licebat: obfepti enim eramus magno coetu incolarum, gentis avidae et ad furanda arma noftra et quaecunque e ferro facta funt intentiffimae: homines maxime agiles, vaferrimi, curiofi, irrequieti ubique nos circumdabant; amicitiam et bona officia prae fe ferebant et ideo maxima cum familiaritate fe noftro circulo immifcebant. Ego cum filio et amiciffimo Sparmanno, unico famulo et vix uno alterove milite vel nauta ftipatus, a centenis faepe hominibus cincti eramus, quorum fermonem vel proríus ignorabamus, vel hinc inde vix fingula vocabula linguae eorum in tabellas pugillares notata nofcebamus. Ipfi incolae curiofe ufum cultelli, vel pugillarium et calami fcriptorii, atramenti, vel graphii molybdaena vel plum; bagine farcti mirabantur;; et id imprimis blanditisis et officiis minutis obtinere ftudebant, ut minus attenti ad eorum artes effemus, et aditus ad marfupia noftra manibus furacibus paterent.

Verum enimvero, non folum linguam harum gentium addifcere, fed quogue ritus, cerimonias, cultumque religiofum, mythos et traditiones, quin et mores, viktum, amictum, arma, commercia, agrieulturam omnemque vitae privatae publicaeque ra- 
tionem explorare et inveftigare mihi in mandatis erat. His ommibus negotiis multum temporis erat infumendun; et poltquam a primo mane in feram usque nokem, magnam partem infulae perreptaffemus, collectis undique plantis, avibus, pifcibus, conchyliis et lithophytis, tandem his onufti in navem reduces facti, vix cibo fumto corpus curare potera. mus, nec raro in multam noctem maxime neceffaria momenta raptim in chartam conjicere folebamus; ne ea, quae tum recenti memoria tenebamus, quae. que comperta habebamus, inter tot novas res, quae mentes agitabant, rurfus memoria exciderent. Verum tum etram ea imprimis feligere, quae maxime neceffaria in defcribendis plantis vel animalibus effent, nuaxime ingratum erat negotium; membra enim excarfione difficilluna laffata, animus ipfe labore hebetatus, vires prorfus exhauftae fomnum defideratiffmum expetebant. Saepius itaque id egi, ut oculos, quibus jam obrepere folebat fomnus, aqua frigida eluerem, vel faciem imo et totum corpus aqua marina in dolium infufa lavarem, et fic demum lotus, novisque quafi viribus hauftis refectus ad, laborem in multam noetcm continuandum accederem, et ea in libellos digererem, quae in pofterum diem differri non poterant. Ut igitur raptim notatu digna defcribere poffem, id confilium cepi, data occafione, quum primum per otium liceret, typun vel normam quandam ad delineandas aves, pifces, infecta et plantas: in chartam conjicere; unde, fi haererem circa verbum, quo exprimerem figuram vel partem qualitatenuve plantae vel animalis, fine temporis jactura in mentem revocarem, quae vires exhauftae animi faepius fubminiftrare recufabant.

Id conflium quogue executus fum, poftquam Nova Zeelandia relicta Anni cIolocclxxiri. menfibus Julio et Augufto mare Auftrale inter N. Zeelandiam et Infulas Societatis trajiceremus; quibus vocabula 
Adumbrationibus Avium, Pifcium et Plantarum infervitura collegi e magni Equitis a LIN NE fcriptis; et ad eam rationem difpofui, , ut uno veluti obtutu poffem difcernere ea, quae in animali plantave defcribenda primaria funt, fiınul et vocabula in adumbrationibus ab Equite a LINNE, ejusque dif́cipulis ad: hibita illico ad manus, neque diu quaerenda effent; praeterea et addiderañ, quo fenfu unumquodque vocabulum in hisce adumbrationibus adhiberi folet; ne in futurum id imprimis moram faceret iis, qui in hoc ftudio nondun fatis verfati funt. Menfe quoque Martio Anni MDCCLXXIV. terminos et normarn adumbrationis pro Infectis congeff.

His igitur deinde fum ufus auxiliis in defcribendis.animalibus et plantis ad normam artis. 'Simul et expertus fum, quantum compendium laboris et temporis haecce opufcula mihi fubminiftraverint imprimis in adumbratione animalium. Hinc quum hasce opellas in Europam redux non raro lamicis, difcipulis et aliis monftraffem, plures me orarunt, ut eas pu. blici facerem iuris; quia earum ope ftudium hiftoriae naturalis magnopere fperabant promoveri poffe. Itaque dum et Vir honeftus Bibliopola idem fentiret, non haefitavi utilitati publicae infervire et hasce opellas prelo fubjicere. Haec igitur de origine et occafione edendi libelli praefari volui, ut Leetores aequi inde dijudicare poffent, hujusce opellae utilitatem ad faciliorem ftudii naturae viam pandendam experientia utique comprobatam effe.

Praevideo praeterea fore quosdam, quibus omné hoc genus fcribendi minus arriferit; fcilicet quod barbara vocabula contineat, yel etiam quod latino fermone fit publicata noftra feriptiuncula. Illis id tantum reponam, magni LINNAEI fcripta a tyronibus vel fine hujusmodi enchiridio, vel viva voce magiftri intelligi non poffe. Magnum autem hunc virum, utique magna cura id praeftare ftuduiffe; ut quam pau- 
ciffmis verbis charąteres rerum naturalium exprimeret, ideoque vocabulis ufum fuiffe, quibus femper conftanterque eundem fenfum tribuere folitus erat. Latino vero ufus eft fermone, ut ab omni Europa intelligeretur; praeterea hisce vocabulis connexis non caftae, pulcrae, elegantisque Latinitatis fpecimina dare fibi propofuerat, verum id iatis habuit, dummodo brevis effet et $a b$ omnibus intelligeretur. Jlli igitur, qui inmortalis Viri veftigiis infiftunt, utique dum fcientiae pomoeria proferre cupiunt, ad id attendere neceffarinm habebunt, 'ut eadem methodo, iisdemque vocabulis adhibitis eum quantum fieri licet, fequantur. Et quum in hac eruditionis parte, quotidie nova in lucem pro. ferantur, quae Romanis nunquam videre contigerat, quaeque ne auditione quidem comperta habuerant; utique de novis rebus nova vocabula funt adhibenda, quorum magna pars apud bońos Latinitatis auctores nunquam reperiri potuit, quaeque neceffario aliena et peregrina i. e. barbara effe debet. Aequi Judices, facile jam ex is argumentis, quae haçtenus protuli, magno immortalique Viro, CAROLO A LINNE patri, optime de hiftoria naturali merito, ejus difcipulis et aliis praețerea praecellentibus Viris, qui in ftudio hiftoriae naturalis veftigia ejus fequuntur, denique et mihi id condonabunt, quod minus bene Latinis vocabulis in adumbrationibus hiftoriae naturalis uti, neceffum habuerimus.

Iis qui Latini fermonis ufum in hac feriptiuncula improbant, quibus nil placet, quam-id, quod patrio fermone eft fcriptum; quia forte, fi Diis placet, Mufas latinas nec a limine quidem falutarunt; vel quod male acti temporis in Scholis fiti confcii, nunc excufationem defidiae et ignaviae fuae id effe credunt, fi omnia quac graeco, latinove fermone fcripta funt, an gue pefteve magis fugiant et averfentur: iis accura tius quidquam reponere, vix operae pretium effe duco. Magni et immortalis LIN NAEI fcripta, ab eo confulto 
et ob brevitatem in tanto opere necefiariam, et quod in commodum totius litterati orbis fcribere vellet, latino fermone funt concepta ; endem et ego ea quae patris hiftoriae naturalis operibus addenda cenfui, confcripfi: ideoque et hasce opellas, quae ad opera Linnaei et ciifcipulorum melius faciliusve intelligenda plurimum faciunt, latinis verbis concinnare debui. - Si igitur hi, quibus haec latina enchiridia difplicent, vel parum patientiae reliquuin babuerint: paucis menfibus elapfis, patrio fermone haec enchiridia videbunt proditura: pertinax enim noftri aevi cacoëthes, omnia latino vel alio quocunque fermone concinnata fcripta in patriann transfundendi linguam, fieri non finet, quo minus in haec enchiridia temere quoque manus injiciant $\mathrm{ii}$, qui in ergaftulis bibliopolarum defubant.

Monebunt forte alii, Cel. Farлicium jam dediffe philofophiam entomologicam, ideoque hoc opere hanc noftram opellam, quae de Infectis agit, minus effe redditain neceffariam. Verum ii qui rem curatius infpexerint, facile intelligent, Fabricium relicta methodo et fyftemate Magni Lr N N E r novam fibi viam aperuiffe, ideoque ejus opufculum minus illis infervire poffe, qui folum LINNAEU M fibi ducem eligunt; his itaque mea opella proderit. Amicus meus fummus Fa в R Icrus, idem mecum fentiet, et ut Viros bonos et vere litteratos, liberalibusque enutritos artibus decet, lectoribus permittet de utilitate commodisque noftrorum librorum judicare, qui utique nil commune vel alterutri derogaturum continent, verum uterque in publican utilitatem funt compofiti. Valete B. L. et ut coepiftis, conatus meos publicae utilitati inferviendi, aequis excipite mentibus. Dabam'Halac ad Salam d. XV. Febr MDCCLXXXVIII. 


\title{
FUNDA MENTA
}

Ex

\author{
T E R M I N I
}

\section{OR N I T HOLO G IAE}

SECUNDUM METHODUM

ET AD DUCTUM

CELEBERIMI EQUITIS

CAROLI A LIN NÉ. 
1

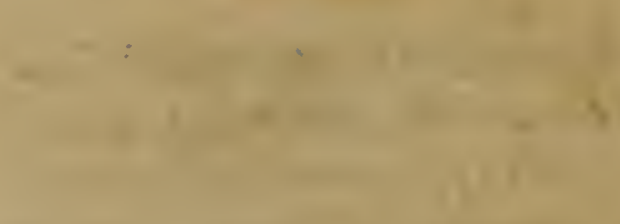

$$
\text { - }
$$

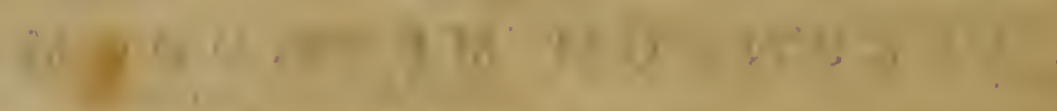

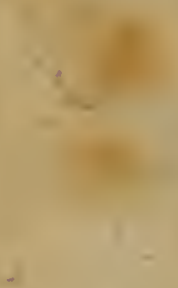

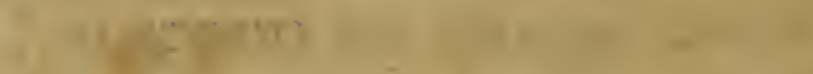

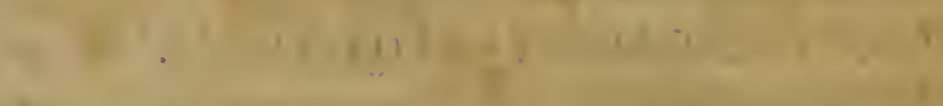

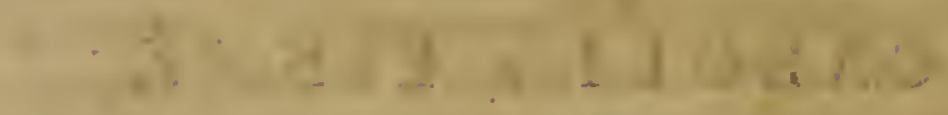

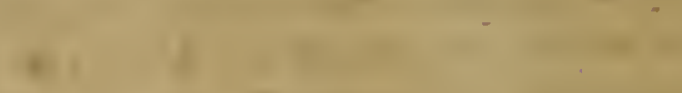
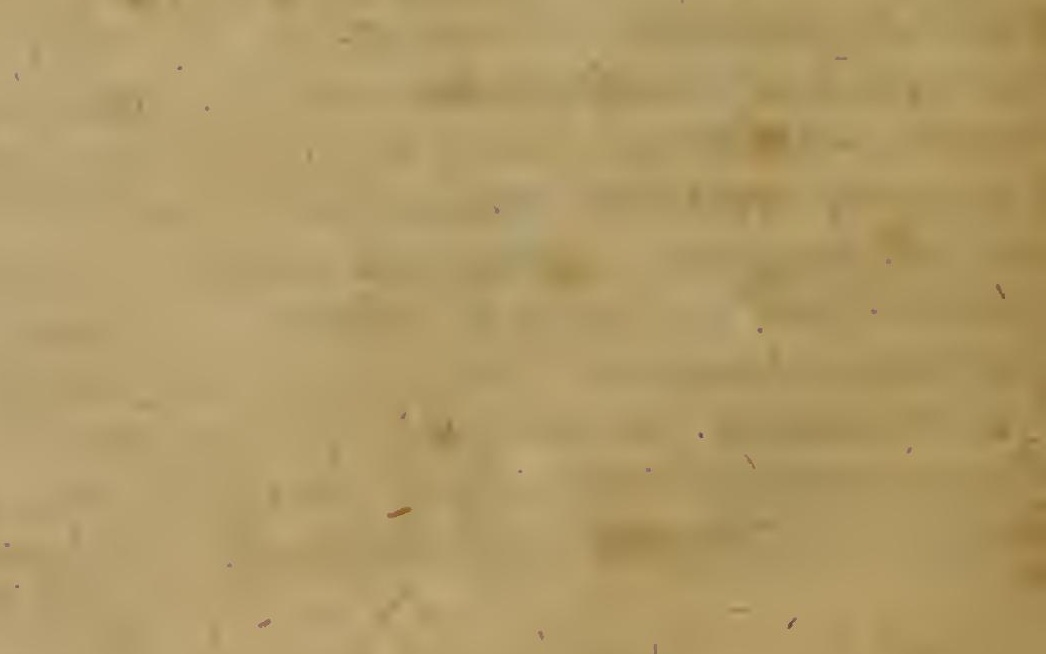


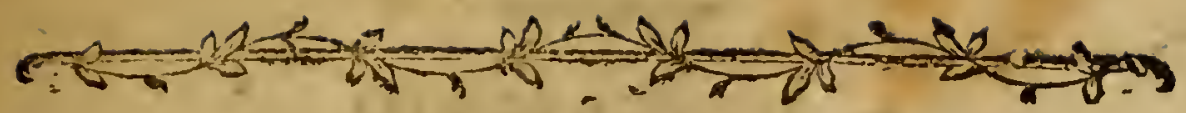

\section{T E R M I N I}

\section{O R N I T H O L O G I C I.}

\section{SECUNDUM METHODUM}

\author{
CELEBERRIMIEQUITIS
}
C A R O L I A L I N N E.

\section{DELINEATIO AVIS.}

\section{THEORIA.}

\section{A. GENUS, Nomen felectifimum.}

Churacion naturalis et effentinlis ǵenericus a partibus denusatis tantum decerpendus.

Clafis, ordoque Jyftematis praeftantifimi.

Orcio naturaiis demongtrandus, ut at connexio generum.

B. SPECIES, Nomen triviale.

Differentia fpecifica demonftranda; certifima, brevifima, imprimis a remizibus et reciricibus.

Synongrna cun Defcriptione, feu Figura felecta.

C. CRITICA, Etymologia nominis generici, feeciffict.

Inventor cum tempore.

Eruditio Hiftorica, Critica, Antiqua. 


\section{DESCRIPTIO.}

In ave confiderandae, examinandae, defcribentae

A. PARTES EXTERNAE corporis, fine fectione videndae.

I. NUDAE, implumes, membrana fola tectae, vel cornea fubftantia factae.

2. ROSTRUM, pars corporis nuda, cornea, elongata, os rictu recludens, linguam includens, naribus perforata.

a. DIREC IIONE

I. Rectum, fine flexura. Rectirsculum, fere rectum.

2. Porrectum, a capite rects protenfum.

3. Arcuatum, in arcum flexum. Subarcuatum, parum arcuatum.

4. Curvatum, apice flexum.

5. Incurvum, introrfum flexum.

6. Recurvatum, furfum fiextim, ut arcus fuperiora fpętet.

7. Adfcendens, arcuatim furfum flexus. Subadfcendens, fenfim adfcendens.

8. Infractum, vi quafi flexum. Infracto - curvatum, vi quafi extrorfum flexum.

b. FIGURA

9. Teres, angulis deftitutum.

Teretiulculum, fere angulis deftitutum.

10. Cylindricum, forma cylindri. Semicylindricum, hine planum, inde cylindricuin.

11. Filiforme, tenue, aequabili ubique craflitie.

12. Angulatum, pluribus quam duobus angulis cavis longitudinalibus excavatum. 
I 3. Polyedrum, pluribus lateribus planis.

1 4. Triquetrum, lateribus 3 exacte planis.

I 5. Trigonum, angulis 3 prominentibus longitudinalibus.

16. Subquadrangulare, angulis 4 prominentibus obfoletis longitudinalibus.

17. Conicum, teres in acumen definens.

I 8. Cultratum, dorfo rotundato craffo, fubtus fubcarinatum.

c. MAKG I N E

19. Integrum, margine mandibulae vix unquam fecto.

20. Integerrimum, margine lineari, nec minimum fecto.

2r. Serratum, margine omnibus incifuris refpicientibus apicem.

22. Extrorfum ferratum, ferraturis ita incifis, ut non fint acutae, fed obtufae antrorfum apicem verfus.

23. Dentatuin, margine mandibulse acuminibus patentibus remotis.

24. Denticulatum, dentatum dentibus minutis.

Dente utrimque, margine utriusque mandibulae acumine utrimque.

25. Lamellofo - dentatum, margine mandibulae lamellis patentibus remotis inftructo.

26. Edentulum, dentibus deftitutum.

27. Emarginatum, mandibulae margine verfus apicem utrimque fectione fexuofa.

28. Obfolete emarginatum, fectione flexu vix a linea recta deviante.

Emarginatum utrimque, utraque mandibu. la margine utroque emarginato.

d. APICE

29. Obtufum, terminatum intra fegmentum circuli. 
30. Obtufufculum, magis ad acutum accedens.

3r. Acutum, terminatum angulo acuto.

32. Acutifs:mum, terminatum angulo maxime acuto.

33. Acuminatum, terminatum spice fubulato (73). 34. Aduncum, in uncum incurvum flexum.

35. Truncatum, terminatum linea transverfali.

36. Defcendens, arcuatim deorfum verfus.

37. Deflexum, in arcun deorfum declinatum.

38. Declive; fenfun defcendens.

39. Cuneatum, fenfim verfus apicem" lateribus anguitatum.

40. Tabulatum, duobus femicylindris tubulum formante.

41. Unguiculatum, lobo inftar unguis in apice roftri.

42. Dilatatum, apice latiore quam bafi.

43. Orbiculatum, parte dilatata, peripheria circinaza.

44. Planum, fuperficie aequali.

45. Mandibulis acqualibus, utraque aequalis longitudinis.

46. Mandibula Juperiore longiore, fuperante longitudinem inferioris.

47. Mandibula inferiore longiore, fuperante longitudinem fuperioris.

48. Flexile, flexionis patiens.

49. Apicis laterius dilatutis, membrana faccida nigra.

2. BASI

50. Cera infruetum, membrana (faepe colo.

. rata) tectum.

5I. Nudum, oppofitum Nr. 50.

52. Crafjum, non aequalis craffitiei cum reliqua parte roftsi. 
53. Depreffum, roftrum diametro horizontali transverfo mandibularum ad bafin majore, quam utriusque perpendiculari.

54. Frontis bafi rotundata verfus capurt, fegmento femicirculari verfus frontem.

55. Tuberculatum, cesa in tuberculum gibbum excrefcente.

$f$. SU PERFICIE

56. Epidernicie tectum, fubftantia cornea invo. luta membrana.

57. Denudatum, faciem nudam, conftituente membrana ejus fupra faciem extenfa.

58. Sulcatum lineis profundis excavatum.

59. Sulcatum transverfim, ad perpendicnlum excavatis fulcis.

60. - - longitudinaliter, fulcis a bafi vel naribus verfus apicem directis.

6I. - - oblique antrorfum, fulcis a dorfo roitri, circa bafin verfus maroinem mandibulae in apice linea a perpendiculari deviante diretis.

62. - - oblique retrorflum, fulcis obliquis a dorfo roftri circa apicem, in marginem mandibulae circa faucem, dire?tis.

63. Candiculatum, fupra fulco profundo longi. tudinaliter excavatum.

64. Coarctatum rugis trensureris, medio diametro anguffiore quam ante et poft.

g. EXPANSIONE ET SUESTANTIA

65. Planum, fuperficie aequali.

66. Planiulfullim, feré planum.

67. Convexum, dorfo elevato, marginibus deprefiss.

68. Depreffum, diametro horizontali transverfo latiore, quam perpendiculari. 
69. Depreffiuf culeun, àcprefio proximum.

70. Carinatum, dorfo longitudinaliter acute prominente.'

71. Gibbum, utraque fuperficie latersli roftri convexa.

72. Dorfo attenuatum, dorfo epicem verfus anguftiore.

73. Subulatum, ad bafin lineare, verfus apicem anguftatum.

74. Inare, fubftantia cellulofa levi farctum, tenui integumento corneo involutum.

75. Comaprefsum lateraliter, diametro horizontali, transverfo minore, quam perpendiculari.

76. Subcompreffum, ad compreffum accedens.

7\%. Mandibula fuperiore cymbae refupinatae for$m a$, dorfo carinato apice incurvo.

78. Mandibula fuperiore vaginante inferiorem, inferiore inclufa intra fuperiorem at fimul efficiant tubum cylindricum.

79. Mandibula faperiore fornicata fupra inferiorem, inferiore inclufa intra fuperiorem, ut fornicem fuperior repraefentet.

80. Nandibula marginibus patentiufculis, mandi( bula fuperiore ad angulum acutum ultra in: feriorem prominente.

81. Mandibula inferiore margine laterali inflexa, introrfum verfus os arcuata. Loxia.

82. Mandibula inforior lateribus inflexo - coarctata, introrfum arcuata et marginibus angufiata.

F. MENSURA

83. Capite longins, excedens caput longitudine.

84. - brevius, non aequans caput longitudine.

85. Longitudine capitis, aeqqusns (non excedens) caput longitudine. 
86. Longum, capite longius.

87. Breve, capite brevius.

88. Longifimum, aliquoties capite longius.

89. Brevifinnum, aliquoties capite brevius.

90. Maximum, latitudine et profunditate capitis longifimum.

9г. Magnum, latitudine et profunditate capitis longum.

92. Craflum, latitudine horizontali capitis.

93. Tenue, capitis latitudinem horizontalem non aequans.

b. 94. CERA, membrana (faepe colorata) bafin roftri tegens.

95. Papillofa, punctis carnofis elevatis afperfa.

96. Carunculata, tuberculis et rugis carnofis tecta.

97. Furfuracen, veftita fquamulis albis deciduis.

98. Tuberculata f. gibba, in tuberculum gibbun excref́cente.

99. Nuda, oppofita Nr. $95-97$.

c. 100. NARES, Aperturae factae in parte fuperiore ad bafin roftri, infervientes refpirationi et ducentes ad nervos olfactorios.

a. FIGURA

101. Ovatae, diametro longitudinali fuperante transverfalem, bafi fegmento circuli circumfriptae apice anguftiore.

102. Obovatac, ovatae ita ut pars anguftior bafin refpiciat roftri.

103. Subrotusidae, figura orbiculatae proxima.

I04. Orbicsulatae, peripheria circinata.

105. Oblongae, diametro longitudinali aliquoties fuperante transverfalem.

106. Lineares, aequali ubique latitudine.
A 5
b. STRU- 


\section{b. STRUCTURA}

107. Concawae, intra fcrobiculum feu foveolam roftri fitae.

108. Marginatae, margine prominulo cinetae.

109. Membranula semitectae, membranis fornicatis, convexis dorfo roftri fupra nares ad mediun teetis.

110. Patulae, prorfus apertae, fine fquama aut alio operimento.

11 I. Prominulae, fupra planum feu fúperficiem roftri elevatae.

112. Pervide, utroque foramine in aiterum communicante.

II 3. Septo diftinctae, membranula nares utraseque feparante.

114. Septo lineari fomidivifae, fepto linesri apice clavato in medium cujuslibet naris procurrente (ut in Falconibus quibusdam).

115. Conicae, tubulo conico roftro utrimque inferto.

16. Cylindricae, tubulo cylindrico, fupra bafin roftri decumbente, truncáto.

II 7. Pennis fetaceis recumbentibus teč́ae, coopertae pennulis apice letaceis, quarum bafes in fronte, apices in roftro recumbunt.

Ir S. Vibrififis, pilis rigidis recumbentibus celatae.

1 i9. Denudatae, nec pennis, nec vibrifis tectae.

120. Nudae, nec concavae, nec prominulae.

c. SITU

121. Ln bafi roftri, jaxta ip Fam infertionem roftri in caput.

122. Intra ceram, in parte roftri cera tecta.

123. Pone roflum, in fronte, pone infertionem roftri in caput.

124. In meäio rofri, in medio inter spicem et balin. 
125. Submediae, ante medium roftri fitae. 126. Superae, in dorfo roftri fitac.

1 27. Laterales, lateri roftri infertae.

128. Paralielae, lineares, dorfo roftri parallelae.

129. Obliquae, alia directione, quam dorfum roftri fitae.

130. Rima obliterata, vix confuicua in fulco roftri.

d. I 3 I. LIN GUA, organon inferviens cibationi et guftui in avibus, roftro inclufum.

a. STRUCTURA

132. Carnofa, ex fubftantia mufculari confiftens.

133. Cartilaginea, fubftantia cartilaginis (mar-

$$
\text { gine fubojfeo): }
$$

34. Teres, fere cylindrica.

135. Lumbriciformis, teres, flexilis.

136. Filiformis, aequabili ubique crafitie.

137. Tubulofa, filis duobus fenicylindricis coalitis.

13\%. Triquetra, lateribus tribus planis.

139. Plana, fuperficie aequali.

b. MASGINE

₹ 40. Intcgra, margine vix unquam feeto.

141. Integerrina, margine lineari, nec minimum feeto.

142. Lacera, margine varie divifa, fegmentis difformibus.

143. Ciliata, margine fetis parallelis longitudinaliter digentis.

c. A P ICE

144. Obtuff, intra fegmentutn circuli terminata.

145. Emarginata, terminata crena.

146. Trilkcats, terminata linea transverfali.

147. Acrita, terminata angulo acuto. 
I 48. Acutiufcula; terminata angulo acuto proximo.

149. Mucronata, terminata mucrone exftante.

150. Setis terminata, pilis rigidiufculis.

51. Penicilliformis, fetis in fafciculum colle tis terminata.

152. Apice laciniata, varie et indeterminate in partes fecta.

I 53. Apice pennacea, fetis parallelis oppofitis ob: liquis antrorfum.

I 54. Apice retrorfum aculeata Jetis.

155. Sagittata, triangularis, angulis potticis acutis, finu divifis.

I56. Bifida, divifa finu unico lineari, margine recto.

d. SUPERFICIE

I 57. Papilloja, teeta villis carnofis.

58. Nervofa, vafe fimplici a bafi ad apicem.

I59. Nuda, nec nervola nec papillora.

c. MEN SURA

160. Brevifima, aliquoties non attingéns longitudinem roltri.

161. Brevis, nondum longitudinem roftri ad. tingens.

162. Longitudine roftri, S. mediocris.

I63. Longa, fuperans longitudinem roftri.

764. Longiffima, aliquoties fuperans longitudi-

nem roftri.

165. Lata, diametro rofti.

166. Nulla, non difcernibilis.

c. 167. FRONS, ea pars capitis quae eft contigua roltio fupra.

a. NUDA, fine ullis pennis.

168. Offeo - gibbofa, ofre fuperficic convexa inftrueta. 
169. Carmofo - gibbofa, caruncula fuperficie convexa.

170. Calua, pennis deftituta, membrana adpreffa tecta, faepe colorata.

17 I. Cartunculata, tecta membrana fpongiof elevata.

172. Globofa, caruncula ab omni parte rotunda.

173. Criftata, caruncula longitudinali compreffa.

174. Cormuta, Spina cornea elongata.

b. VESTITA

Pilis et Pennis, fed haec ad partes veftitas fpeEtant, ideoque poftea pertractanda.

f. 175. FACIES, eft pars capitis comprehendens re. gionem oculorum cum genis et temporibus. (Saepe et Frons cum vertice inclufa.)

I 76. Genae, regio inter oculos et gulam.

177. Tempora, regio inter oculos et aures.

178. Facies nuda, pennis deftituta, membrana faepe colorata, tecta.

179. Papillofa, punctis carnofis elevatis afperfa.

g. 180. PALEARIA, funt carunculae geminae ad latera maxillae inferioris, verfus gulam.

h. I8I. CARUNCUI.A, eft excrefcentia carnofa, nuda, mollis, caput ornans, ejusque partes videl. Frontem, Verticem, nucham, Supercilia, Gulam, Jugulum.

182. Compre $\int \mathfrak{a}$, eft lateribus complanatis.

183. Retractilis, quae relaxata fit elongata pen dula, alias brevis, erecta, laxa.

184. Laxa, libere flexibilis.

185. Spongiofa, tubftantia molli papillofo-cellulofa. .

186. Bipartita, ad bafin fere divifa in 2 partes.

187. Laciniata, varie et indeterminate in partes fectr. 
i. 188. o C ULI, funt organa fubfervientia vifui.

a. 189. PALPEBRAE, funt inembranae mobiles externae, pro occludendis oculis.

b. 190. MEMBRANA nictitans, eft interior pro detềigendis oculis.

c. I 91 ORBITA, eft regio circum oculos, faepe colorata,

192. Nuda, pennis deftituta, membranaque tềa.

193. Elevata, non horizontaiis cum oculis et facie.

194. Rugofa, rugis confita:

195. Papillofa, punetis carnofis elevatis afperfa.

d. 196. SU'P ECILI I bram a caeteris diftineta.

197. Carunculatum, teêtum excrefcentia carnofa nuda, molli.

198. Papillofum, punctis, carnofis elevatis afperfum.

e. 199. IR I $S$, eft circulus coloratus cingens pupillam.

f. 200. P UPILLA, eft apertura oculi pro admit. tendis radiis, in retina excipiendis.

201. Orbiculata, peripheria circinata.

202. 'Perpendicularis oblonga, utrimque acuta, dilatabilis.

k. 203. LORUM, eft linea nuda inter canthum oculi anteriorem et roftrum:

1. 204. GALEA, eft tuberculum callofun, fubetantia cornea tectum, pilcum capitis occupans.

m. 205. PEDES, funt geminae pa:tes corporis nudae, quibus aves moventur et infiftunt.

Componuntur Femoribus, Tibiis, Digitis et Unguibiss. Differunt ftt tiêtura.

a. Pe. 
a. Pedes femoribus extra corpus prominent.

2. FEMORA.

206. Semiruta, inferne fupra genua denudata. 207. Armilla, annulus coloratus partis nudae femoris fupra genus,

b. TIBIAE.

208. Teretes, fere cylindricac.

209: Comprefjae, literibus complanatis.

21 C. Carinatae, linea longitudinali prominula acutac.

2 I . Nudae, pennis et omni veftitu deftitutae; 212. Tectae, villis, plumis rel pennis veftitae, 2I3. Calcaratae, calcari parte poftica tibiae.

214 . Bicalcaratai, calcari gemino in utraque tibis.

c. DIGITI, diftinguunt aves, pedibus.

PEDES.

I. 215. Fijipedes aves, digitis omnibus di. ftinctis.

216. Curforii, digito pontico deficiente. (tridactyli, didaćtyli.).

21 7. Ambulatorii, digitis tribus anticis diftinctis, uno poftico, (tetradactyli.)

218. Grefforii, digitis tribus anticis, quorum duo absque membrana coaliti, uno poftico.

219. Seanforit, digitis duobus anticis, duo. bus ponticis.

220. Natatorii, digitis omnibus, anticis membrana integra connexis. (te. tradactyli, trida(tyli.)

221. Semipalinati, digitis anticis membra. na bafi tantum connexis.

222. Lobati, digitis nuembrana connexis, fed fita more digitorum. 


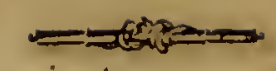

223. Pinnati, ubi digitorum utrinque fin. guli articuli membrana, tanquam lobo laterali, funt inttrueti.

224. Compedes, pedibus intra abdominis tegmen reconditis.

225. Aequiliorres, pedes natatorii, extra corporis tergmen exferti.

\section{PEDES}

II. 226. Longifimi, trunco multo longiores.

227. Brevifimi, trunco aliquoties breviores.

228. Longi, truncum longitudine fuperantes.

229. Breves, truncum nondum aeģuantes.

230. Mediocres, longitudine trunci.

23 I, Hirfuti, tecti pennis pilorum inftar, in digitis quoque.

232. Lanati, induti pennis pilofis fponte curvatis usque ad digitos.

233. Semilanati, lanati ultra/genua, fed non ad digitos.

234. Hirfuto - pennati, teeti pennis communibus, non pilofis.

235. Pectinati, pectinibus cartilagineis in latere utroque digitoruin.

D I G I T I

236. Longifimi, Tibiis aliquoties longiores.

237. Brevifimi, Tibiis aliquoties breviores.

238. Mediocres, longitudine Tibiarum.

239. Longi, Tibias longitudine fuperantes.

240. Breves, Tibias nondum aequantes.

24I. Antici, antrorfun exferti.

242. Poftici, retrorfum expanfi.

243. Validi, tibiis non multo tenuiores.

244. Intermedius, in tridactylis, vel anticis tridactylis, medium occupans locum.

245. Exterior, qui in utroque pede extrorfum clt verfus. 
246. Interior, introrfuin verfus.

247. Marginato exteriore, In quibusảam pa!matis, digitus exterior iatere exceriore membrana longitudinali eft außus.

248. Phalanges, funt articuli digitorum. In plerisque anticis 4 . in quibusdam numerus phalangum varist. In Diomedea digitus interior eft phalangibus 5 , medius 4 .. et exterior 3 .

249. Plantae, pars inferior digitorum. 250. Callus, tuberculata pars poftica plantae. 25 r. Mutici, digiti unguibus deftituti.

d. 252. UN GU Es, proceffus cartilagineo -iofleus in apicibus ultimae phalangis digitorum.

253. Adunci, apice in uncum incurvum flexi. 254. Incuvi, introrfum flexi.

255. Recti, fine flexura.

256. Rectinfculi, ad reetum proximi.

257. Comprefji, dianetro laterali breviore perpendiculari.

258. Semilylindrici, intus concavi, extra convexi, tubuioli.

259. Oblongi, diametro longitudinali aliquo. ties fuperante transverfalem.

260. Obtr:fi, apice intra fegmentum circuli.

261. Acuti, terminati angulo acuto.

262. Subulati, ad bafin lineares, verfus apicem attenuati.

263. Marginati, extrorfum margine infruati. 264. Crenati, margine alterutro crenis inftućto. (margo interior Pclecanis, exterior Ardeis.)

n. 265. SPINAE, funt arma, quibus aves dimicant prater roftrum, calcaria et ungues. 


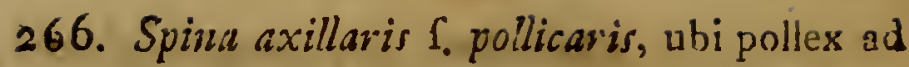
alulam nudus, abit in mucronem re. curvatum, fubcoineum.

II. VESTITAE, partes corporis tętae pennis, plumis, barba.

\section{VESTITUS}

2. $P E \times N A$ eft organon veftiens corpus, infixum bafi corpori avis in quincuncem, cylindro tubulofo, exeunte in rachin fubquadrongulam arcuatam, fupra planam, fubtus canaliculatam, bifariam pinnatam radiis parallelis, itidem pinnatis, approximatis in figuram fupra convexam, fubtus concavam, latcre extcriore, anguftione, interiare latiore, poferiore - plumofo, anteriore arctiore laxiore.

b. PL Una e funt pili rariofi, radiis flaccidis, fporfis, fubramofis. (duae plumae fempcr funt interpofitae inter fingulas pennas.).

C. B AR B A confiftit pennis finplicioribus pilofis.

a. PEN NAE.

267. Ligulatae, elongatae, enfiformes, anguftae, laxae, acutae.

268. Setaccae, laxae, rachide in fetam impennem definentes.

269. Imóricatae, qua dinidiam partem fe invicem tegentes.

270. Nutantes, apice extrófum reflexae.

$27 \mathrm{I}$. Revolutae, fpiraliter antrorfum tortae.

272. Rigidae, flexionis impatientes.

273. Recumbentes, adprefiae, spice roftrum verfus.

274. Reverfae, apice furfum verfo.

275. Filofac, apice in filum terminatae.

276. Pilofae, pennae radiis flaccidis, laxis, elongatis.

277. Strifal, perpendiculares absque flexura, 
278. Decompofitae, radiis diferetis, (non appro. ximatis.)

279. Ocellatae, maculis fubrotundis cocentricis non concoloribus

280. Truacatas, apice linea transverfa.

6. BA $\mathrm{A} \subset \mathrm{A}$.

2\&I. Myfulies, funt pennae fimplices, ad genas refixge, i. e. perpendiculariter dependen. tes, faepius letacene.

282. Vibrifju, funt pennae fumplices, ad marginem facis ciliation difpofitie.

233. Earba, funt pennae finulices, radiis laxis, penculis. (In gula, peftore.)

\section{A. PARTES EXTERNAE VESTITAE.}

a. CAPUT.

284. P I I E S, capitis fumma fupra roftum, oculos et nucham.

285. Frous, pars anterior pilei (Synciput).

286. Virtex, pars medis pilei.

$28 \%$ Occiput, pars pefterior pilei.

288. Supercilium, linea fupra paipebram fupe. riorem, a caeteris penris colore difinca.

289. Genae, regio inter oculos et gulam.

290. Temporia, regio inter oculos et aures.

291. Capiftrum, margo capitis pone roftum.

292. Cirifta, conftat pennis elongatis pilei.

a. Loco

293. Frontalis, in fronte pofita.

294. Verticalis, in verice pofits.

295. Occipitalis, occipiti inferta,

296. Auricularis, tegens aures.

b. DIRECTIONE

297. Reficxa, perpendiculariter dependens.

295. Deflexa, in arcum deorfum declinata.

B 2

299. 
299. Erećta, fere ad perpendiculum $\mathrm{re}$ attollens.

300: Recurvata, deorfun flexa arcu feor. fum fpeEtante.

30r. Revoluta, in fpiran recurvata.

c. FIGURA

302. Compreffa, lateribus sngufrata,

303. Fafciculata, pennis ex eodem centro prodeuntibus.

304. Globoja, ab omini parte rotunda.

305. 'Bifida, divifa linea recta, in duas partes.

306. Oblonga, dianetro longitudinali fu. perante aliquoties transverfalem.

j07. Sctofa, pennis fetaceis conftans.

d. STRU C T U R $\Lambda$

308. Sparfa, ex pennis fine certo ordine.

309. Plicatilis, quáe deprimi et rurfus erigi

- poteft, pennis bifariam alternatim pofitis.

310. Gemina, duabus criftis.

3 x. Unica, non excedente unam.

3 I 2. Collum, pars teres elongata, conneftens ca-

put cuin trunco.

313. Nucha, pars colli fuperior occipiti proxima.

3 I 4. Crvix, pars colli fuperior dorfum verfus a nucha.

3 I 5. Gula, pars colli fubtus, rofto proxima. 316. Fugulum, pars cnlii fubtus a gula pectus veríus.

317. Aücs, truncatse absque auriculis prominentibus, faepe tectae pennis decompofrt is.

318. Auriculae, funt criftac geminae pennis ereEtis fupra oculos in vertice Cápitis pofitae. (neculiares frivibus auritis.)

319. Regio ophthalmica, circa oculos.

320. Regio parotica, circa aures. 
b. TRUNCUS ovatus.

321. Dorfum, pars trunci fuperior collum inter et caudam.

322. Interfcapulium, regio dorfi anterior inter alas.

323. Humeri, pars snterior alis incumben's inter offa brachii et cubiti apicem.

324. Scapulaves, pennae humeris infertae, faepe elongatae.

325. Pectus, regio fternum carinatum tegens mufculofa inter collum et abdomen.

326. Sternum callofum, pars ferni callo fuboffeo tecta.

327. Axillae, latera pedtoris, fub bafi alarum.

328. Abdomén, regio inter apicem fterni et anum. 329. Hypochondria, latera peetoris et abdominis polteriora.

330. Hypochondriae yennae, elongatae, radiis difcretis.

c. ARTUS.

a. ALAE, artus gुeminilaterales, curfui, volatui vel na. tattii infervientes.

331. Impennes; funt alae remigibus perfectis deflitutae, curfui fubfervientes.

332. Pinnifownes, funt alae diatatae membranaque tetae, remirgibus omnino deftitutae, natatui infervientes.

333. Pennatac, remigibus ciliatre, volatui infervientes.

334. Remiges, pennae validae elongatae, margini inferiori alac infertas, imbricantes fe invicem latcre et fecundariis, primarias.

335. Remiges apice rhombear. |Loxia Corrophantes. 
336. Remiges apice membranaceo, apice terminato membranula comprefra, niti. diffima, colorata, lanceolata.

337. Remiges acuminatae, terminatae apice fubuiato.

338. Remiges ferratale, margine extimo remigum radiis difcretis ut videantur ferratue (frigisis.)

339. Primores, plerumque 10 digitorum et matacarpi, illis $1 \cdots 4$, his $5-10$.

Primorcs, plerumque margine exteriore anguftiore, frristiores et acutiores funt.

340. Sicundariae, p!erumque $11=20$. feu 28. Cubiti.

Secundariae, plerumque, latiores laxiores, obtufiores funt, non raro cum acumine.

34r. Alula, ( $($, ala notha) pennis 3 feu 5 brevioribus, pollici infidentibus.

312. Teetrices primae feu penultimae, quae funt a remigibus remotiores.

$3 \div 3$. Tettrices fecussdae feu ultimae, renigibus proximse.

344. Tectrices fuperiores, pennae tegentes alas et remiges fupra.

345. Textrices inferiores, pennae tegentes alas et remiges fubtus,

346. Speculum, macula colorata nitens in marginibus anticis teetricum pita (praecipue in Anatibus).

6. PBDES

Feno:ibus, Tibiis et Digitis conítant, frepius veftitis pennis frrmplicibus, pilofis erc. unde Hirfuti, Lanati, fonilanati, hirfuto - renatat $i$ ets, pedes appeliantur. 
c. 347. CAUDA, artus fingulus terminalis uropygio ciliato rectricibus, tecto Tectricibus fuperis et inferis feu Criffo.

348. Uropygium, corpufculu'm fefrile, cordatum glandula gemina foetum, poro oleifero pertufum fupra, infra proximum ano, genitalibus communi (faepe pro pennis tétricibus caudae).

349. Rectrices, pennae elongatae validae, pares, margini poftico uropyyii infertae, imbricantes fe invicem lateraliter, a medio incipiendo; in plerisque 12 ; in quuibusdam I 8 , frepe etiom ro tantum.

350. Criffum, Uropygii latus inferius inter anum et apicen' uropygii.

8. CAUDA PEOPORTIÓNE

351. Bacinyura, pedibus brcvior.

352. Macroura, pedibus lnngior.

353. Mediocris, longitudine pedum.

b. FIGURA

354. Aegualis f. Integra, fi retrices expanfae funt foftigiatae.

355. Cumeata, rectricibus lateralibus fenfim brevioribus.

356. Forficata, rêtricibus lateralibus fenfim lon. - circo gioribus.

357. Fotrendata, recivicibus expanfis fectione!n circuli defcribentibus.

358. Bifisicatil, rectricibus lateralibus extrorfun falcatis.

e. STRUCTURA rectrices

359. Falcatae, rectricibus enfiformibus, elongatis, curvatis.

360.'Acuminatre, terminatae apice fubulato:

$36 \mathbf{r}$. Filofac, apice in filum definente.

B 4 
362. Setiferae; feta ex alveolo, cui rectris inferta eft, orto, et partem radiorum exteriorum fimbriante, denique libern pendula.

363. Apice lanceolatae, longiffimae, rachi to. mentofa fubnuda, apice pinnis radiatis Ianceolatis.

364. Incurvae, introrfun flexae.

365. Medio attenuatae, longiffmae, rachi medio radiis breviffmis, bafi apiceque lationibus.

366. Apice dilatatae; longiffmae, rachi radiis brevifimis, apice dilatatis.

367. Setaceae; longiffimae, rachi radiis nuda, apice vel lanceolato biradiato, vel cirrhis lunatis uno latere radiatis.

B. PARTES INTERNAE, non fine fectione viden. dae: ideo ad Anatomiam fpeztant.

\section{HABITUS abfolvitur.}

A. VENERE.

I. NUPTIAE celebrantur veftitu, mufica, ofculatione, lufu. .

a. MONOGAMAE, juncto uno mare cum fingula femina.

b. P OLYGAMAE, uno mare pluribus feninis, inferviente.

\section{NIDIFICATIO.}

a. A ETIFICES.

a. Mater fola.

b. Uterque Parens.

b. MATERIA.

a. Rami srborum.

b. Virgulta. 
c. Caules plentarum.

d. Mufci et Lichenes.

c. Pennae et Plumae.

$f$. Pili et Crines.

g. Lutum.

h. Cefpites.

i. Pappi plantarum.

c. Lo c us.

a. Rupes.

b. Arbores.

c. Fruticeta.

d. Herbaceae plantae.

e. Apices ramorum.

f. Folia.

g. In terra, fupèr terra.

13. Sub terra.

i. In fcopulis mari cinctis.

k. In locis vadofis elevata argilla.

l. In aqua.

d. RÁtío ET FIGÚRA NIDI.

a. Intertextis furculis pilis mufcis in fenicupium feu globum excavatum dimidiatum.

b. Foraminojus, cuniculo fub terra effofio.

c. Concameratus, ex luto in cameram digeftus.

d. Argillofus, ex argilla aggefta in ldcis vadofis.

e. Natans, ex plantis aquae impofitis.

f. Pendulus, fufpenfus ex apice rami, apertura laterali, fupera, infera.

g. Foliaceus, foliis confutis in formam facci.

h. Nullus, ovis depofitis fupra terram vel in nuda rupe.

III. O VATJO.

a. Suestanta Ovi.

a. Vitellum, pars ovi lutea, deftinata pro nutriendo foetu tempore incubationis.

$$
\text { B } 5 \quad \text { b. Purs. }
$$


b. Punctum faliens, infidet Vitello et eft gelatinofum ftamen futurae avis.

c. Albusmen, eft fubftantia gelàtinofa, exterior magis ferofa, Liquori anmii fimilis.

d. Chalaza, eft tunica conglomerata terminans utrum. que polun vitelli.

e. Poli vitelli, funt ligamenta gelatinofae vitelli, affixa bafi et apici ovi.

f. Vefica ä̈rea, eft regio ovi ad bafin ejusdem vacua, aëre repleta, inter utramque tunicam.

g. Tefta, externum integumentum ovi, calcareae fubftantiae, idem ibique tegens.

b. NUMERUS.
a. I. Alca et Aptenodytae.
b. 2. Colymbus et Columbs.
c. 3. Larus.
d. 4. Corvus, Strix, Falco.
e. 5-8. Hirundo et plerique Pafferes.
$f$. Plures, Gallinae et Anates: provida in hoc inftinetu Naturae cura, ut fcilicet victui optime infer- vientes fint numerofiores.

c. COLOR.

IV. INCUBATIO.

a. An mater fola incubet, (in Poiygamis)?

b. An uterque parens per vices fuccedat?

c. An mas conjugi incubanti cibum prófpiciat?

d. An incubantes ferninae cibos fibi ipfae colligant?

c. An parentes incubcrt, vel potius pulli a fole exchudantur.

v. EDUCATIO.

a. GENUS CIBI.
a. Mammalia, Aves.
b. Pifces, Amphibia.
c. Infeeta, Cáncelli. 
d. Vermes.

c. Grana.

f. Baccae.

g. Folia plantarum.

b. RATIO CIBANII.

a. Párens commanfrat, oftendit.

b. - colligit, carpit, porrigit.

c. - ingurgitat et ex prolobo evomit.

c. Cuka et Tutela.

a. In nido occulto.

b. Curfitantibus pullis in terra.

c. Natantibus pullis in aqua.

d. Sonus, quo mater pullos admonet, periculum adefre.

e. Artificia matris pro hofte feducendo in ahas partes.

f. Defenfio et Tutela pugnando animo ingenti fupra vires.

g. Forendo et calefaciendo pullos fub alis, contra pluviam, frigus.

\section{B, VICTUS}

I. CARIIVORAE ET ZOOPHAGAE.

a. Animalia mortua, Cadazera.

Accipitres et Corvi.

b. Animalia viva et ova.

Accipitres et Corvi.

c. Pijes et Amphibis.

Anferes et Grallae.

त. Injecta.

Fafieres tenuiroftres et Picae.

e. Vermes et Cancri.

Gialiue et Alcedines.

f. 'Conchite.

Hawnatogus. 
1I. PHYTIPHAGAE.

a. Plantae et Gramina. Anferes quidam.

b. Grana et Serinina. Gallinae, Columbae et Pafteres multi.

c. Poma et Baccae. Pfittaci.

d. Nuces.

Picae et Corvi.

e. Neifar Florum.

Certhiae et Trochili.

C. PLUMATIO.

I. STRUCTURA

- Peculiaris in variis avibus, Vide pennas et veftitum. pag. 18.

II. DIFFERENTIA, ratione
a. Aetatis.
b. Sexus.
c. Temporis anni.
d. Regionis et Climatis.

D. SOCIETAS.

I. An fint gregariae?

11. An folitariae?

E. VOLATUS.

Gravis, celer, indefeffus, brevis etc.

\section{STA TIO.}

A. HABITATIO, feu loca, ubi,aves degunt.

I. O:eanus, altifimum mare, procul ab omni terra.

Marc, breve, littoribus inclufum.

Littora, arenofa, glareofa maris terrae juncts.

Sio. 
Scopuli, rupes mari cinctae.

Syrtes, arenofa mari cincia et inundata.

Snifuginofa, paludcs argillaceae, infufo mari.

II. Lacus, aqua dulcis pura, fundo confiftente.

Fluvius, aqua dulcis defuens.

Ripae, margines locuun et fuminum.

Paludes, aqua dulci fagnante, fundo lutofo, plantis inundacis et aquaticis plena.

III. Alpes, feries maximorum montium verticibus nive te:tis.

Rupes, loca faxofa montofa.

Compi, loca aprica, ficca, alpera, ventola.

Prata, campi deprefil et convalles herbis luxuriantcs.

IV. Syliae, umbrofa arborihus continue tecta.

Arúufa, arborum nemoribus difcretis.

Fruticeta, loca confita fruticibus, fentibas.

V. Arva, loca culta campeftria.

Pagi, loca humanis habitationibus confita.

\section{B. REGIO.}

\section{CLIMA}

a. Intra Tropicos.

b. Locis Temperstis.

c. Circa Pclos.

II. GEOGRAPHICE

a. Africa.

b. Americia foptenti. et auflia?.

c. Indiae Contineas st injulas.

d. Mare pacificum. 


\section{TEM P US.}

\section{A. CONJUGIUM.}

I. NUPTIAE ET AMORES.

Tempore ex forefcentia, grojificatione, watusatione et meffe plantarum praccipue fumenco: practerea Duratio amoris, an femcl vel bis in anno.

II. NIDIFICA TIO

a. Teripus, qृuando nidam fruant.

b. Structio, ciuantum temporis in fruendo nido impenciant.

c. Duratio, quamdiu nidus inferviat, et an rurfum codem utantur, vel an eacdam aves vel diverfae.

III. O V A TIO.

a. Tempus, quamdiu ovatio duret.

b. Intervalla, quantum temporis intercedat inter fin•! gula ova.

c. Numerus, quot ova ab unica femina folesnt deponi, - in nido incubando.

IV. IN CUBATIO:

Quamdiu ová fint calefacienda, antequam pulli excludantur.

V. EDUCATIO

a. Puliorum, quamdiu parentes curam gerant et tutentur pullos. :

b. Adclefcentiae, quamdiu cum parentibus poft primam actatem in focietate vivant.

c. Maturitatis, quo tempore aetatis et vitae fint maturae aves ad procreandain novam progeniem, in utroque fexu.

B. VITALES ACTIONES.

I. VICTUS.

a. Quando praecipue cibum qquaerant, diu, noetu, mane, vefperi.

b. Quo 
b. Quo anni tempore vietum varient.

c. Qua tempeftate cibum appetant et conquirant, fole fplendente, tempore ventofo, tempore pluvio, ante vel poft pluviam.

\section{SOMNUS.}

a. Quando fornnum capiant, et ubi.

b. Quamdiu requici indulgeant.

III. MORS.

Quot annos vitae agant, quum ex fenio moriuntur.

C. DEPLUMATIO.

Qua praefertim anni tempeftate plumas amittant et novis veftiantur.

Quantum tempus requiratur a deplumatione ad novarum pennasum fixcceflonen.

D. MIGRATIO.

I. LO,CUS

a. A quo

b. et ad quem.

\section{TEMPUS}
a. Aeftivum.
b. Vernale.
c. Autumnale.
d. Hybernum.

III. CAUSAE, dies longiores, cibi, cojia, veftitus den' fas, nuptiae.

IV. TORPOR, in rupium cavernis, in cuniculis, atboribus putridis, aqua.

V. DISCESSUS f. mutatio foli, pró anni tempeftate. Coturnices hyeme ad littora maris difcedunt. 
A. COLOR.

\section{QUALITAS.}

Vide quae de coluribus funt dika in Terminis En. tomologicis.

368. Collare, frriga collum cingens.

36 . Torques, fafcia collum cingens.

370. Linea, eft longitudinaliter extenfa acquali fed tenui latitudine.

37 1. Fufciu, transverfalis latiori plaga extenfa.

372. Strigae, farciae tenuinimae capilli inftar.

373. Striae, funt lineae latiores.

374. PundEa, funt maculae fubrotundae minores, praècipue nigrae, vel obfcurioris coloris quam reliqua.

375. Guttae, funt maculae fubrotundae miajores albae in parte obfcuriore.

376. Maculae, funt partes inajores colore differenti notatse quain reliqua.

377. Ocelli, funt maculae orbiculatae, in medio cocentrice diverficolores.

378. Scolopaceus color, fufco grifeoque nebulofus.

379. Nebulofus, duobus coloribus per ftrigas un. dulatas mixtis.

380. Grifens, ex fufco et ochracco commiftus.

B. MENSURA.

Vide menfuras in Terminis Botanicis.

$$
\text { 7. U S U S. }
$$

A. NATURALIS.

Oeconomia naturae ejusque politia in compefendis - et diffeminandis fpeciebus.

B. ARTIFICIALIS

I. CULINARIS, pro cibo, Gallinarum et Anferum inprimis, praterea Grallae et PaJjeres, et Ova.

II. DIAE- 
II. DIAETETICUS, qui funt edendi in certis morbis, et quae remedia ex avibus petenda.

III. OECONOMICUS.

a. Venatus, Falcones.

b. Pifcatus, Pelecanus Pifcator a Chinenfibus adhibitus annulo aeneo collum ambiente.

c. Cuffodia avium domefticarum, contra Accipitres et Vultures, Parrae Chavariae.

d. Educatio, Gallinarum et Anferum pro mercata et in cibum.

e. Scriptura, remiges Anferum, Corvorum et Cygno:um ad fribendum adhibitae.

f. Culcitae et pulvinaria, faretae piumis pennisque anferum, inprimis Anatis mollifimae.

IV. METEREOLOGICUS ad praefagiendas tempeltatcs et mutationes aëris, ventorum, etc.

\section{ORDINUM CHARACTERES}

\section{ET GENERUM.}

A. ACCIPITRES, roftrum, e mandibula fuperiore, an gulum utrinque exferens.

i. VUL T UR, iofrum aduncum, caput denudatum,

2. F A L C O, roftrum aduncum, bafi cera te fum. $^{-}$

3. S TEI I, rofrmm aduncum, absque cera, remige

primo vel fecundo ferrato, capiftro reverfo:

4. LAN Y US, rofrum rectiufculum, absque ceras emarginatum, $\int_{0}$ dente utrimque.

13. CLIVIAE, i. e. prohibitoriae f. slamatoriae aves. (L6: vivoftres, Blumenbachii Prof, Goetting.)

5. PsitTacus, rof?rum cera obduetum, adun. cum, lingua carnola, pedes fcanforii. 


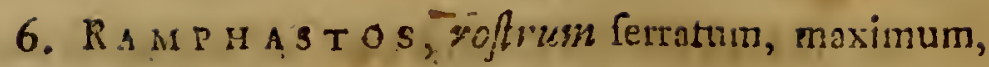
inane, convexum, lingua penracea, pedes fcanforii.

7. BUCER OS, roffrum ferratum, fronte offea; $p c$ des greforii.

C. GLOTTIDES, lingua praelonga, (Pici Blumenbachii Prof. Goetingenis ).

8. P: C U s, rofurun polyedrum, lingua longifima lumbricifornis.

9. JYNX, rofrum laeve, teres, lingua longiffuna lumbricifornis.

10. TROCH IL S, rofmm incurvatum, filiforme apice tubulofo; lingua filis duobus coalitis.

1 I. CER T H A, rofrum incurvatum, acuminatum, lingua acuta.

12. ME R O S , roftrum incurvatum, compreffurn, lingua apice laciniata.

13. UP UPA, roftrimi incurvatum, obtufinfeulum, lingua obtufa, integerrima.

14. A.ICE D 0, roftrum trigonum, retum, tingua carnofa, brevis.

15. S I тт A, roftrum reeum fubulaium, apice cuneato: Nares ribiifis tectae.

D. CORACES.

16. C OR A C I S , roftrum cultratum, apice incurvo.

17. GR: $\mathrm{C} \cup \mathrm{LA}$, roftrum cultratum aequale, bafi calva.

18. C O R V S , roftrum cultratum, capiftro reverfo, pennis feraccis.

I. PA R A D ISEA rof?rum fubcuitratun, capiftro holofericeo.

20. 'IR०GON, rofrum ferratum, cuirratum; ad. เทcu!n.

21. Du c c o, rofurum lesve, emarginatum, aduncum, ingenti riotu, ciliato pennis recumbentibus. 
22. CKO IOPHAGA, roffrum rugofum, margine angulatum.

23. CA I, LAEAS (great Wattle bird of N. Zeeland). Roftrim incurvatum, fornicatum: Paleare caruncuiaccum : ling $u$ a lacera, cilints.

24. BUPHAGA, roftritin rętum, quadrangulare, extrostum gibbum.

25. Cuculus, roftrum laeve, teres, Nares inarginatae.

26. TO D U , roftrum teşum, lineare, fubulatum bafi fetis patulis.

27. OKIOLUS, roftrum reetum, conicum, вcutifimum.

E. PASSERES.

28. S T U R $x$ U S, rofrum fubulatum, apice depreffo marginatum. Nares fupsa marginatae.

29. TURDUS, roftrum emerginatum fubulatum, bafi compreffa. Ling zua lacero - emsrginata.

30. AMPELIS, roftrum enarginatura, fubulatum, bafi depreflum. Ling $u a$ bifida.

3r. Loxia, rofortm conico ovatum.

32. A I A U D A, roftrum fubuatum: Lingua bifids. Ungzits pofticus elongatus, reciurculus.

33. IM E E I ZA, rofirum fubconicum, mandibula inferiori latere, coarctata.

34. TANAG R A, roftrum emarginatum, fubulatum, bafi conoideum.

35. FRINGILLA, roftrum conicuin, acutum, reetum.

36. M บ S C I C A P A, rofrium emarginatum, fubulatum, fubtrigonum, bafi cilintum.

37. M OTACILLA, roftrun fubulatum. Lingua incifn. Unguruis polticus modicus,

38. P I PRA, roftrum incurvatum, fubulatum, bafi trigonum, capitc bievius.

C. 2 
39. PARUS, roftum fubulatim. Lingua truncata, Capiftrum reverfum.

40. HIRUND O, roftrum incurvum, depreffum; riktu ingenti.

4I. CAPRIMULG US, roftrum incurvum, depref. fum, ciliatum, nares tubulofae.

F. GALLINAE, roftro convexo. Mandibula fuperiore fornicata. Femoribus tectis.

42. C O I ч м в , roftrum fubfornicatum. Niares gibbofae, membrana obliterata.

"43. TE TRA O, Jupercilia nuda, papillofa.

44. $P$ H A $S$ I A N US, genae nudae, láeves.

45. NUMIDA, carunculae binae ad bafin mandibularum. Caput vertice galeatum. Roftrum cera tectum.

46. CRAX, cera bafin roftri tegens, caput pennis revolutis.

47. MELEAGRI5, Facies carunculis verrucofa.

48. $P$ A $\vee$ o, roftrum nudum, Vertex pennis revolutis.

4. Or Is roftrum fubfornicatum. ,Lingua emarginata, Pedibus curforiis.

50. Str UT H O, roftrum conicum.' Alae ad vola. tum ineptae. Pcdibus tri - et didactylis.

5I. D I U S, roftrum medio coarctatum, rugofum, facie nud, Alae impennes.

c. GRALLAE, roftro fubcylindrio, obtufiufculo. Femoribus nudis.

52. ARDEA (quo et Pfophia referenda). Roftrum rectum acutiufculum. Nares lineares.

53. S C O L O PAX, roftrum rectuin, teretiufculum, obtufiufculum. Pedes fiff.

54. RE C URVIR O STRA, roftrum fubulato - attenuatum depreffurn, recurvura. Pedes palreati tridastyli. 
55. TrINGA, roftrum teretiufculum, obtufum. Pollex vix infiftens.

56. C H I ONIS, roftrum conico- convexum, compreffum. Cera cornea emarginato - lacera. Nares ovatąe, fub cera. Lingua lanceolsta, truncata, fagittata. Facies nuda papillofa. Pedes tetradactyli, fifi.

57. RALLU S, roftrum fubcarinatum. Corpus com. preffiufculum. Pedes fiffi.

58. F U I I C A r roftribafis fronte calva. Pedes tetra. dactyli fuepinnati.

59. PARRA, rofiri bafis fronte carunculis inobilibus. Pedes 4 dactyli, fiffi. Digiti et Ungues elongati.

60. TAN T A I Us, roftrum arcustum. Saccogulari, Facics nuda ultra oculos. Pedes tetradastyli bafi palmati.

6I. MYC T E I I , roftrum mandibula inferiore craffiore fubadfcendente.

62. CA C R O MA, roftrum ventricofun, cymbiforme,

63. PLAT A L EA, roftrum depreffum, fpatulatum. Pedes tetradactyli fubpalmati.

64. PH OEN IC OPTER US, rofrm teretiufculum, denticulatum. Pedes palmati, tetradątyli.

65. CHARADRIUS, roftrum teretiufculum, obtufum. Pedes tridactyli curforii.

66. НА М А T O U S, roftrum comprefiufculum, apice cuneato. Pedes tridactyli curforii.

H. ANSERES. Roftrum obtufum, epidermide tectum, apice aufum.

67. RHY C H OPS, roftrum mandibula fuperiore breviore.

68. Р М A ratum, Nares oblongae. 
69. STERNA, roftrum fubulatuin, edentulum, apice compreffo. Nare; lineares $\left.{ }_{d}\right]$ bafin.

70. LARUs, roftrum fub apice fubtus gibbum, edentulum. Nares lineares in medio rofiro.

7 I. D I O MEDEA, roftrum reetum apice aduncum maxilla inferiore truncata.

72. A N AS., roftrum unguiculatum, denticulis nembranaceis.

73. MEKGUS, roftrum unguiculatum, denticulis fubulatis.

74. C O I Y M U S, roftrum fubulatum lateribus comprefiufculum. Pedes lobàti, Tibiac pofti. ce carinsto-ferratae.

75. UR I A, roftrim fubulatum, compreffum. Pedes palmati, tridastyli, tiliits poftice mutivis.

76. G A V A, roftrum fubulatum, comprefurn. Pe. des palmati, tetradaetyli.

77. PR OCELLARIA, roftrum edentulum, fubcompreffum. Nares fuperincumbentes, fub. cylindricae.

78. A L C A, roftrum rugis lateralibus. Pedes trida. ctyli. Naves pone roftrtim in latere inferiore mandibulae fuper.

79. APTEN ODY TES, roftrum compreffum, maxilla inferiore truncata. Lingua et palatum villofum. Alae pinniformes.

80. PELECANUS roftrum cinctum facie nuda. Nares rima obliterata.

8x. PL o T U S, roftrum fubulatum, facies tefta. 


\title{
FUNDAMENTA
}

\author{
in
}

T E R M I N I

\section{C H T HYOL O GIAE, \\ CONGESTA}

EX CELEEERTMO EQUITE

. L I N N É,

ARTEDIO, GOUAN, ALIIS. 


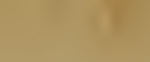

$1, x+x_{1}$

$-$

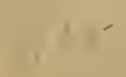

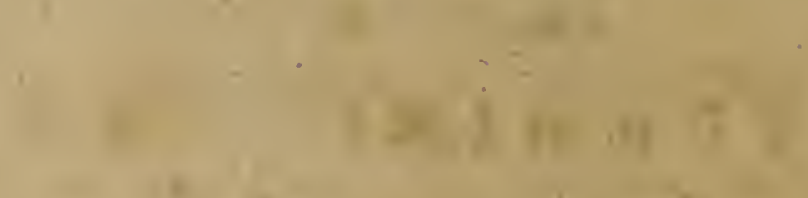

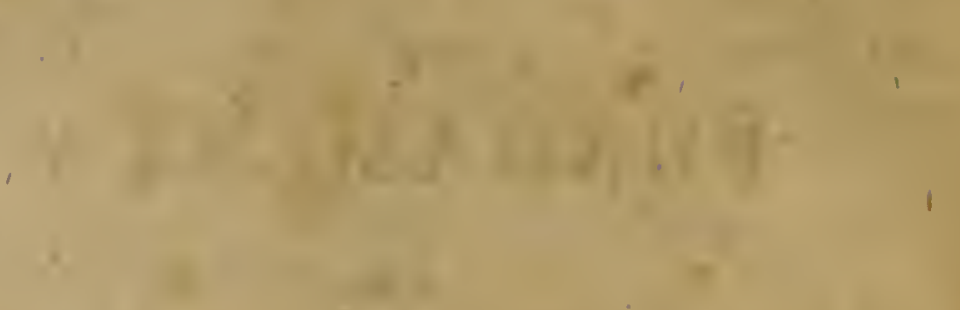

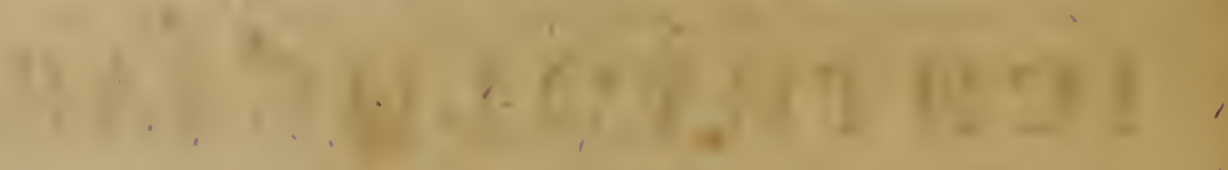

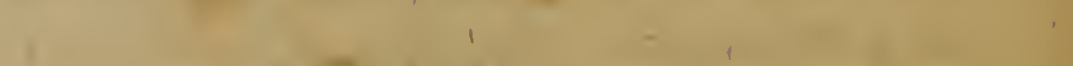
$19+10$

I

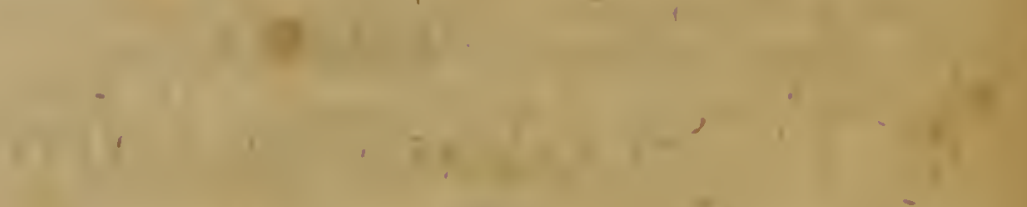
$+$,

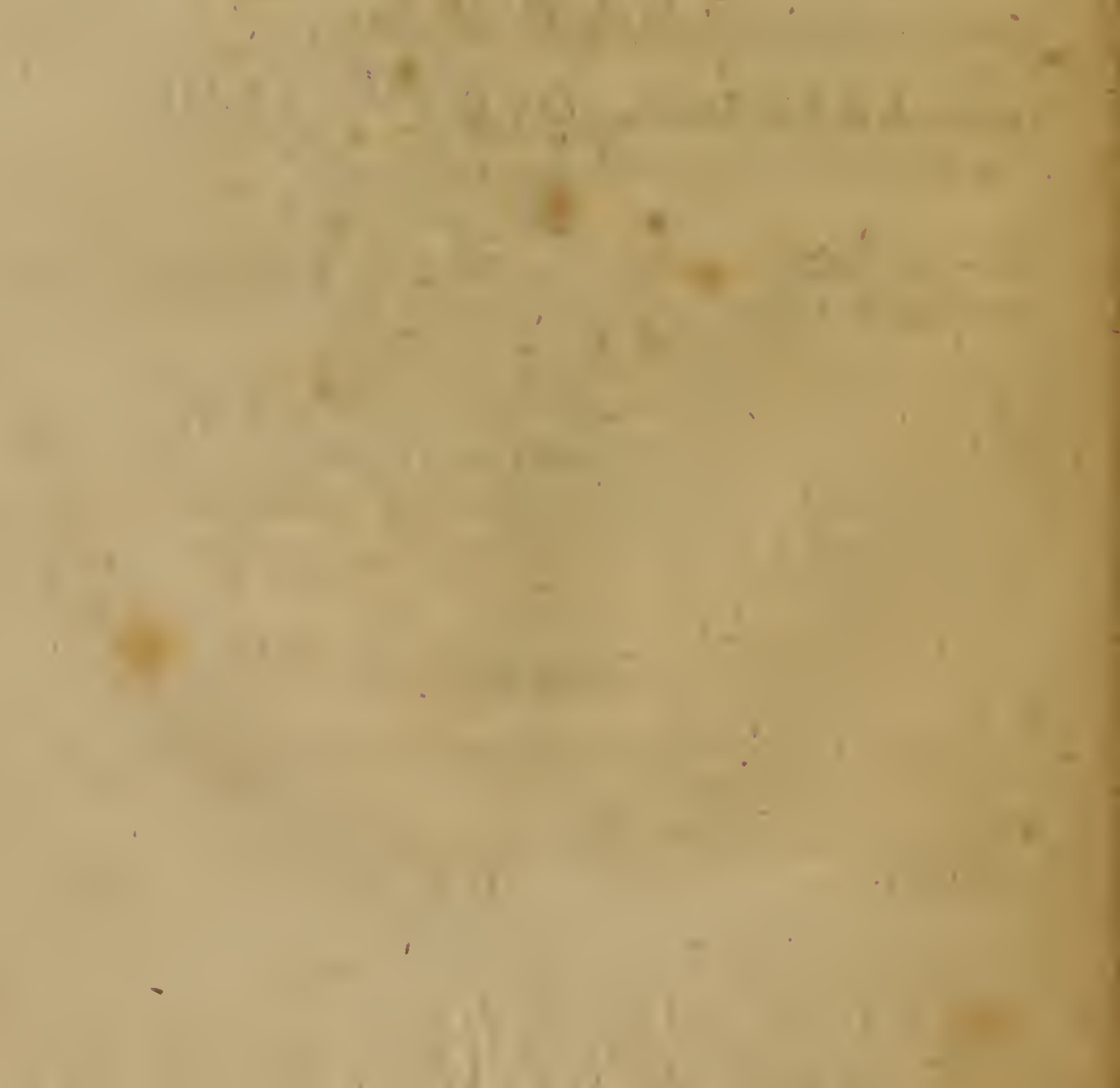




\section{DESCRIPTIO.}

In $p i f c e$ confulderandae, examinandae, deforibendae

A. IARTES EXTERNAE pifcis, funt eae, quas

- fne feetione anatomica obfervari poflunt.

1. CORPUS TOTUM in genere.

¿ FIGUR $A$.

1. Catheioplateum, diametro perpendiculari fu. perante horizontalem. (Latevibus compreffirm.)

2. Plagioplateum, diametro horizontali transverfali excedente perpendicularem. . $\left(-D_{\ell}\right.$ procfum.)

3. Teres, fubcylindricum, angulis deftitutum.

4. Anceps, angulis oppofitis duobus acutis, difeo convexiore.

5. Cultratum, dorfo planiufculo, infra angulo aciato.

6. Carinatum, dorfo rotundato, parte prons ventris longitudinaliter acuts.

7. Ovatum, diametro longitudinali fuperante transverfalem, bafi fegmento circuli circumfcripta, apice anguftore.

8. Orbiculatum, peripheria circinata, dismetro longitudinali et transverfali fubaequalibus.

9. Oblongum, diametro loniritudinali aliquoties fuperante transverfalem.

10. Enfiforme anceps, a capite ad caudam fenfim attenuatum.

I. Lanceolatum oblongum, ab ntraque extreni. tate attenuatum.

1 2. Globofum, ab omni parte rotundum. (Sphatricums.)

13. Anzulatum, annulis feu lineis elcvatis corpus cingentibus.

14. Avsigulatum, con?tat Jamellis conceteratis. 
15. Trigonum, Tetragonum, angulis 3 aut 4 prominentibus longitudinalibus, laterali. bus exacte planis.

16. Polygonum, angunlis $5-6$ prominentibus etc. 17. Diacanihum, Triacanthum, Polyecanthum, tpinis 2. 3. pluribus.

18. Cuneiforme, fenfim verfus caudam angaftatuin.

19. Conicum, teres, fed fenfim ad caudan de. crefcens.

20. Ventricofum, ventre dcorfum prominente. 21. Tuberofim feu Gibbum, dorfo prominente. fuperficie convexa.

b. SUPERFICIES ET INTEGUMENTA.

22. Alepidotum, nuduim, fquamis defitutum.

23. Squarnofum, fquamis tectum.

24. Macrolepidotum, fquamis longis.

25. Glabrum feu laeve, fquamis deftitutis angu. lo, fulco, afperitudine vel inaequalitate. 26. Lubricum, tenaci humore feu muco oblitum. 27. Siabrum, Tuberculatum fuperficie, tubercu. lis prominulis exafperatum.

28. Papillofum, tectum punetis carnofis, loco fquamarum.

29. Cataphractum, cute dura callofa, aut fqua. mis fubofeis adnatis, diftinsis numerabilibus.

30. Loricatum, integumento ofeo, feu fqua. mis ita arcte unitis, ut quafi unicain conftituant.

31. Vittatzm, zonis longitudinalibus per latera a capite ad caudan pietum.

32. Fuffiatum, zonis transwcris s dorfo ad ven. trem notatum.

33. Lineatum, lineis anguftifimis farfis. 
34. Reticulatum, cancollatum, lineis decuftatis, i. e. a capite ad caudam et aliis a dorfo ad ventrem fofe interfecantibus, notatum.

35. Punctatum, punzis per feries longitudinales, vel inordinate digeftis.

36. Bicoloratum, colore unius lateris diverfo ab alterius.

37. Variegatum, coloribus variis pietum.

38. Maculatum, partibus majoribus, colore differenti notatis, quam reliqua.

II. PER PARTES CORPUS CONSIDERANDUM.

a. CAPUT.

a. FIGURA.

39. Obtufum; intra fegmentun circuli terminatum.

40. Truncatum, linea transverfa terminatum.

41. Acutum, terminatum angulo acuto.

42. Subquadratum, figurs ad quadratam accedente.

43. Defcendens, arcuatim fenfim ab oculis ad roftrun. Declive.

44. Cuneiforme (1 8.) fenfim verfus roftum anguftatum.

45. Trigonum, Tetragonum. (15.)

b. PEOPORTIONE.

46. Corpore anguffitus.

47. Corpore latius.

4.8. Breve, Paruusm.

49. Rofiratum.

50. Elongatum, porreçitim.

51. Angufizm.

52. Latum, Amplum.

53. P'oportionale. 
54. Metiocre.

5.5. Hlinutsh.

56. Cisulfism.

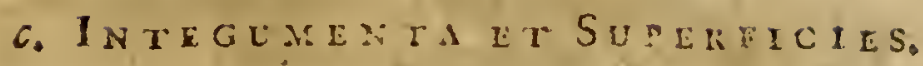

57. Sgramofum, Teium, (23.)

58. Alcpidotum, Nudum. (22.)

59. Cataphraćlum. (29.)

6c. Loricatum. (30).

61. Glabrum. (25.)

62. Papillofum. (28.)

63. Scabrum, afperum. (27.)

64. Aculeatum, tuberculis fpinofis aculeisve armatum.

65. Tuberculatum, prominentiis callisve obtufis, duris.

d. ADD ITAMENTA.

66. Cirrhus eft appendix fetifomis membranacea, mobilis fimplex, ex mexillis vel ore dependens.

67. Nulli, fi defunt in pifce.

68. Unicus, Solitarius, exclufis pluribus quam uno.

69. Plurimi, plures.

70. In inferiore maxilla.

71. In utraque maxilla.

72. Ad angulos oris.

73. Eniguri, capite breviores.

74. Magui, capite longiores.

75. Medivcres, longitudine capitis.

76. Caput cirrofun.

77. Imberbe, cirrhis deftitutum.

78. Cirrlis nares teitae, ut in Gado Lots,

79. Pirmula, Tentaculum eft appendix fetofa, mem. branacea mobilis, interdum inftar cri- 
ftre difiecta, inter oculos $€ t$ nares vel retro porita.

80. Criftatum Coput, pivaulis orizatum.

81. Aosque criftis, pinzulis defitutum.

32. Ciyjucus, ef corpus planum, orale margina. tum, lamellis transverfs parallelis, pe. Einatis.

83. Clypeaturn: caput, clypeo tefum.

8. Aculci, oflicula fimplicia, punerentia, raro bifida, nuda, nec meanbrana ut aculei pin:za:um obvoluta.

85. Aculeatum caput.

86. Inerme, aculeis tuberculisve deftitutum.

a) $8:^{\circ}$ Os, eft cavim antice rictu, latere branchiarum operculis, poftice gula f. fauce, fuperne. et inferne palato terminatum, Dentes et Linguam includens, cum officulis palati.

88. Ritus, eft hiatus feu apertura anterior.

2. 89. Superus, in fuprema parte capitis fitus.

90. Verticalis; fuperus, fed peipendiculariter defcerdens.

91. Inforus, infra roftrum, aut in prona capitis parte.

92. Trassverjus, hovizontalis, oris incifura transverfin fecsns pifcem, ndeo ut continuata fecaret dorfum a ventre.

93. Obliquzs, neque verticalis, nec horizontalis.

R. 94. Arcuatus, fi a linea recta deviar.

95. Linearis, reftus, non arcuatus.

96. Cincularis, anmblaris, margine circirato. 
97. Tubulofus, Fiffulclus, orificio angurto, rotundo, protundo.

98. Simus, tion prominens, nee profundus.

c. 99. Mediocris, proportionatus, circiter latitudi. ne capitis,

100. Intrus, excedens lstitudinem capitis.

101. Porizus, Exiguzs,' Minimus, multo minor latitudine Copitis.

b) 102. ROSTRUM, pars capitis anterior ab oculis of naribus ad maxiltartun apices protenfa.

a. 1 23. Obtufunh. (39.)

10 . Acutum. (4I.)

105. Cufpidatum, terminatum opice fe. taceo.

106. Colindricum, Fifulofum, Tubulofun interne. (97.)

107. Pligioplatemin; (2) fuperficie com. pisnata dep:chia.

108. Diffum, Furcatum, Lobatum, divifum in duas (piuresve) partes.

109. Calistoplatcum, (s) laterilus cons. planntis, compretis.

I I0. Anizps, angulis duobus oppofitis acutis, difco convexicre.

II1. Triguetrun, Tetraguetrum, tribus phuribusve lateribus exacte pianis.

13. Inflexsm, quun partim aut omnino firfum arcuatur.

I 3. Deflexwh, gum deorfun incruatur.

b. 114. Ereve, refpetu corporis (vel religui $C_{A}$.

$$
\text { p เ } 15 .)
$$

19. Longum, Propeciums. 116. Medionge, frojortionale.

c) $M . \mathrm{A}$ 


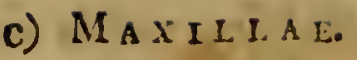

a. I 1 . Subulatae, bafi fublineares, a bafi ad apicem fenfin attenuatae.

I 1 8. Plagioplateae. (2.)

1 19. Acutac. (41.)

120. Carinatae, maxilla inferior parte vel interna vel externa longitudinaliter prominens, intus vel exilis.

12 1. Nudae, Denudatae, labiis dętitutae.

122. Labiatae, labio unico in qualibet maxilla.

123. Bilabiatae, labio duplicato.

6. I 24. Edentulae, dentibus deftitutae.

1 25. Dentatae, dentibus diverfi generis, anomalis inftructae.

126. Denticulatae, dentibus minutis fubaequalibus, fimilibus.

c. 127. Aequales, ejusdem longitudinis et latitudinis.

I 28. Superior longior inferiore.

129. Inferior longior fuperiore.

130. Minimae; ? refpectu ad molem cor.

I 31. Mediocres,

132. Maximae, $\}$ poris habito.

d. i33. Supremae, in fumma capitis parte.

134. Inferae, in ina capitis parte.

35. Terminales, in apice roftri.

36. Mcdiae, in media capitis parte fitae.

e. 137 . Mobiles, quando funt extractili et retractili

- motu donatae.

138. Immobiles, nec extrachiles, nec retratiles.

f. 139. Cirrofae, cirratae (76.) Maxilla fuperiore tantum, vel inferiore foln.

I 40. Imberbes, utaque maxilla tine cirris. 
141. Siabrae, afperae. (27.)

142. Vaginatae, margine unius maxillae tegente marginem alterius.

143. Fornicatae, velo membranaceo intus antice annexo, poftice libero, intra quod et fuperiora $v e l$ inferiora oris, linguam recondit piícis, vel aquam ex ore excludit.

d) 144. Mxstaces funt officula duo connetentir maxillam fuperiorem cum inferiore, lateralia max. fuperiori, in aperiendo ri. Elu oris, motui infervientia.

LABIA in paucis Pifcibus, pracipue tamen Sparis et Labris, funt obvia, et qui. dem vel ofjea, vel carnofa.

e) DENTES.

c. 145. In utraque maxilla.

1 46. In maxillis at lingua.

147. In maxillis, lingua et palato.

1 48. In maxillis, lingua, palato ct foucibus.

149. In muxillis et faucibus.

I50, In maxillis, palato et faucibus.

b. I51. Granulof, mole et figura minimi grani.

152. Acuti, $(+1$.$) apice pungente.$

153. Obtufi, oblongi et granulofi ( 9 , et I $5 \mathrm{r}$.)

5 4. Conici. (19.)

155. Plani, lateribus compreffi.

156. Semifagittati, uno tantum latere hamati.

157. Subulati. (I I 7.)

158. Acerofi, lineares, tenues, acuti]jimi.

159. Serrati, margine incifuris refpicientibus apicem, (femper fere triangulares.)

160. Recti, nusquam flexi. 
16 r. Retraflexi, verfus gulam Rexi.

162. Semiconici, conici diffekt, uno latere pleni, altero convexi.

163. Emarginati, apice paulluilum bifidi.

$\therefore$ 164. Inaequales inter fe, feu diverfae longitudinis.

165. Aequales inter fe.

166. Minimi, Minuti, Exilifjini.

167. Mediocres.

168. Paralleli, ejusdeın fitus, longitudinis et figurae.

169. Divergentes, apicibus contiguorum diftantibus.

1 70. Diffimiles, aliis acutis, aliis obtufis. Viz. Melaribus et Inciforibus.

I 7 . Similes, ejusdem magnitudinis et figurse, omnes acuti, aut obtufi.

d. 172. Nulli, i. e. maxillis edentulis.

173. Ordinati, difpofiti una vel pluribus fe. riebus.

174. Confufi, conferti, fparjt nulio fervato ordine.

c. 175. Mobiles, bafi fiexiles.

1 7 . Immobiles, bai fixi.

i) L I N GUA.

a. $17 \%$. Acuta. (41.)

178. Sibbuluta. (I ? ?).

179. Obtiafa. (39.)

180. Integra, apice et margine nec minimum fecto.

181. Bifida Seu Lindriginata.

182. Carinata, fubtus angulata.

b. 183. Carnofa, fubftentia mufculofa referta.

184. Ciaffa, diametro perpendiculari amp!o. 
I85. Cartilaginea, fubftantia fubofiea.

886. Papillifa. (28.)

187. Glibra, papillis (186) dentibusque (189) denituta.

188. Afpera, fiaíra. (27.)

189. Denticulata, dentibus fimilibus aequalibus confita.

190. Dentata, dentibus anomalis, et inter fe figura et proportione diverfis teda.

c. igf. Lilieva, foltita, mobilis, nullo ligamento motum impediente.

192. Annexa, immobilis, oppofitun (191).

193. Vaginata, maxillis fcilicet fornicatis (143.)

g) PALATUM, pars oris interni a rictu ad infertio. nem oefophagi, pers ima oris quo. que ad palatum fpeetat, et Fauces efficit.

194. Glabrum, cute laevi veftitum.

195. Ajperum, fiabrum. (27.)

I96. Donticilutum. (19\%)

197. Edenitulum. (1 24.)

198. Tuberculatusi, officulis palati glabris et rotundis, nec denticulatis. (65.) 199. Pspillofsesiz. (28.)

200. Ossicula Palati, funt ut plurimuin quatuor, in utro. que latere faucium gemina, ovata, planiufcula; faepe den. tibus confertis exafperata, vel fcabra tuberculis, vel rugis transverfis fulcata; bafi unius, spici alterius connexa, brann-. chiis 4 cujusvis lateris cartila. gine junctis.
D 2
h) $20 \mathrm{r}$. 
h) 201. NAKES, funt foramira, organi olfactorii, fere femper in roftro ante oculos polita.

a. 202. Marginales, in apice roftri.

203. Anteriores, anticam roftri partem occupantes.

204. Mediae, in medio roftri fitae. 205. Poftremae, prope aut fupra oculos pertufae.

206. Supremae, in fummo capite inter oculos iisque contiguae.

207. Remotae, foraminibus a fe invicem di. ftantibus.

208. Vicinae, fibi invicem approximatae.

209. In os hiantes, poftice, vel fub labio pofteriore.

210. Extus inconspicuae, obliteratae, in os hiantes. (209.)

b. 2 I. Rotundae, peripheria circinnata, (foramina anticu.)

212. Ouales, ex orbiculato (8.) oblongae (9.), utraque extremitate rotundata aequali, (foramina poftica.)

213. Tubulofae, Fiftulofae, Cylindricae et intus cavae. (97.)

c. 21 4. Solitariae, unico utrimque foramine.

215. Geminae, Binae duplici utrimque foramine, per paria.

216. Inaequales, in geminis fere femper foramen anterius minus eft.

217. Parvae, exiguae, minimae.

i) $218.0 \mathrm{cuI}$, funt organa vifus, gemina.

a. 219 . Verticales, in vertice pofiti.

220. Supremi, fuperi, ad fuprema capitis latera. 
22.I. Laterales, medii, medium capitis latus oc. cupantes.

222. Binati, ambo in eodem latere, altero latere coeco.

223. Dextri, in latere dextro pofiti.

224 . Sinifiri, in latere finiftro obvii.

225. Approximati, fibi invicen vicini, fupremi.

226. Remoti, diftantes 2 fe invicem, laterales.

227. Marginales, antici, in apice fere rofti. 228. Vicini rofiro, medii inter roftrum et frontem.

229. Pofteri, pofici, a roftro remoti, fronti propiores.

6. 230. Plani, bulbo oculi non ultra orbitam pro. minulo.

231. Corsvexi, paululum prominuli extra orbitam.

232. Protulierantes, multum fupra fuperficiem capitis prominentes.

233. Globofi, ab omni parte rotundi.

234 . Oblongi. (9.)

235. Ovati. (7)

c. 236. Magni.

237. Proportionales, mediocres.

238. Minismi.

d. 239. Tecii, membrana niktitante undique involuti.

240. Semitecti, membrana riflitante tantum arcuata feu lunata, aut annulata feu perforata.

24I. Nudi, Cute feu sunica Corporis communi tesi. 
242. PUPILLA, cyeftallins globofa, vel oblonga.

243. IR I s, coloratus orbis pupillam cingens faepe amnulo diftincto pracditus.

k) OPERCULA BRANCHIAI.IA.

244. Operculum eft pars pofterio: maxillarum, fuperioris pracfertim, erigibilis, in utroque capitis latcre pone oculos fita, apcrturam branchialem claudens, branchias tegens et defendens et neminanam branchialem funtinens.

A. 245. Simplicia, unica et fimplici lamina compolita.

246. Diphylla, Triphylla, Tetrapiylla;, laminis 2.3. 4. conftans.

247. Offea, fubftantia dura, ner flexili.

243. Flexilia, mollia fexionis patientia.

249. Carnofa, fubftantia inufculni et cute craffa adipofa tecta.

250. Subarcuata, margine poftico rotundato. 25 I. Acuminata. lamina poftica procefru acuto. 252. Dinidiata, non omnina fed ex parte tantum tegens aperturam branchialem.

253. Fiftulofa, apertura branchiali excarata quafi in fubitantia operculorum.

254. Ciliata, margine appendicious cutaneis, fetaceis, parallelis longitudinaliter digctis.

6. 255. Cloula, fracnata, annera corpori cute. 
256. Libera, mobilia, elevationis et deprefrio. nis capacia.

c. 257. Solitaria, unum utrimque operculum.

258. Nulla, Apertura branchiali, patula denudata (in Branchioftegis et Nantibus.)

d. 259 . Proportionalia. 260. Mininna.

c. 26 I. Glabra. (25.)

262. Ajpera, fiabra. (27.)

263. Loricata. (30.).

264. Striata, lineis parallclis excavatis.

265. Radiata, friis e centro ad peripherian radiatim duatis.

266. Crataia rivofa, fulcis fuarfis fine certo crdine, et connexis.

267. Aculeata margine, aculeo uno, pluri. busve.

263. Serratu margine, incifuris refpicicntibus apicem.

269. Lucida, vitida, glabritie refpicndente,

270. Lacivia, glabra absque nitore.

f. 27 1. Nuda, fquamis et cute communi deftituta.

272. Alepiduta, fquamis, nec cute corcntia.

273. Squamofa, fquamis te?ta.

1) MEMBRANA SRANCHIALIS.

274. Eft Pinna ofliculis feu radiis membrana tenui junctis, cartilagineis, incurvis conflans: Operculis adiacrens, eorum que fub margine latitans; plicotilis et cxpanfilis, refpirationi praecipue inferviens,

27.5. Uismadistn, unico radio confans. 276. Biradiata, Triradiata ete. 


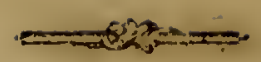

277. Patens, apparens, expanfa, morginem operculi excedens.

278 . Semipatcus, non omnino operculis tecta.

279. Inconjpicua, occulta, retroucta, nonnili diffracto opercuío conipicus.

280. Tecta, operculis celata, illiefis operculis confricus.

28i. Craffa, cute pingui camofa confans. 282. Aimpla, luta.

283. Guluris, infima, fuhtus in gula. 284. Latcralis, ad latera corporis fita.

m) 285. ATERTURA BRANCHIAIs eft rima hions in os, inter opercula et trun. cum, per branchias.

a. 286. Gularis, infra culam hians, nec a latere tho. racis vel capitis. (283).

287. Latcralis. (284.)

$2 x^{2}$. Cevcicalis, ad fupreina istera capitis.

289. Oicipitalis, ad nucham.

6. 290. Arcuata, femicircularis.

29r. Túbilofa, finulofa. (253.)

292. Revanda, margine flexuolo.

293. Ouata, limbo uno prae altero magis hiante.

c. 294: Minima.

295. Mediocris.

296. Amplifima.

d. 297. Operculata, operculis omnino tota teeta.

293. Seminuda, operculo dimidiato aperturam tontuin ex parte tegente.

n) 299. NuCHA pars capitis poftrema, trunco annexa.

b. TRU $:$. 
b. 30c. TRUNCUS eft pais corporis ab apertura branchiali, cauda teminsta, exciufis Artubus.

a. 301. BRANCHIAE funt organa refpirationis, caput inter et truncuns fita, conforntis oficulis (ut plucimum) quatuor falcatis, 'inciciualibus, incumbentibus, extrorfurri pectinntis, pro exchrdenda aqua ex gula, dein motu cpercuiorum et membranae branchioftegrae inde quoque cienda $f$, exprimenda.

a) 302. Vicinae, refirondentes eidem aperturâe branchiali.

303. Operculatac, operculis omnino toto: tectae.

304. Demudatae, operculo omnino deftiturat. 305. Laterales, ad latera fitae. 306. Occipitales, ad nucham fitae. 307. Occultae, Incourpicune, ronnifi fraptoperculis videndae.

308. Retroatfae, minus confpicuse, proi: gulam laterites.

b) 309. Simplices, Aequales, omnes ejusden noturae.

310. Anomalae, quibusdan cilintis, aliis tu berculatis, vel diversae frtueturne.

311. Tubercultatae, parte interiore in guls ofliculis tubcreulis exa.peratis.

312. Glabrae, inersncs, tiberculis deftitutec.

313. Sectinatab, ciliatae, parte exteriore ver. fus aperturain branchialem, rediis inftrêta feteceis, ve! lamellis.

314. Aculentale, parte intriore aculcis ar. matas.
D 5
b. 315 
6. 3I5. G U I A, pars trunci branchiis fuppoíta. 316. Ventricofa, turgida deorfum.

317. Carinata, fubtus angulo acuto. 3 I 8. Plaza, fiperficie aequabili.

c. 319 . Т нолАX, pars trunci incipiens ab extrema gula, terminata linea ducta ad ex. ortum pinnarum pectoralium.

d. 320 . D O R S U M, pars trunci fuperior, incipiens a nucha ad bafin caudae usque protenfa.

2.) 321. Apteryyizm, pinnis deftitutum.

322. Monoptcygizm, Dipterygium, Triptery. gizm, pinna una, duaivus, tribus in. ftructum.

b) 323 . Convexum, medio magis elevato, quan verfus latera.

3:4. Arcuatum, in arcum flexum.

325. ReCizm, linean rcetan fuperficie fequens.

326. Carinatum, margine fupero acuto.

327. Suliatim, excavatum fofluli, pro recon: denda pinna dorfali.

32S. Serratum, lamina gemina ferrata, recipiente pinnam dorfalem in furnmo dorfo.

329. Planum, fuperficie aequabili.

e. 330. LATERA, pars trunci a branchiis ad anum, dorfo abdomineque intercepta.

f. 33I. ABDOMEN, pars trunci ima, inter thoracem et coudse initium fita.

332. Carinatum; margine acuto.

333. Serratum, fquamis carinam conftituentibus apice dehifcentibus.

334. Planum (329).

335. Tumidum, pronineris, ventricofum, dcorfun turgens. 
g. 336, LxNEA Lateralis, linea per latera a capite in cauciam ducta, orta a fquamarum defectı, vel tuberculis, vel carina,

a) 337. Kedia, a capite ad caudam fine fexurn extenfa.

338. Curva, flexura vifibili.

339. Flexugfa, horfum vo:fum curva.

340. Infracta, pars lineae ab altera angulo acuro vel obtufo declinata.

34I. Abrupta, in partes duas pluresve non contigutas divifa.

342. Deficndens, a capite vel nucha oblique in caudam procedens.

343. Oblitcrata, obfoleta, vix confpicua.

b) 344. Suprema, fupera, dorfo proxina.

345. Lna, infima, infera in lateris parte inferiore.

346. Media, medium latus pervadens:

c) 347. Nulla, omnino abfens.

348. Solitaria, unica in latere unoquogue.

349. Duplex, gemina, binis in utroque lstere.

d) 350 . Mutica, laevis, glabra, aculeis tuberculis. ve deftituta.

35 I. Aculeata, aculeis vel verfus caput, vel verfus caudam inclinatis.

352. Vittata, zona longitudinali colorata ve! argentea tecta.

35 3. Porofa, poris pertufa.

354. Loricata, officulis tuberculisve fquamofis, duris, exafperata.

355. AN US, orificium externun inteftini reati. 356. Gularis, fub operculis branchi2. libus, 
357. Pectoralis, prope pectus infra bran. chisas.

358. Anticus, capiti vicinus.

35\%. Remotus, caudac vicinus.

360. Medizs, inter caput et caudam medio fratio.

i. $36 \mathrm{r}$, CAUDA, pars trunci folida, vertebris mufculisque lunbaribus formata, poft anum fita, tcrminàis truncum. 362. Teres. (3.)

353. Tetragoina. (15.)

354. Carinata. (31 7.)

365. Angulofa, lateribus carinata.

366. Muricata, aculeis tuberculisve exafperata.

367. Apterygia, pinna caudali nulla. 368. Dipterygia, pinna ad bafin usque bipartita.

369. Pinnata, pinna cognomine terminata,

₹ 370. SQYA MAE, funt corpufcula pellucida cartilaginea feu comea, corpus pifcium tégentia.

a) 325 . Imbricatae, fe invicem tegentes, dimidia plus minus parte.

372. Remotac, non inbricatim corpori adhaerentes.

373. In capite et corpore.

374. Iit trunco folum.

37.5. In pizmis.

376. Verticillatae, fquamis corpus snnulation ambientibus.

b) 377 . Nullac. (22.)

378. Rarae, intertitis fyuamarum confipicuis. 3':9. Confertal, denfe fibi invicem fuperimpofitae. 
c) 380 . Ovales. $(211$.

381 . Orficialdite: (8.)

382. Angrilatae, angu!is confpicuis notatae.

d) 393 . Deciatuae, luive, facillinic cafurae.

384. Tonaces, corpori fimiter sdhuerentes.

e) 335 . Fiexiles. $(248$.

386. Glabrae, inermes, lasues. (25.)

38\%. Striatae. (26\%)

388. Afperne, Aculeis exafperatie.

389. Punctatae, pindis confitae.

390. Ciliatae, margine procenfibus cartilagineis fetaceis, parallelis iongitudinaliter digeßis.

39 . Serratae, margine incifuris acutis notatae.

f) 392 . Amplae.

393. Paruae, tcunses.

394. Minimar.

l. 395. ADDITAMENTA, varige fartes trunci, non in omnibus pifcibus obviae.

a. 396. PIN N S S PUIAE, funt pinnse cuta. neae, raciis nulits fuftentatae.

397. Longitudimules, dorfo vel abdomini longitudinaliter infertae.

398. Obisuae, horfum vorfum oblique iniertae.

b. 399. DI G I TI, appendices cartilagineae fetaceae, faepe aiticulatae, liberae inter pinnas peetorales et ventrales trunco annexae.

c. 400. LORICA, eft tefta offa, funumaeformis, corpus vel partem tegens.

d. 40I. S CUTEL LA, eft corpus fenngiofo-carnofun, fuborbiculatum, concavum, marginatum, abdomini rel pefori impo. 
impofitum, po affigendo corpore faxis fuctione, faepe ex connatis pinnis ventroibus ortum, aliquando ct inter pinnas ventrales liberas fitum. SCUTEL L A Gouani. A CE. TA B ULUM, COTYLEDON, PIN NAE COTYLOIDEAE Pallas. PINNAE VEXTRALES IN ORBICULUM CONNATA A Artedio et Linnaeo. Co T U. L A Pallas. In Cyclopteris et Gobiis quibusdarn, ad priores pertinet Le. pidogafter Gouani.

c. ARTUS, funt pinnae, i. e. partes corporis officulis radiatae, difpofitis intra mem. branam conduplicatam, natationi in. Lervientes.

a. 402. Radii, officula feu tendines, articulats, inermia, flexilia, dichotoma. Malacopterygit.

403. Aculci, fpinne, oficula fimplicifina, (i. c. nee articulata, nec dichotoma,) rigiciufcula, pungentia. Acanthopte. ygii.

404. Radii friplices, articulati, flexiles, inermes, nec dichotomi.

6. Pinnae Dosfales.

- Pectorales.

- Ventrales.

- Analis.

- Caudalis.

- Branchialis, branchiofegia. 405. Simplices Pinnae, conftantes radiis vel aculeis. 406. Compofitae Pinnae, officulis diverfit conftantss. (i. e. radiis et aculeis.)

a. $40 \%$. 
a. 407. PIN NAEDORSAIES, funt pinnae dor. fo infertne, verticaliter expanfae.

a) 408. Longitudinales, longitudine totius dorfi.

409. Semi - longicudinalis, unsm partem dimidian dorfi occlipantes.

410. Occipitales, prope nuciam fitae.

41 1. Scapulares, jnter nucham et medium dorfum (i. e. fcapulis) infertae.

412. Mediae, Aequilibrantes, in aequilibrio pofitae.

413. Lumbares, pone aequilibrium, prope caudam (i. e. circa lumbos) infertae.

4r4. Diftinctae, feparatae a fe invicem et s cauda.

415. Approximatae, fere contiguae. 416. Remotae, longo fpatio divifae.

417. Coalitae, Adnatae, pluribus in unam junetis.

b) 418. Nullae, dotfo apteyggio. (320.)

419. Solitariae, unica in dorfo monopte. rygio. ( 322 .)

420. Binae, Geminae, Ternae, Onater. nae, diftinctae vel fubcoaleficentes in Dorfo di-tri-tetrayterygio.

6) 42 I. Radiatae, officulis insmibus leu radis conftans.

422. Aculeatae, א. fpinofae, oficulis fimplicibus pungentibus, $f_{0}$ aculis, $\mathbb{f}$. frinis.

423. Afperae, radiis vel aculeis, Sed dengi culatis et fcabris.

d) 424. Aequales ofruculis ejusem loneitudinis. 425. Declinatae, apice defendentes fenfim \& capite ad caudam brevioribus. 
426. Intcrruptae, officuilis meciiis brevifi. mis, caudali ct cervicali longrfimis, reliquis e medio fenfim afcendentibus.

427. Triangulata, acuminata, officulo medio aitifimo anticis pofticisque brevioribus, vel primo longifimo po. ftico breviffmo triangulum forman. te pinna.

428. Arcuatae, apicibus officulorum forman. tibus marginem arcuatum feu fegmento circuli factum.

e) 429. Exiguat, vix fupra dorfum eminentes.

430. Afjurgentes, altiffnnae, officulis pluribus praelongis.

f) 431. Carnofae, udipofae, cute carnofa tectae. 432. Squamofac, fquamis veftitae.

433. Kanicntaceae appendiculis membranaceis fimplicious vel palmatis, criftatisve apice vel lateribus adnatis, inftructae.

b. Pinnae Pectorales, funt pinnae, la. teri thoracis affixae.

a) 434. Supremae, f:perae, prope dorfum, -fupra inedium lateris aftixae.

435. Niediae in medio latere pofitae.

436. Imae, infimae, inferae, prope imam pectoris partem.

b) 437. Nuilae, if defunt.

$43 \%$. Solitariae, fingulae ad utrumque latus.

. 43\%. Geminae, duabus in utroque latere, inaequalibus.

c) 440. Longifintuae, capite longiores. 44r. Minimae, brevifimae, capite breviores. 442. Mediocres, longitudine capitis. 44.3. Volatiles, amplae. 
444. Rotundatae, margine poftico fegmento circuli.

445. Acuminatae fupra, radio fupremo lon. giffimo.

446. Acuminatae medio, radio medio longiffimo.

447. Falcatae, intus feu infra concavae, fupra

c. 448. PINNAE VENTRALES, funt pintae in ventre (late fumto) pofitae, vel faepe, jugulo, thorscique affixae.

1) 449. Fugulares, in jugulo, ante pinnas pe. Ctorales pófitae, claviculis affixae. 450. Thoracicae, fub pinnis pectoralibus, fae. pe pone eas parvo fpatio, at fem. per.jerno affixae.

45 1 . Abdominales, pone pinnas peetorales in ventre, nec in fterni apice, fed in offe pubis pofitae.

452. Antm ambientes, liberae vel connexae anum includentes.

453. Approximatae, fibi invicem vicinae, ca. rinze proximae.

454. Romotae inter fe, et carina interjacente.

455. Coslitac, cosmatae, coadunatae, mem. brana conjunctae.

b) 456. Nallae, fi defunt, in A Р О 457. Solitariae, unica tantum in ambobus 12 teribus finul fumtis.

458. Bisne, utrinque unica.

c) 459. Minimae, Pectoralibus breviores.

4fo. Mediocres, Peetcralium longitudine. 46I. Longifimac, Petoralibus fea capite
longiores.

E

d) 462 
d) 462. Didactylae, radiis muticis binis partitis. 463. Multiradiatae, radiis pluribus feptena. rium non excedentibus.

464. Difformes, fpina et cirrho conftant.

d. 465. PINNA ANALIs, eft pinna abdomini ab Ano ad caudam inferta, perpen. - diculariter expanla.

a) 466. Longitudinalis, ab ano ad caudam ejus. que longitudine extenfa.

467. Media, occupans parvum fpatium inter anum et caudam.

468. Poftica, in extrema cauda verfus pinnam caudalem.

469. Diftincta; a pinna caudae divifa.

470. Coalita, cum pinna calidae unita.

b) 47 I. Solitaria, unica.

472. Gemina, duabus.

c) $473^{\circ}$ Aequalis, radiis ejusdem longitudinis.

474. Declinata, radio antico longiore, reli. quis fenfim brevioribus.

475. Triangulata, radiis mediis longioribus. 476. Sinulata, radiis mediis breviffimis, antico ct. poftico Jongiffunis, reliquis fen. $f \sin$ e inedio afcendentibus. Interrupta.

477. Arcuata. (428).

6. 478. PINina CaUdalis, eft pinna extremo trunco, apici caudae verticaliter affixa.

2)! 479. Integra, Aequalis, officulis apice linean . reêam transwerfan conftituentibus. Truncata.

480. Rotundata, margine spicis fegmento cir culi. 
481. Bifida, bifurca, divifa finu lineari unico, marginibus rectis.

482. Triffida, trifurca, divifa finubus duobus. 483. Lunata, divifa finu arcuato, introrfum, marginibus exterioribus fublinearibus.

484. Subbifida, Enarginata, paululum fiffa, crena terminata.

485. Lobata, bifida, fed partibus inaequalibus. 486. Falcata, divifa finu introrfum arcuato, marginibus exterioribus convexis.

487. Cufpidata, lanceolata, attenuata apice, vel terminata apice fetaceo.

488. Setifera, Filo e divilura pinnae caudalis procedente.

b) 489. Diftincta, nec dorfali nec anali junca.

490. Coalita, cum dorfali et anali connexa.

c) $49 \mathrm{I}$. Nullar, cauda fine pinna truncum teriminante.

492. Unica, foliturib.

B. 493. PARTES INTERNAE, nonnifi integumentis et partibus externis remotis et feetione anatomica examinandae.

I. OSSA. funt partes induratae, naturae calcareae et ge. latinofae, pro formandis cavitatibus, tuendis partibus, et punctis fixis organorum motus, connexae in com$\mathrm{p} s \mathrm{gem}$, articulationibus variis ligamentisque.

In pifcibus Ca OND R O PT ERYGIIS fen $\mathrm{Am}$ phibiis Nasttibus Linn. omnia ofra funt mere cartilaginea, et ideo ficcata formam, molem et colorem amittunt.

a. OSSA CAPITIS, numerofiffina usque ad 80 , at praecipua funt fequentia. (8.)

494. Cranium $\mathrm{x}$. caput tegens, cerebrumque continens, Fronte fupera antica naribus pertufs. 
495. Offa Maxillaria 2. fuperiore faepe deficiente. 496. Offa Palati 2. (200.).

497. Opercula 2. branchialia $(244-273$.

498. Os Hyoideum inter crura maxillae inferioris, pro fuftentanda lingua.

$O \sqrt{a}$ auditus, nequaquam dubis.

b. OSSA THORACIS, parvam cavitatem claudentia, ideoque pauca.

499. Claviculae, funt officula falcata, pone aperturam branchialem fita, fupra primae vertebrae adnata, infra inter crura offis hyoidei unita. (Suftentant pinnam ventralem in $\mathcal{F}_{u g u}$. laribus.)

500. Sternum, os triangulare, vel fagittatum, vel rhomboideum, claudens Thoracem infra fir tum inter claviculas, (fuftentat pinnam ven. tralem in Thoracicis.)

501. Scapulae, offa arcuata rhomboidalia, in angulo inter fternuin et chrviculas fita, et plerumque pinnas pectorales fuftentant, unum utrimque.

502. Vertebrac Thoracicae, pars columnae offeae (articulatae, ferie longitudinali difpofitae, a capite ad extremitatem caudae) veftiens et fuftentans Thoracis cavuin; paucae funt ${ }_{2}$ et apophylibus brevifimis inftructae, medullam fpinalem foramine recipiunt.

c. OSSA ABDOMINIS, majorem cavitatem clau. dentia, offibus thoracis numerofiora.

503. Vertebrae Abdominis, pars columnae offeae (502.) veftiens et fuftentans cavum abdominis. Apophyfibus longioribus inftruetae, mc. dullam fpinalem foramine recipientes.

504. Coftae, offa arcuata, cingentia transverfun abdo. men, inferta apophyfibus vertebrarum abdo. minis. (Ubi defunt apophyfes, funt elongatae.) 
505. Offa Pelvis, funt offa bina abdomen pifcium claudentia, approximata vel diftineta (et pin. nain ventralem fuftentant in Abdominalibus.)

d. 506. C A D A, conftat vertebris caudalibus feu reliqua parte columnae offeae, truncum terminentis, apophyfibus 4. vel 3 . longis.

507. Apophyfis poftrema, vel Urechus, eft officulum verticale feu cathetoplateum, dpice crenatuin, pro fuftentandis pinnae caudalis radiis.

c. 508. OSSA INTERSPINOSA, funt officula, inter apophyfes vertebrarum inferta, iisque ligamento annexa. pro fuftentanda pinna dorfali et anali.

11. 509. MUSCULI, inftrumenta varia, fafciculis fibrarum in carnem et tendinem collecta, contratione et relaxatione motum pifcium producentia.

5I0. Mufculi laterales, funt mufculi majores, ex minoribus conipofiti, corpus a eapite ad caudam lateraliter obtegentes, pro feetendo corpore in latus utrumque, claviculis antice, vertebris, latere, poftice, ultimo off vertebrali caudae affixi.

5II. Mufculi Pinnae caudales, in quolibet larere funt quatuo: fublongitudinales, unus rectus fupra, obliqui duo fuperior et inferior, quartus imus, omnes expandendae caudae fubferviunt: at preterea duo transverfi funt Confrictores, fuperior et inferior, medio coaliti, pro conftringenda cauda.

512. Mufculi Pinnarum Pectoralium utrimque funt quatuor, viz. duo fuprafcapulares Ere. atores, et duo infrafcapulares Depreffores. 
51 3. Mufculi Pinnarum Ventralium, fex funt, duo offa pelvis exteriori parte veftientes Erectores, quatuor interiora offum occupantes Depreffores.

5 1 4. Mufculi carinales Dorfi et caudae, fulcum lon. gitudinalem dorfi a conniventibus mufculis lateralibus formatum occupant Mufculi carinales, et fic quoque in parte prona caudae.

515: Mufculi interfpinales pro quolibet offe interfpinofo 4, viz. duo antici Erectores, duo pottici Depreffores.

5I6. Mufuuli Membranae Branchialis plures, at praecipuus Dilatator off maxillae inferioris et off hyoïdi affixus, in quemlibet radium nembranae branchialis tendinem emittit.

III. 517. ORGA NA ET VIS CERA, funt partes folidae at molles, cavitatibus variis capitis, thoracis et Abdominis contentre, pro fenfuum ufu, et actionibus vitalibus formandis.

2) $518.0 \mathrm{C} \mathrm{ULI}$, ejus partes externae (2 18-243.) Lens cryftallina, corpus lenticulare vel fphaericum, pelluciduin, gelatinofum, pro colligendis radiis lucis in fundo oculi in retina, et fenfatione inde per nervos opticos in cerebrum transmittenda.

b) 519. CEREBRUM, eft vifcus cranio inclufum, in quod omnes nervi corporis convergunt, continuatur Medulla fpinali, per canalem a pro. cefluum Spinalium concurlu formatum procedente.

c) 520. О Е О Р H GUS, tubus membranaceus, glaber, a faucibus ad orificium Ventriculi reeta procedens. (Larynge, uvula et Pharynge pifces carent.)

d) $52 \mathrm{I}$. 
d) 52 r. VENTKICUIus, eft vifus facciforme, membranaceun, longitudinaliter fitum, pro digeftione vikus ingefti. (Saepe carnofus, faepe mufculofus, faepe geminus feu bilobus.)

e) 522. VESICA AEREA, eft folliculus tendinofus, plerumque oblongus, non raro pluribus lobis, fitus longitudinaliter, inclufus peritonaeo, inter vertebras et ventriculum, aëre plenus, et ductu preumatico in aliam partem internam adhucdum ignotam hians, pro sequilibrio pifcium in aquis. (Vefica aёrea deftituti, nonnifi in| fundo aquae obrepunt.)

f) 523. INTES.TINA, tubus membranaceus bis vel quater abdominis longitudinem aequans, longitudinaliter plerumque fitus, a ventriculi pyloro ortus mox inteftinis coecis pluribus $(1-100$.$) inftructus, inferius continuatur$ inteffino recto, fuhjecto veficae urinariae, terninatur ano donato fphinctere proprio.

g) 524. HEPAR, vifcus fimplex, aliquando bilobum vel trilobum, indifcriminatim dextram, finiftram vel anticam abdominis obtinet, pro fecernenda bile.

h) 525. VESICA.BILIARIS, CYSTIS FELLEA, eft folliculus membranaceus oblongus, annexus fuperficiei interiori dextri lobi hepatis, longo duEtu cyftico diftinguitur, et du. ctu choledocho in pylorum vel inteftinum inferto.

i) 526. $S P L E N$, vifcus finiftro lateri ventriculi fubjectum, hepate multo minus, planum, coloratum, oblongum, pro fanguinis dilutione, vel ufu adhucdum non fatis perfpecto.,

$$
\text { E } 4 \text { k) } 527 \text {. }
$$


k) $52 \%$ V ESICA URINARIA, eft folliculus membranaceus, ovatus, (non in inteftinum recum et anum) fed in foremen peculiare poft anum et ante pinnam analem hians, in. teftinoque recto fuperincumbens, pro continenda et emittenda urina.

1) 528. REN ES, funt vifcera gemina, compreffa, longitudine fere Abdominis, Vertebris appreffa, péritonaeo incumbentia, fenfim verfus ureteves attenuata, et veficae urinariae fundo ureteribus coalitis inferta.

m) 529. PAKTES GENITALIS, funt organa pro fecernendis, fovendis et emittenciis in ma. fculis genitura, in feminis ovulis.

a) Organe maris, duo corpora oblonga, carnofa, oblique fefe approximantia et veficae urinariae duobus foraminulis inferta, foventia genituram, per urethram emittendam.

b) Organum feminae, corpus oblongum bi - vel trilobum, ex globulis vel orulis tenui mein. brana involutis conftans, et quoque Veficae urinariae infertum; ovula emittenda per urethram.

C) Obfervatio, vix credibile pifces, preeter haec orga. na aut fi mavis genitalia, habere penem et vulvam, et revera eosdem coire, (nifi in Chondropterygiis) nam notiflma res eft, in Germania ova Salınonum matura ex abdomine expreffa in fitulam aqua plenam, dein genituram Salmonis eodem modo in fitulam ex. preffam, commixtamque in pifcinam effe effufa et brevi pifcinam featuife plurimis minutis Salmunculis, adeo ut fola mixtio Geniturae cum ovulis fufficiat, pro foecundatione ovuloruin, fine coitu. 
n) 530. BRANCHIAE funt defrriptae (par. 57 .

n. 301.) hic tantum monendum, ä̈ren squa contentum et una cum aq̧ua ore pilcium hauftain, per branchias ex ore excludi, fi. mul vero opercula aquam ex ea parte quae pone branchias eft expellunit tum aqua per branchias et ejus laminas fetasque percolata aërem dimittit, et is a vafculis quibusdam minutis ofculantibus abforbetur, ct illico fan. guini per sortam ex corde diffufo, hranchiis. que recepto mifcetur et dein duobus Truncis, uno ad Receptaculum Verncyi, altero fecundum Vertebras defcendente per corpus difpefcitur.

o) 531. PECTUS eft cavam thoracis, a branchiis fe. paratur concurfu clavicularum, vertebrarum, fcspularum et fterni; praeterea ab sbcomine diftinguitur fuperne Oefophago, poftice Dia. phragmate.

p) 532. DIA PHKAGMA eft membrana tendineocarnofa, fuperne vertebris atfixa, Oefophago perforata, fcapulis fternoque ac claviculis annexa, Abdomen a pectore feparans.

q) 533. PERICARDIUM, folliculus tenuior, coloratus, cor includens cum aquae portiuncula, partim liber, partim fterno, claviculis, et vertebris snnexus.

r) 534. Cor, vifcus mufculofum, fubrotundum at plurimum, aliquando pyramidale, raro tetraëdrum, ventriculo unico, longitudinaliter pofitum, mucrone caput, bafi diaphragma refpiciente, pro recipiendo et rurfus cifftribuendo fanguine per corpus.

8) 535. A UR I CULA eft folliculus inufculofus, cordi fupra finiftra affixus, corde capacios; infra finui venofo junictus.
E 5
t) 536 . 
t) 536. Sinus Ven asus eft cavum feu Receptaculum auricula capacius, eique fubjectum infertunque, infra recipit 3 truncos Venarum, quorum medius et maximus vegae cavae eft anslngus, reliqui fanguinem - ex partibus genitalibus, hepate et fplene collectum huic Receptaculo communicant.

פ) 537. A о к $\mathrm{TA}$ eft arteria conica apici cordis inferta, mox dilatatur, et in ramulos divifa branchiss permeat, dein rurfus in unum collecta aortann dcfcendentem format, quae rurfum in varios ramos divifa fanguinem variis corporis partibus communicat, unde reduEtus tandem in venas ad Sinum Venofum memoratum intrat et per hos receptaculum Auriculac et deniqua cordi redditur.

Obfervatio. Medulla fpinalis in pluribus Pifcium fpecicous, fecundun vertcbras dccurrit et eis junEta eft.

\section{HABITUS.}

A. GENERATIO. Adhucdum fub judice lis eft: alii ftatuunt Genituram Maris emifiam a Femina devorari, eamque fic impracgnari, et foecundata parese ovula : alii fufpicantur Mares coire cum feminis et penem ininimum immittere urethrae: (quod in Rajis, fqualis et aliis utique accidit) alii denique volunt Feminam emittere ovula, turgido ventre ovario repleto ovulis ad majorem molem excretis pru. riente; ideoque'vel fundum petunt vel loca plantis aquaticis et marinis feu fucis foeta, ubi fricant inferiora abdominis, tunc membranula colligente ovula dirupta, ea per urethram emittuntur. Mas eodem pruritu in loca eadem ad fricationem aptis inpellitur, ibique fundit genituram fuper ovula, eaque foecundat, quae dein calore folis et aquae temperie excluduntur. Haec forte falubrior fententia, nam

alias 
alias provida natura nimiam geniturae quantitatem in mafculis procreaffet; minime admittendo argumento, quum videamus nihil fupervacaneum in rstura efie.

Praeterea genitura falmonum mixta cum ovulis ex ventre expreffis in fitula, et inde pifcinae immifia, procrea. vit falmunculos perfectos; id reftat ut genitura fepara. tim, ovula feparatim in diverfis pifcinis reponantur, et fi tunc nulli oriuntur pifciculi, certo fundamento ftabit po. fterior fenténtia.

I. NUPTIAE, uti videtur promifcuae, indifcriminatim pluribus maribus fequentibus natando feminas plures.

II. NIDIFICATIO.

a. Certa, Cotti Gobii, in fundo glareofo.

b. Vaga, in arena, faxis, plantis fundi maris et aqua. rum dulcium.

III. FOETUS.

a. Vivus, productus ab Anguilla et Blennio vivipro; Raja, Squalo, Chimaera, Sygnatho, aliis.

b. Ovula, dein temperie aquae excludenda.

Numero prorfus ftupendo, exemplis Gadi Moruae $3,686,760$. Cyprini Carpionis 203, 109 . Pleuroneetis Flefi $1,357,400$. etc. ARt. Angl. a. 1767.

Colore, plerumque luteo, vel teftaceo.

\section{B. VICTUS.}

\section{CARNIVORI ET ZOOPHAGI.}

a. Animalia mortua ct Cadavera.

Muraenae et Petromyzones et alii pifces.

b. Animalia viva.

a. Homines, a Squalis et Rajis.

b. Avium et imprimis Anferum Pulli a Squalis, Luciis etc. 


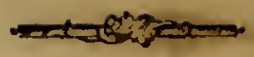

c. Pifces, a Coryphaenis, Scombris, Luciis, Percis, aliis.

d. Infecta, a Truttis et aliis Lacuftribus.

e. Carcelli, a Cottis, Gobiis et pluribus.

f. Vermes, a plerisque lacuftribus, fluviatilibus.

\section{PHYTIPHAGI.}

Fucis, Algis et plantis fubmarinis, imprimis Sparus Salpa et Labrus Scarus.

C. MORES.

I. SOCIETAS.

a. Soliturii.

b. Grigarii, Clupea Harengus, Sprattus, Pilcardus.

11. PECULIARES MORES.

a. Alii fugendo lambunt pctras, ut fiant ftabiles.

b. Alii affiguntur clypeo capitis Squalis.

c. Alii praecedunt Squalos, Gafteroffeus Ductor.

d. Alii jaculantur aquae guttas in infeeta ramis foliisve plantarum aquae vicinarum infidentia.

e. Alii pifcantur cirris oris,

f. Alii inertes fe defendunt electrico vel torporifico ictu.

g. Alii pinnis peßtoralibus elongatis evolant e mari.

L. Anguilla e lacubus in continentem procedit et poft pluviam inter pifa verınes limaces et infceta colleEtura latitat.

i. Alii natant in aqua fuprema, media, fundo.

k. Alii nonnifi in fundo obrepunt. 


\section{STATIO.}

A. HABITATIO.

I. SALUM.

a. Oceanus, mare altifimum procul ab omini terra.

b. Mare breve, littoribus inclufum, Baithicum, Mediterraneuin, Albuin, Pontus Euxinus, Mare Cafpium, Sinus Arabicus, Perfictss. etc.

c. Litiora; arenofa, glareofa, faxofa.

d. Scopsli, mare et brevia inter fcopulos i. e. rupes mari cinctas.

e. Lapides littorei, qui jacent in littore aeftu meris te. gendi, et recedente mari nudi.

f. Syrtes, loca asenofa, mari cinfta et tecta plus vel minus.

II. AQUAE DULCES.

a. Lacus, aqua dulcis pura, fundo ftabili,

b. Flurii, aqua dulcis defluens, magno volumine.

c. Rivuli, aqua dulcis defiuens, parvae molis, fundo faxofo, vel fabulofo praecipiti.

d. Paludes et Stagna, aqua dulcis ftagnans, fundo lotofo, plantis inundatis et aquaticis fcatens.

III. PISCINAE, habitationes Arrificiales.

a. Aqua mariza repletae, et emiftario inftruatae.

b. Aqua dulci, vel ftagnante vel fluviatili plenae.

B. REGIO.

I. CLIMA.

2. Intra Tropicos:

b. Zo. 
b. Zonis temperatis.

c. Circa Polos.

II. GEOGRAPHICE.

a. Mare Indicum.

b. Mare Anericanum.

c. Mare Pacificum, etc.

\section{TEMPUS.}

A. GENERATIONIS.

I. Anni, et tempeftatum, hyeme fub folftitiun ova ponit Gadus Lota.

II. Vitae, quo pifes a nativitate funt apti et generationi pares.

III. Durationis.
a. Quoties per annum
b. - per vitae curriculum $\}$ pariunt.
c. Quamdiu generationis tempus duret?

B. VITALIUM ACTIONUM.

\section{VICTUS.}

a. Alimenta quacrunt, mane, diu, vefperi, nostu.

b. Alimenta mutant pro anni tempeftate.

c. Alimenta sppetunt, fole fplendente, tempore ventofo, pluvio, ante vel poft pluviam.

\section{SOMNUS.}

a. Quando fomnum capiant?

b. Quamdiu requiei indulgeant?

III. MORS.

Quoto anno vitae ex mero fenio moriantur?

C. DE. 
C. DESQUAMATIONIS.

Qua praefertim anni tenpefate fquamss omittant fuccrelcentibus novis? et an?

Quantum temporis intercedat a Defquamatione ad fucceffionem novarum fquamarum? et an?

D. MIGRATIO.

\section{LOCUS}

a. a quo,

b. ad quein.

II. TEMPUS anni, vernum, aeftivum, hýbernum?'

III. CAUSAE, cibi copia, generatio, tempéries aquae.

IV. HYBERNATIO, torpo: in locis profundis lacuum, maris, fluviorum (Acipenferes, ) in luto (Anguillse).

\section{QUALITAS.}

A. SAPOR, vix defcribendus in plerisque.

B. COLOR, vide Terminos Entimologicos.

C. MENSURAE, vide Terminos Botanicos.

\section{US U S.}

\section{A. NATURALIS.}

Oeconomia Naturae, ejusque Politia in compefcendis

- Pifcium fpeciebus, ut fe femetipfos devorent.

Provida cura, in multiplicandis fpeciebus fapidis, utiliffinis: eorunque ovis difleminandis per Anates imprimis.

\section{B. ARTIFICIALIS.}

I. CULINARIS, offerentibus pifcibus vikum fapiaum, facilern paratu, copiofurn; non magni pretii, et tenuem, nec nimis nocaum.

$$
\text { II. DIAE- }
$$


II. DIAETETICUS, qui pifces in certis morbis aut praeferibcndi aut prohibendi, quaeque remedia ex piscious petenda.

III. OECONOMICUS.

a. Reditus publici, ex pifcatura ut et privati, fimal lucslii cupidinss reipublicae educat in pifcatoribus optimos, peritiffimos, numerofifimos Nautas.

b. Pifcinac, pro pifciun generibus propagandis, educandis, pinguefaciendis.

c. Cuttes, Squalorum et Rajarum pro fcriniariis et pro operiendis ciftulis et arcis; Acipenferis Peritonaeum pro Ichthyocolla; ejus Ova et Mugilis pro Garo. Gadus Cullarias, Morhisa, Molva, Clupea Harengus, iPilicardus et Encraficholus pro Salfamentis; Argentinae Sphyraenae veficula aërea et furfuraceae fquanulae cutis pro margaritis artificialibus.

IV. METEOROLOGICUS.

a. Colitis fofflis, in phiala, longa vitrea aqua plena, Barometrum.

b. Scombri Thynni et Pclamydes, cum vento natant occurluri Exocoetis volitantibus, qui contrario motu evolant ex aqua, ut hoftes evadant.

V. Leges pifcatoriae, prohibentes pifcari certos pifces, certis anni temporibus, et praefcribentes-magnitudinem pif́cium capiendorum et retium menfurain.

\section{CHARACTERES}

ORDINUM ET GENERUM.

A. CHONDROPTERYGII.

AMPHIBIA NANTES Linn. fpirantes non Pulmonibuș, fed veris Branchiis lateralibus per fpiracula ad ea ducentibus, offa et pinnae cartilngineae.

I. SPF. 
I. SPIRACULIS COMPOSITIS SEU PLURI. BUS, ( Jubvivipari.).

I. P ет то муz о , Spiracula 7. lateralis, Bran. chiae tectae, Fiftula in vertice vel roftro, Os-fub capite, Pinnae pectorales et ventra. les nullae.

2. RA JA, Spiracula 5. fübtus ad collum. Corpus depreffum, Os fub capite (vivipara.)

3. SQualus, fpiracula 5. lateralia. Corpus oblongum teretiufculum, $O_{s}$ in anteriore cor. poris parte fubtus. (vivipara.)

4. C н I M A E RA, Spiracula 5. quadrifida, fub collo. Oris labium fuperius quinquepartitum. Den. tes primores incifores, bini fupra infraque. (vivipara?)

II. SPIRACULA SOLITARIA. (ovipara?)

a. APODES.

5. E c h i na. Pinnae Ventiales, PeEtoralesve o.

Corpus anguilliforme? Os horizontale.Cirrhi 2. Labium lubricum

prope nares.

6. S Y N G N A T U S, (viviparus) Pinnae ventrales o.

Corpus articulatum, polygonum. Roftrum cylindricum, maxilla inferiore fuperam clau. dente. Apertura minima Opercula claufa.

7. Ostracion Pinn. Ventr. O.. Corpus loricr offea teffelata. Dentes utrobigue 10. Aper. tura linearis.

8. Tetra O D O , Pinn. Vent. O. Corpus fubtus muricatum. Dentes Maxilla bipartita. Aper. tura linearis.

9. DIODON, Pinn. Ventr. O. Corpus fpinis mobilibus. Dentes Maxill, offeae porrectae, indivifae. Apertura linearis.

10. BaL Is tes, Pinn. vent. I. carinata, vel o. Corpus compreffum fquamis corio adunatis. 
Dentes utrimque 8. longiores anter. 2. Apertura linearis, lateralis, fupra pinnas peztorales (quidam Baliftae fünt Abdominales.)

b. JUGULARES.

I1. L O P н I U s, Pinn, vent. 2. Corpus depreffum, Dentes minimi, Os anticuur, Apert. fubtubu. lofa. M. B. 9. P. P. talo $f$. brachio infidens.

12. CYCLOPTERUS, Pinn. vent. 2. in orbiculum coalitae. Corpus oblongo gibbofum. Os denticulatum. M. B. I. 4. 7. (ad Jugulares fpeetat.) lruc referatur Gouani Le. paảogafter.

\section{ABDOMINALES.}

13. A C I P E N E R, Pinn. ventr. 2. Corpus oblongum, Os edentulum fnb capite, Spivacula linearia, later. Cirri ante os. Squanis ofieis.

14. Cen triscus, Pinn. vent. 2. unitae. Corpius oblongum fpina loricatum, Abdomen carinatum, Caput roftratum, Apert. repanda.

15. Pegasus, Pinn. Ventr. 2. Corpús articulatum offeis incifuris, cataphractum. Caput roftro enfiformi, denticulato, Ore retractili: Apert. ante P. Peetorales.

B. PISCES PROPRIE DICTI (fpinofi).

I. APODES, Pinnis ventralibus nullis.

A. MALACOPTERYGII, pinnis muticis.

16. MuraENa, 'Corpus teres, lubricum. Nares tubulofae P. D. A. et C. unitae. Apertura branch. pone caput tubulofa ad P. P. M. B. 10. (vivipara?)

17. Gy m o tus, Corpus fubcultratum, Tentacula duo ad labium fuperius. Dorfum fubapterygium, Oculi cute communi teati. M..B. 5 . 
I8. A var h IC has, Corpus teretiufculum. Caput obtufum P. C. diftineta. Dentes primores co. nici 6. utrinque, molares et palatini rotundati. M. B. 6.

19. Stromateus, Corpus ovatum, lubricum, Caput compreffum, Dentes maxillares, palatini, acutiufculi. Cauda bifida. M. B, 5 vel 6 .

20. A m M O Y TEs, Corpus fubteres, Caput corpore anguftius. Labium fuperius duplicatum. Dentes acerofi. . Causda diftincta. M. B. 7 .

21, LEP T OC'EPHALUS, Corpus compreffum enfiforme, Cuput exiguum, compreflum, Octs$l i$ laterales maximi. Dentes minutiffini. P. P. V. et C. nullae D. et A. unitae, Apertura patula. M. B. . . .

b. ACANTH OPTERYGII, pinnis fpinofis. 22. TRICHIURUS, Corpus comprefro-enfiforme. Caput porrectum. Dentes enfiformes, apice femifagittati. Caudá fubulata aptera. M. B. 7 .

23. O P I DIUM, Corpus enfiforme. Caput obtufum, nudum. Os obliguum. Dertes maxil. lis, palato faucibus. Pinnae. D. A. C. unitae M. B. 7 .

24. X I р н I A S, Corpiss teretiufculum. Caput roftro enfiformi max. fup. Os edentulum. M. B. 8.

II. JUGULARES, pinnis ventralibus ante pectorales. a. MALACOPTERYGII.

25. Ga Dus, Corpus oblongum. Caput laeve. P. Ventrales in acumen attenuatae. P. D. A. que plures. M. B. 7 .

6. ACANTHOPTERYGII。 26. BLENxIUS, Corpus lanceolatum. Capus declive. Dentes ordinati, ferie fimplici. $F_{2}$ P.V. 
P. V. didactyla mutica. M. B. 6. (Blennius viviparus.)

27. Uran o,scopus, Corpus cuneiforme, Caput depreffiufculum corpore latius. Os fimum. Oculi verticales. Anus in medio. M. B. 5 .

28. Tra h I N Us, Corpus oblongum, Caput obtufum, compreffum, Opèrculorum lamina ferrata. Anus prope pectus. M. B. 6.

29. Callyonymus, Cospus fubcuneiforme, fubnudum. Caput Labio fuperiore duplicato. Os horizontale. Oculi approximati: OpercusLum claufum. Apertura occipitalis. M. B. 6.

HI.-THORACICI, pinnis, ventralibus fub pectoralibus et in fterno.

a. MALAC OPTERYGII.

30. LE P I O P U S, Corpus enfiforme. Caput porrectum. Max. inf. longior. P. D. longitudinุaiis. P. V. et A. fquamaeformes. $M$ B. Z.

31. EC MEN EIS, Corpus fubcuneiforme, nuduin, Caput depreflum, Clypeo plano, ovato, tran's. verfum fulcato ferrato. M. B. ro. "

32. Pieuronectes, Corpus compreflum, ovato lanceolatum, latere alrero dorfun, altero abdomen referens. Oculi binati. M. B. 47 .

6. ACANTOPTERYGII.

33. C H A ET о D о N Corpus ovatum, comprenum, pißum. Dentes fetacei flexiles, confertifini. P. D. et $\Lambda$. carnofa et fquamofa, M. B. 5. vel 6 . 34. HARPURUS (Acanthurus Forfkalii) Corpus ovatum, compreffum, fquamolum 'Roftrum elongatum, Dentes utrimque contigui, rigidi, unius ordinis, (nec fetacei, nec flexiles) P. D. et $A$. longitudinales, nudae (nec carno. 
fae ) fere fermper pictae. Spinae vel fquamae offeae falcatae utrimque ad latera caudae. M. B. 4. vel 5.

35. ZEUs, Corpus compreffum, ovatum. Caput declive. Mlax. fuper. fornicate. Linguza ramentacea. M. B. 7. Superioribus perpendicularibus, infina transverfa.

36. Mullus, Corpus attenuatum, fquamis magnis facile deciduis. Caput declive fquamofum, Cirris in quibusdam M. B. 3 .

37. Gastrerosteus, Córpus obverfe lanceolatum, ad caudam utrimque carinatum. $\mathrm{Ca}$ put ovatum. Aivlei recumbentes ante pinnam darfi (P. V. pone P. fed fupra fternuin.) M. B. $3-8$.

38. Trigla, Corpus conicum. Caput loricatum, radiatum. Digiti liberi ad pinnas peetorales. M. B. ?.

39. Cоттus, Corpus fubcuneiforme, Caput corpore latius, planum, fpinofum, aculeatuni, cirratum, tuberculatum. M. B. 6.

40. Sc orpaena, Corpus lancenlatum. Caput magnum cirrhofum. Opercula aculeata. OCtbli vicini. M. B. 7.

4I. PERCA, Corpus oblongum, Caput declive. Opercula fquamofa, ferrata. Os dentatuin. Pinnae finofae. M. B. $3-7$.

42. SCraena, Corpus ovato-lanceolatum, Caput declive, Opercula fquamofa et caput. P. D. infoffula recondenda, vel inter duo folia fquarnofa. M. B. 6.

43. L A RRUs, Corpus ovato-oblongum, compreffum, Caput fquamofun, Os dentatum inciforibus acutis. Labia carnofa, duplicata, ma. gna. P. D. et A. poft fpiras ramentaceae. P.P. rotundatae. M. B. 5. vel 6. Linea lat. parallela incurva, poftice infracta, media recta. 
44. SPARU S, Corpus oblongo - ovatum, compreffum: Caput fquamofum: Os maxillis ducti. libus. Labiis parvis, Dentes, incifores validi, molares conferti. P. P. acuminatae. P. D. compofita plicatilis (raro in foflula dorfi) P. V. ftrietae, cum fquama laterali ftrifta utrimque adjacente. Lin. lat. parallela arcuata. M.B. 5.

45. Sс омвек, Corpus ovale, linea laterali pofice carinata, Caput acutum, compreffum. Pinnulae verfus caudam. M. B. 7 .

46. С огтрн а е а, Corpus cuneiforme. Caput maxime truncato- declive. P. D. longitudinalis. M. B. 5 .

47. Trachipterus, (Falx Venetorum) Cor-

- pus enfiforme, Caput declive, Maxilla utrimque fornicata. Linea lat. reeta, fquamis terie fimplici, Pinnis aculeatis, ferratis, fcabris. M. B. 6.

48. C е P O L A, Corpus enfiforme, nudum. Caput fubrotundum compreffum. Os fimum. Den. tes curvati finplici ordine. Abdomen vix ca. pitis longitudine. M. B. 6.

49. Go i i us, Corpus tereti lanceolatum. Caput poris 2 inter oculos altero anteriore. P. V. unitae in ovatam. M. B. $2-5$.

IV. ABDOMINALES, Pinnis ventralibus pone Pectorales in OfJe pelvis, nec in fterno.

a. MAL A C O PTERYGII. 50. Совгтгs, Corpus fubaequale, oblongum, vix ad caudam anguftatum. Caput parvum. Oculi fupremi. Opercula inferne claufa: plerique cirrati. M. B. $4-6$.

5I. A si A, Corpus teretiufculum fquamofum. Ca. put nudum, offeum, feabrum, futuris confpicuis. Cirri 2. nafales. Dentes in maxillis palatoque conferti, acuti. M. B. 12. 
52. CYPRIN US, Corpus ovato - oblongum. Caput fubroftratum Os edentulum. Os siafale bifulcum. Opercula poftice et fuperne emarginata $P . V$. faepe 9 radiata. M. B. 3.

53. Clupea, Corpus lineari lanceolatum, Caput rofratum. Maxillae fuper. myftacibus ferratis. Aúdçninis carina ferrata. Branchiat interne fetacene. P. V. faepe 9. radiata, M. B. 8.

54. Ex O C OETus, Corpus oblongum, argenteum.

- Caput fubtrigonum fquamofum. Max. edentulae, utroque latere connexae. $P$. P. fupremae; longitudine trunci, radiis antice carinatis P. D. lumbaris, M. B. 10.

55. Mогмтвиs, Curpus ovatum, fauamofim. Caput porrecturn, laeve. Dentes plures emarginati. Apertura linsaris, absque operculis. M. B. I.

56. Aтt her I A , Corpus oblongum. Caput me. diocre. Max. fuperiore planiuferla, Labia denticulata. Linea later. fafciata, argentea. $M$ B. 6.

57. ARGENTINA, Corpus tereti oblongum, Caput roftratum corpore latius. Antis car. dae vicinus. P. V. multiradiatae. P. fruria lumbaris. M, B. 8 .

58. Sa Imo, Corpus lanceolatum. Caput laeve fubacutum. $P . V$. multiradiatae. Dentcs in maxillis, ct lingus. P. D. poftica adipofa. M. D. 4 - IO.

59. Es ox, Corpus teres, elongatum. Caput roftràtum, plagio-plateum. Mandibula fup. planiufcula, infer. longitudinaliter poris pun. cata, longior. Dentcs in maxillis, lingua. M.'B. 7 - 12.

60. Fistularia, Corpus angulofum, fubfuaforme. Caput cylindricum, roftratum, apice F 4 maxil 
maxiliofum, inferiore ut operculo clauden. te fuperiorem. M. B. 7 .

6I. L or I C A R I A, Corpuis cataphractum. Caput latuin, depreflum, roftratum, Os edentulum retractile. M. B. 6.

b. ACANTH OPTERYGII.

62. Si l u r U S, Corpus oblongum. Caput magnum nudum Os cirris filiformibus 2. 4. 6. aut 8 . tentaculatum. Radius primus P.D. et P. fpinofus retrodentatus. M, B. $4-14$.

63. Tе U T is, Corpus ovato lanceolatum. Caput antice fubtruncatum. Dentes ferie fimplici, sequales, rigidi approximati. M. B. 5 .

64. P о у х е м U S, Corpus oblonguin. Caput roftratum compreffum, undique fquamofum. Digiti liberi ad pinnas pectoris, non articulati. M. B. $5-7$.

65. M v GIL, Corpus lanceolatum. Caput fubconicum. Labia membranacea. Max. Juper. intus fiffa, fulcata, carinam inferioris excipiens. Denticulus inflexus fupra finus oris. - Dentes nulli. Opercula laevia rorundata. M. B. 4. 5. aut 7 .

66. E L O P S, Corpus lanceolato -attenuatum. Caput magnum, lacve. Dentium fcabrities in maxillarum margine, palato. M. B. duplex 30 . exterior minor prasterea armata dentibus 5 . Cauda infra fupraque armata fquama offea feu fpina lanceolata horizontali, 


\title{
FUNDAMENTA E T
} T E R M I N I

\section{EN TOMOLOG I A E,}

CONGESTA

SECUNDUM MET.HODUM ET AD DUCTUM

\author{
CELEBERRIMI EQUITIS \\ CAROLI A L IN NÉ.
}




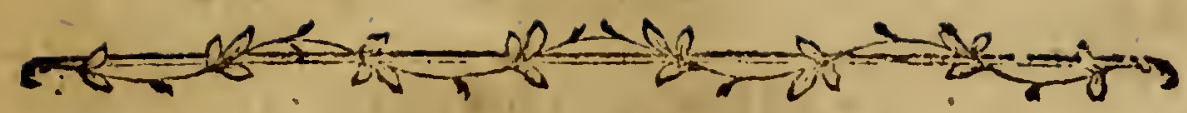

T E R M I N I

\section{E N $N$ T O M O L O G I C I} SECUNDUM METHODUM

ET A D

E X P L I C A N D U M S Y S T E M A

CELEBERRIMIEQUITIS

C A R O L I A L I N N É.

A. $\mathcal{E}$ ENUS, Nomen felcetifimum.

Character naturalis et effentialis generis ab alis, elytris, antennis, ore (feu roftro, maxillis etc.) aculeo, pedibus petendus.

Claffis, ordoque fy/tematis praefantifimi.

Ordo naturalis demonftrandus, et connexio generum.

B. SPECIES, Nomen trivialc.

Differentia fpecifica demonftranda; certifima, brovifluma, imprimis a fcutellis, cornubus, figura thoracis et elytrorum, longitudine antennarum, figurá, colore, Ariis, punctis, maculis, fafciis, lineis, alarum et elytrorum, figura femorum, fpinis, dentibus, pilis, tomento, hirfutie partium, ftructura caudae, antennarum etc. at me. liora nomina a victu in plantis certis, vel animalibus. Synonyma cum Defcriptione et Figura felecta.

C. CRITICA, Etymologia nominis generici; Jpecifici. Inventor cum tempore. Eruditio Hiftorica, Critica, Antiqua. 


\section{DESCR IPTIO.}

1. Infecta, animalia polypoda, cruftaceo integumento teeta, Cpiraculis lateralibus refpirantia, antennis mobilibus capiti affixis, inftrueta, (corde uniloculari, uniaurito, fanguine ichorofo, frigido, non colorato.)

In Infecto confideranda, examinanda, defcribenda:

A. PARTES EXTERNAE Infecti, funt eae quae fine fectione anatomica obfervari poffunt.

1. CORPUS TOTUM in genere.

a. FIGURA.

2. Orbiculatum $\uparrow$. rotundatum, peripheria circinata (diameter longitudinalis aequalis transveriali.)

3. Ovatum, cujus diameter longitudinalis fu. perat transverfalem, bafi fegmento circuli circumfcripta, apice anguftiore.

4. Ovale, ex orbiculato oblongum, utraque ex. tremitate rotundata aequali.

5. Oblongum, diametro transverfali parte aliquota longitudinalis.

6. Lineare, oblongum, aequali ubique latitudine.

b. INTEG U ME N TO teêum.

7. Cutaceo, molli, impreffioni digiti cedens.

8. Cruftacco, duriufculo, elaftico, impreffioni digiti refiftens, fubftantis plerumque epiIpaftica.

9. Calcareo - cruftaceo, cruftaceo, fubftantia fub. calcarea.

c. SU B STA N T IA.

10. Membranaceum, feu foliaceum, fubtantia tenui ad folium accedente.

I I. Teres, fere cylindricum.

12. Compreflum, pulpofum, lateribus magis quam difco complanatis. 
1 3. Cylindricum, lineare, teres.

14. Hemifphaericum, fubftantia globora, fupra convexa, fubtus plana, globùn diffectum imitante.

d. SUPERFICIE.

15. 'Pubifcens $\mathrm{f}$. villofum, tectum pilis mollibus.

16. Tomentofum, villis intertextis, nec difcernendis obductum.

7. Pilofum, pilis diftinctis elongatis confitum.

I8. Sericcum, pilis adpreffis nitentibus inollifimis tectum.

19. Rugofum, rugis obfitum.

20. Scalorum, punftis rigidiufculis prominentibus exafperatum.

21. Punctatum, adiperfum punctis excavatis.

22. Hifpidum, fetis rigidis fcatens.

23. Nudum, fetis et pilis (15-18. et 22.) deftitutum.

24. Imbricatum, fquamis variis fuperimpolitis confitum.

25. Glabrum, fuperficie lubrica,

26. Nitidum, glabritie lucente.

II. PER PARTES CORPUS CONSIDERAN. DUM.

a. C A P U T inftruitur Oculis et Antennis femper, ore plerumque, faepius palpis et femmatibus.

a.' F I G U R A.

27. Rotundum f. orbiculatum. (2.)

28. Ovatum. (3.)

29. Obtufum, intra fegmentum circuli termi. natum.

30. Anyulatum, margine figuram angulofam re. praefentante. ( 3 - 6 etc. angulare.)

3r. Integrum, indivifum, omnique finu deftitutum. 
32. Lunatum, fubrotundum, bafi finu divifum, angulis pofticis acutis.

33. Conicum, teres, apice attenuatum.

34. Attenuatum antice, bafi obtufa, apice anguftatum.

35. Attenuatum poftice, apice obtufo, bafi anguftatum.

36. Dentatum, margine acuminibus patentibus remotis.

37. Emarginatum, terminatum crena.

38. Retufum, terminatum finu obtufo.

39. Truncatum, terminatum linea transverfali.

b. STRUCTURA.

40. Prolongatum tubo, apice excurrente in tubum. 4. - - vefica, apice excurrente in ve. ficam.

42. Cornutum, parte aliqua capitis in cornu de. finente.

c. SUPERFICIE ET SUBSTANTIA.

43. Tuberculatim, puncto uno vel pluribus rigidis prominentibus exafperatum.

44. Rugofum, linea undata, elevata, vel pluribus notatum, longitudinaliter vel transverfim.

45. Canaliculatum r. fulcatum, linea una pluribusve profundis excavatum.

46. Nudum, fetis (22.) et pilis ( $15 .-1$ \&.) deftitutum.

47. Muticum, cornubus (42.) et tuberculis (43.) deftitutum.

48. Gibbusm, utraque fuperficie convexa.

49. Deprefum, difco magis quam lateribus complanatis.

50. Clypeatum, fupra tectum fubftantia foliaces dilatato - complanata, 
d. IN S ERTIONE.

51. Retractile, intra thoracem pro lubitu retrahendum et ahfcondendum.

52. Retractum, intra thoracem pofitum, nec ab eo-exterius difcernenduin, (in Cancris, Scorpionibus.)

53. Exfertum, a thorsce divifum, et bene difcernendum.

54. Prominens, thoraci recta in eodem plano affixum, eoque multo angufius.

55. Porrectum, prominens (54), elongatum. 56. Inflexum, thoraci non in eodem plano affxuin, verum ut apex deorfum fpectet.

57. Nutans, thoraci ad angulum rectum trans. verfim affixum.

2) 58. O C u I funt organa, quibus Infecta vident objecta.

a) 59. Simplices, funt oculi unica lente in. Atructi.

b) 6o. Compc/iti, pluribus, faepe numerofifi. mis lentibus infructi, ad videnda ob. jecta e propinquo, et lateribus.

a. S I T U.

6. Verticales, in capitis vertice fiti. 62. Laterales, ad latera capitis.

63. Inferi, fub capite fiti.

64. Contigui, uno latere vel puncto fe tangente.

65. Approximati, fibi invicem vicini. 66. Remoti, diftantes a fe inviccm.

b. I NSERTIONE.

67. Immobiles, ita inferti capiti, ut mo. veri nequeant.

68. Mobiles, ita adnati, ut moveri polfint. 69. Pedunculati, atixi pedunculo 
C. SUPERFICIE.

7o. Convexi, paululum prominuli extra caput.

7. Plani, ejusdem fuperficiei quam caput.

72. Prominuli, multum fupra capitis fuperficiem elevati.

73. Lunati, figura lunam falcatam referentes.

74. Concolores, ejusdem cum capite et corpore coloris.

75. Colorati, coloris diverfi a capite.

76. Punctati, pundis variis afperfi.

77. Fafciati, fafciis coloris diverfi trans.

d. NU MER O. verfin picti.

78. Bini, ad utrumque latus capitis uno.

79. Quaterni, oculis diftinctis quatuor, omnibus verticalibus, duobus an. te duobusque poft antennas; vel duobus verticalibus, duobus in. feris, vel duobus verticalibus, duobus lateralibus:

80. Seni et OCEoni, oculis diftinctis 6. vel 8. (in Araneis et Siorpiis.)

b) 8 I. STEMMATA funt oculi fimplices bini vel terni plerumque vertici adnati, ad videnda objecta e longinquo et fupra infectum pofita.

c) 82: Os eft organon, quo utuntur ad capienda alimente fibi propria.

a) FiguRA ET PAKTIBUS.

8. 83. ROSTRUM. os elongatum apice acuıninatuul.

84. Corneum, fubftantia dura, elaftica. 
85. Cylindricum $f$, teres, lineare, so. tundum.

86. Conicum, teres, apice attenuatum.

87. Setaceum, tenue, flexile, fenfim. verfus apicem attenuatum.

88. Tubulofum, tubo perforatum, integrum.

89. Bivalve, valvulis duabus concavis coeuntibus tubumque formah. tibus:

90. Multivalve, valvulis pluribus etc.

91. Rectum, flexura deftitutum.

92. Porrectum. (55.)

93. Geniculatum, flexum, angulo.

94. Inflexum, nec porretum, nec geniculatum, tendens ventrem et pectus verfus.

95. Arcuatum, flexum fegmento circuli. 96. Nutans, capiti transverfo affixum.

97. Acutum, terminatum apice angulo acuto.

98. Obtufum, intra fegmentum circuli, - apice terminato.

99. Capite, thorace longius.

100. Longifimum, corpore longius.

101. Longum, capite longius (longiro. frris Curculio).

102. Breve, capite brevius (breviro. ftris Curculio).

b. 103. Рвово Ссіs, tubus pertufus, faepe carnofus, apice dilatatus.

104. Recurvata, decrfum fexa, ut arcus fuperiora fpectet.

105. Inflexa, oblique affixa capiti, ver. fus pectus vergens. 
106. Retractilis, intra labia pro lubitu retrahenda.

107. Plicatilis, replicanda apice in pofteriora.

108. Valvulis, inclufa membranulis concavis, (dusobus, pluribus.)

c. I09. LINGUA eft organon" membranaceum vel carnofum interius canaliculo excavatum.

110. Replicatilis, apice in pofteriora plicanda.

I I I. Spiralis, in fpiram collecta, inter duos palpos.

112. Univalvis, unica valva excavata femicylindrica.

II 3. Bivalvis, valvis dusbus concavis coeuntibus in tubum.

d. I I 4. MAX I L I A E funt organa, plerumque femicircularia apice muricata, transverfun movenda ad detinendos, comminuendosque cibos.

I 5. Binae, duae tantum.

I16. Plures.

I17. Exfertae, a capite divifae, beneque difcernendae.

1 8. Prominentes, capiti reeta in eodem plano affixae.

I I9. Porrectae, prominentes (I I 8.) elongatae.

120. Dentatae, margine acuminibus patentibus remotis.

I 2 I. Forcipatae, forcipem imitantes.

122. Furcatae, apice in furcam divifae.

123. Lunulatae, forms lunulae, i. e. medio crafliores, bafi et apice anguftiores.

e. 124. 
e. I 24. P A L P I, organa, faepe articulata, ori affixa, antennis plerumque minora.

125. Binis, duobus tantum.

126. Quaternis, plerisque, fenis raro.

I27. Simplices, non articulati.

128. Articulati, in plures artus vel articulos connexos divifa, ad mul. tiplicandam varietatem motus.

129. Recti, flexura deftituti.

1 30. Porrecti, recta antrorfum !petantes.

I 3 1. Incurvi, extrorfum verfus coeluin flexi.

132. Recurvati, deorfum flexi.

133. Pediformes, articulatione geniculata, inftar pedum.

I34. Sululati, ad bafin lineares, verfus apicem attenuati.

135. Setacei, fenfim a bafi ftatim verfus apicem attenuati.

36. Clavati, verfus apicem fenfim lin. craffati.

137. Truncati, apice terminati linea transverfali.

I38. Chelyferi, ungue laterali mobili ante apicem affixo.

139. Pilofi, pilis diftinctis elongatis tekti.

I 40. Elongati, folito longiores, (vel ore longiores.)

f. I 4 I. I A B I A funt partes prominentes, os includentes.

142. Lateralia, ori perpendiculari ad latera appofita.

143. Transoerfa, ori transverfim affixa.

g. 144. PAIATUM, pars interior lsbii, imprimis transverfi. 
b) SI ru.

145. Terminale, in spice capitis.

I 46. Inferum, in parte prona capitis.

147. Pectorale, in pectore tubo feu roftro affixo.

d) I 48. AN TEN N A E, organa bina vel quaterns, plerumque articulata, cruftacea, pro fenforio nobis ignoto infervientia.

a) STRUCTURA.

I 49. Ramofae, ramis pluribus lateralious.

150. Simpliccs, una ferie fine ramis ad apicem extenfae.

15 I. Moniliformes, filiformes (174.) articulis diftinctis furoglobofis.

152. Perfoliato - imbricatae, foliolis concavis imbricatim pofitis, medio connexis,

153. Articulatae, articulis diftinetis. (1 28.)

I5 4. Exarticulatae, nullis articulis dittinguendis.

155. Filatae, antennae Mufcarum et Tabani capitulo orbiculato compreffo de. fitutae.

I 56. Subulatae, ad bafin lineares, apice attenuatae.

157. Clavatae, verfus apicem fenfim incrafiatae.

I 58. Mucronatae, terminatae mucrone extante.

I 59. Acuminato-fetacene, 1. apice fetigerae, terminatae pilo rigidiufculo, apice attenuato.

160. Ariftatae, antennae Mufcarum, capitu. lo orbiculato comprefro laterali inftruftae; cui infidet arifta fetofa, 
16r. Setariae, Ant, ariftatae, feta fim. plici nuda.

162.' Plumatae, Ant. ariftatae, feta bipectinata.

163. lectinatae, emittentes uno alterove latere fetas parallelas, fecundum to. tam longitudinem.

164. Lamellatae, pectinatae (I63.) fquamulis parallelis.

165. Verticillatae, pilis in verticillum ad aticulationes difpofitis-

166. Plumofae, pilis plumulam efficientibus.

167. Chcliferae, apice incraffato, ungueque laterali mobili inftructae.

b) S U I S T A N T IA.

1 68. Cylindricae, teretes, lineares.

169. Comprefjae, lateribus magis quam difco complanatae.

I 70. Comprefjo-lineares, aequabili latitudine.

I 7 I. Lanceolatae, oblongac, utraque cxtremitate attenuatse.

172. Lanceolatae orbiculatae, peripheria circinatae.

173. Prifmaticac, lineares, lateribus planis, pluribus quam duobus.

174. Filiformes, fecundum totam longitudinem ejusdem craffitiei.

175. Setaceae, verfus apicem fenfim attenuatae.

1?6. Fufformes, verfus medium fenfim in. craffsiae.

177. Lunatae, funuatae in lunam cornicu. latam.

178. Clavatae, verfus apicem fenfim incraffatae. 
179. Uncinatae, clavatae, mucronatae, mucrone in uncum reflexo, fere ad an. gulum reetum.

180. Capitatae, clavatae ( 178. ) apice fubrotundo feu capitulo.

I81. Fiffiles, capitatae, capitulo longitu. dinaliter in partes plures parallelas difrecto.

182. Perfoliatae, capitatae, capitulo horizontaliter fiffili, bafi transverfe cingente antennam.

I83. Globofac, capitatae, capitulo glo. bofo.

184. Truncatae, capitatae, capitulo apice terminato linea transverfa.

c) SUPERFICIE.

185. Nudae, fetis et pilis deftitutae.

186. Pilofae f. hirfutae, pilis diftinetis elongatis tectae.

197. Barbatae; pilis ad nodos articulorum fafciculatis.

188. Hifpidac, fetis rigidis adfperfae.

189. Ciliatae, fetis parallelis, uno verfu, fecundum longitudinem antennae, infertis.

190. Aculeatae, mucronibus minoribus armatae.

191. Aculeato-Jerratae, aculeis denfis apicem refpicientibus. -

192. Aculeato - uncinatae, aculeis in uncum flexis.

193. Spinofae, mucronibus majoribus fubulatis horridae.

194. Dentatac, acuminibus patentibus remotis ano verfu difpofitis. 
195. Serratae, omnibus incifuris extremitatem refpicientibus.

d) DIRECTIONE.

196. Rectae, flexura deftitutae.

197. Rigidae, flexionis impatientes.

198. Nutantes, apice extrorfum deorfumque flexo.

199. Spiriformes, in fpiram collectac.

200. Pedatae f. pediformes, inftar pedis, fle. xae angulis.

c) SITU ET INSERTIONE.

201. Bafi coadunatae, infra inter fe connatae. 202. Bafi diftinitac, oppofitum priori (201). 203. Bali approxisnatae, infra inter fe vicinae. 204. Remotae, diftantes a $\mathrm{fe}$ invicem.

205. Pro-ophthalmac, ante oculos pofitne. 206. Catophthalmine, pone oculos pofitae. 207. Hypophthalmae, fub oculis pofitae. 208. Hyperophthalmae, fupra oculos pofitae. 209. Amphiophthálmae, oculis in univerfum vel ex parte cinctre.

f) MENSURA.

210. Breves, corpore breviores.

211. Mediocres, longitudine corporis.

212. Longae, Corpus longitudine excedentes.

213. Longifimae, quarum corpus eft pars aliquota.

214. Elongatae, capite longiores.

215. Capite breviores.

2!6. Palpis longiores.

217 - breviores.

218 Thorace longiores.

2 I9. - breviores.

b, 220 . 
b. 220. TRUNCUS, pars corporis inter Caput et Abdomen intercepta, cui pedes inferti, ejusque partes, funt Thorax, Scutellum, Pectus et Stersitm.

a) 22 I. THORAX eft Dorfum trunci.

a) PARTES.

222. Difcus, pars media thoracis. (xaro lobatus.)

223 . Margo, partes ambientes difcuin.

b) FIGURA.

22 4. Orbiculatus, peripheria circinata (dianetro longitudinali aequali transverfali).

225. Rotundatus, angulis deftitutus.

226. Subrotundus, figura orbiculatae (224.) proxima.

227. Ovatus, cujus diameter longitudinalis eft pars aliquanta transverfalis, bafi fegmento circuli spice anguftiore.

228. Ovalis, ex orbiculato oblongus, utraque extremitate rotundata aequali.

229. Oblongus, dianetro transverfali parte aliquota longitudinalis.

230. Linearis, aequali ubique latitudine.

231 . Transverfus, linearis, fed transverfim.

c) ANGULTS.

232. Integer, indivifus, et omni finu deftitutus.

233. Quadrangularis f. tetragonus, a numero angulorum.

234. Cruciatus, brachiis expanfis, antice pofticeque columnatus.

d) SIN U B U S.

235. Cordatus, fubovatus bafi finu exfculpto, absque angulis pofticis.

236. Obcordatus, obovatus, cordatusque. 


\section{5}

237. Lunatus, fubrotundus, bafi finu divifus, angulis pofticis acutis.

238. Lobatus, divifus in partes ditantes.

239. Squarrofus, divifus in lacinias elevatas nee plano parallelas.

c) MARGINE.

240. Integerrimus, inargine lineari, nec minimum feeto.

24I. Crenatus f. crenulatus, margine incifusis, neutram extremitatem refpicientibus, feeto.

242. Serratus, margine, omnibus incifuris refpicientibus caput.

243. Dentatis, margine, acuminibus patentibus, remotis.

244. Ciliatus, margine fetis parallelis.

245. Spinofus, margine acuminibus fuluulatis, rigidis, pungentibus.

f) A P I C E.

246. Obtufus, intra fegmentum circuli-terminatus.

247. Emarginatus, terminatus crena.

248. Retrifus, terminatus finu obtufo.

249. Truncatus, terminatus linea transverfa.

250. Mucronatus, terminatus mucrone exftante:

g) SUPERFICIE.

25 I. Nudus, fetis pilisque deftitutus.

25 2. Glaber, fuperficie lubrica.

253. Nitidus, glabritie lucens.

254. Lineatus, lineis longitudinaliter. coloratis pictus.

255. Striatus, lineis parallelis leniter exeavatus.

256. Sulcatus, lineis profundis excavatus.

257. Rugofus, rugis refertus.

258. Villojus, tectus pilis mollibus.

G 5 
259. Pilofus, pilis diftinstis elongatis tegtus.

260. Hifpidus, fetis rigidis adfpérfus.

261. Aculeatus, mucronibus minoribas armatus.

262. Tubercsiatus, punetis eminentibus rigidis afperus...

263. Muticus, tuberculis, cornubus et aculeis deftiturus.

264. Cornutis, parte aliqua in cornu definente.

h) $\mathrm{E} X \mathrm{PAN} S \mathrm{I} O \mathrm{NE}$.

265. Planus, fuperficie aequali.

266. Inaequalis, fuperficie, hic elevata, illie deprefra.

267. Convexus, fuperficie fectione globi ele. vetis,

268. Canaliculatus, medio fulco profundo longitudinali exfculpto.

i) SU B STA N TIA.

269. Membranaceus, fubfantia folii.

270. Gibbus, difco elevato, nec fectione globi.

27. Cylindricus, linearis, teres.

272. Teretinfouliss, fere cylindricus.

273. Globofus, fubltantia glohi.

274. Conirus, teres, apice attenuatus.

275. Carinatus, parte fuperiore media difci pro: minente longitudiraliter, linea recta.

276. Criftatus, carina arcuata, dentata, compreffa.

277. Cucullatus, carina antrorfum cavata in cucullum.

k) STRUCTURA.

278. Clypeaitus, tectus membrana, margine libera ultra difcuin dilatata.

279. Marginatus, margine libero, elevato. 280. Submarginatus, margine vix libero, nec elevato. 
281. Immarginatus, nec clypeatus, nec marginatus.

b) 282. S C UTEL I U M eft thoracis pars poftica, faepe triangularis, parte transverfa thoraci proxi$\mathrm{ma}$, divifa inde futura.

283. Longitudine abdominis, fcutello ejusden cum abdomine dimentionis.

284. Abdomine longius f. maximum, abdomine nondum aequante fcutellum longitudine.

285. Criftatum, carina compreffa.

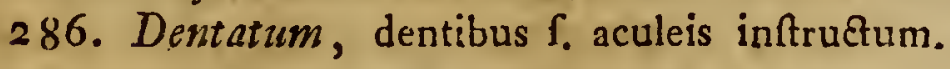

c) 287. PECTus, pars inferior trunci, cui pedes. inferti.

288. Miscronatum, terminatum mucrone exftante.

289. Muticum, mucrone deftitutum.

290. Cruentium, maculis fanguineís piçum.

291. Incruentum, maculis fanguineis deftitutum.

292. Roftratum, roftro loco oris inftructum.

293. Carinatum, parte ima media, prominente longitudinaliter linea recta.

d) 294. STERNUM eft cariña ipfius pectoris.

295. Mucronatum, terminatum mucrone exftante, ad pofteriora vergente.

296. Integrum, apice non divifun.

297. Bifidim, divifum finu lineari.

298. Porrectum, mucrone anteriora spice fpeEtante.

e) 399. EPIGASTRIUM, eft lamina in poftica parte pectoris, inter duo prima paria pedum et pofteriora, (in Mordellis.)

C. 300. ABDOMEN, pars corporis a thorace diftincta, poftica infeßti occupans, fegmentis annularibus conftans.

Ejus partes funt Spiracula, Tergum, Venter; Anus.

a) IN 
a) IN GEN ERE.

30 I. Aequale, ejusdem cum thorace latitudinis.

302. Seffile, affixum thoraci fecundum totam latitudinem.

303. Petiolatum, affixum thoraci mediante tubulo multo anguntiore, elongntöque. -

304. Subpetiolutum, aflisum thoraci tubulo breviore et pene aequante latitudine thoracem.

305. Planum, fuperficie ventris plana.

306. Comprefum, lateribus magis quam difco complanatis.

307. Depreffum; difco magis quam lateribus complanato.

308. Fornicatum fubtus, arcustum parte prona excavata.

309. Foliaceum, fubetantia folii.

310. Conicum, interes, bafi ad thoracem latius, inde verfus anum attenustum.

31r. Falcatum, figura folcem imitante.

312. Lobatum, divifum in partes difnntes.

313. Plicato - pupillofum, papillis lateralibus plicatilibus.

314. Barbatum, pilis fafciculatis ad latera vel apicem.

3 I5. Cingula funt fafcize coloratae abdomen ambientes.

b) IN SPECIE.

a) 3 16. SPIRACULA; funt pori leteralés in fingulo fegmento abdominis, utrimque fo. litarii, connexi dußtibus pulmonaribus pro refuirntione.

b) 2 I7. SQUAMUI. , eft membrana ereata, interjeta thoraci abdominique (in Formicis).

c) 318 . TERGUM eft pars fuperior feu dorfum abdominis.

d) 319. 
d) 3rg. VENTER eft pars inferior abdominis.

c) 320. A Xus eft pars Abdominis poftica perforata pro ejiciendis excrementis, et non raro pro recondendis indeque exferendis genitolibus.

321. Dentatus, dentibus $f$ aculeis inftruetus.

322. Simplex, dentibus et emarginaturis deflitutus.

323. Emarginatus, terninatus crena!

324. Barbatus, pilis fafciculatis parallelis cinctus.

325. Lomatus, indutus quafi-tela araneae, pilis fponte curvatis.

326. Nudus, nec pilofus, nec fetofus.

327. Setofus, fetis rigidis cinetus.

328. Papillofus, cinctus punctis elevatis carnofis.

d. 329. A R T u s funt varia inftrumenta motus, funtque Alae, Pedes, Cauda et Pectinis.

a) 330. A la e funt organa, quibus infecta $f e$ in nërem elevant ac volant.

a) 33 r. ELYTKA funt alae cruftaceae, vel coria. ceae, fub volatu explicandae, alias in futuram conniventes, ac tegentes alias alas membranaceas.

a) PARTES ELYTRORUM.

332. Bajis Elytrae, pars proxima Thoraci, ubi elytra affiguntur corpori.

333. Apex Silytrae, pars vicina ano, bafi oppofita.

334. Margo Elytrae eft pars exterior, vici. naque ventri, a bafi ad apicem.

33.5. Sutura Elytrae eft pars, ubi elytra con. nivent in lineam in medio dorfi, inter bafin et apicem. 
336. Difcus Elytrae, eft pars in medio inter bafin, apicem, marginem et futuram.

b) STRU CTURA.

337. Coadunata f. connata, futura coalitae.

338. Diffincta, Elytro quolibet feparato, nee futura coalito.

339. Mobilia, quae moveri et alatui infervire poffunt.

340. Innmobilia, quae alatui infervire, moverique nequeunt.

34I. Integra, quae tergum fecundum omnem ejus longitudinem et latitudinem tegunt.

342. Mutilata, quae non omnem tergi longitudinem vel latitudinem tegunt.

343. Abbreviata, tergo breviora, ejusque par: tes aliquantae.

344. Dimidiata, tergum dimidium tegente.

345. Anguftata, tergo anguftiora.

c) A P I C E.

346. Truncata, abbreviata (343.) verfus apicem transverfa:

347. Faftigiata, apice transverfa.

348. Praemor $\sqrt{a}$, terminata apice obtufe incifuris inaequalibus.

349. Subulata, ad bafin linearia ad apicem. attenciata.

359. Attenuata, a bafi ad apicem fenfim anguftiora.

$35 \mathrm{I}$. Linearia, aequali ubique latitudine.

352. Mucronata, mucrone uno vel pluribus ad apicem exftantibus.

b) SU BSTANTIA.

353. Flexilia, flexionis patientia.

354. Rigida, quae flecti nequeunt. 355. Mollia, digiti impreffionen ferentia. 
35\%. Coriacea, corii inftar, feu membranacea.

357. Cruflacea, rigidiora coriaceis.

358. Membranacco-cruftacea, ex parte crufracea ( $(c i l . b a f i$ et margine), ex parte membranacea (viz. apice et difco et futura).

e) SUPERFICIE.

359. Laevia f. nuda, fetis et pilis deftituta. 360. Pilofa, pilis diftinetis elongatis teta, $36 \mathrm{I}$. Hirta, villis intertextis ohducta.

362. Hifpida, fetis rigidis ad!perfa.

363. Sericea, pilis adpreffis, mollifimis, nitentibus tecta.

364. Fafciculato-barbata, pilis in fafciculos collectis.

365. Glabra, fuperficie lubrica.

366. Nitida, glabritie lucente.

367. Scabra, puntis eminentiblis rigidiufculis exafperata.

368. Rugofa, rugis confita.

379. Lineata, nervis linearibus deprefis.

370. Striata, lineis parallelis leniter excavata.

37 I. Sulcata, lineis profundis excavata.

372. Porcata, lineis longitudinalibus elevatis.

373. Punctata, punctis excavatis adfperfa.

374. Lineato-punctata, punetis in lineas digeftis.

375. Muricata, aculeis rigidis horrida. 376. Spinofa, margine acuminibus fubulatis, rigidis, pungentibus.

377. Carinata, ad futuram longitudinaliter prominentia:

f) MARGINE.

378. Dentata, margine acuminibus, patentibus remotis. 
379. Serrata, margine omnibus incifuris refpicientibus extremitatem.

380. Marginata, margine elevato, diffincto cineta.

b) 38 I. HEMELYT a funt alae tactae ex fubftantia media inter coriacesm et membranaceam, vel quosd totum, vel quoad partem.

382. Cruciata, margine interiore unius impofita altero.

383. Plana, non complicata, fed fuperficie aequali. 384. Convoluta, cruciate, abdomen obvolventia. 385. Plicata, quae quiefcentia in plicas acutas funt flexa, volitu explicandas.

- 886. Incumbentia, quae quiefcentia tergum abdominis horizontaliter tegunt.

387. Deflexa, incumbentia, fed ad latera nutantia,

388. Erecta, quae quiefcentia furfum ad fe invicem accedunt.

389. Cruciato - complicata, hemelytris aliisque ita cruciatis, ut duplicem crucem marginibus fuperimpofitis efficiant.

c) 390. ALAE LEPIDOPTERAE funt alae membranaceae, duplices, teetae fquamulis imbricatis coloratis.

a) PARTIS ALARUM.

39 r. Bafis, eft pars Alae, ubi connelitur thoraci.

392. Apex, eft pars Alae oppofita bafi, terminans inarginem anticum $f_{\text {. coftam. }}$

3) 3. Alae primores f. fuperiores, funt alae anteriores.

394. Alac fecundariae f. inferiores, f. pofteriores, funt pofticae, quae dum com-

ponun- 
ponuntur in phalaenis a fuperioribus teguntur.

NB. Primores et Secundariae ad Papiliones fpeciantes termini; reliqui ad Phalaenas referendi et ad Gymnoptera te. traptera.

395. Angulus pofticus eft pars Alae extrema in Alis fuperiorious oppofita bafi et apici. 396. Margo exterior, f. anticus f. craffior, eft margo inter bafin ct apicem (qui in Papilionibus quo que Cofta Alae dicitur).

397. Margo poflerior, inter Apicem et angulum ponticun et Ani.

398. Angululus Ani eft angulus pofticus, in - Alis inferioribus.

399. Margo intcrior f. tcnuior, inter bafin et anguluin pofticum f. Ani.

40c. Difcus ent pars media alae, inclufa mar. ginibus, bafi, Apice et Angulo poftico f." Ani.

401. Pagina fuperior eft fuperficiès Alae coe. lum refpiciens.

402. Pagina inferior, quae terran fpectat.

b) DETERMINATIO.

403. Plicatiles, quae quiefcentes funt Alexae in plicas acutas, volatu explicandas.

404. Planae, quae plicari nequeunt.

405. Conzolutae, abdomen obvolventes, fuperficis paginae fuperioris convexa.

406. Erectas, quae quiefcentes, furfum ad fe invicem accedunt.

407. Horizcntales, quae quiefcentes funt horizontalitcr expanfae.

409. Patentes, funt horizontales, (40\%) nec conniventes, nec incumbentes. 
409. Patulae, funt fere horizontales $(407$.$) ,$ fed parum inclinatae, nec incumbentes.

410. Incumbentes, quae quiefcentes, dorfum abdominis horizontaliter tegunt.

4II. Cruciatse, funt incumbentes ( 4 I O.), marginibus intefioribus fibi invicem impofitis.

412. Deflexae r. deprofjae, funt incumbentes $(4 \mathrm{lo})$, fed ad latera nutantes (i. e. parum apice et margine antico extrorfuin deflexo).

413. Reverfae, deflexae $(412$.$) , fed its ut$ margo inferiorum aiarum ultra marginem anticum priorum promincat.

414. Conniventes funt alae, quae quiefcentes, margine antico, poftico vel interiore ex parte funt contiguo; vel erestae, vel incurnbentes.

415. Divaricatae, funt incumbentes $(410$.$) ,$ fed poftice divergentes, (nec conniventes.)

i) FIGU R.A.

416. Oblongae, diametro longitudinali, aliquoties fuperonte transverfalen.

417. Lanceolatae, oblongde, ab utraque extremitate attenustae.

418. Lineares, aequali ubique latitudine.

4!9. Obtufae, apice intra fegmentum circuli terminatae.

420. Retufae, terminatae finu obtufo.

421. Acuminatae, terminatae apice fubulato.

422. Elongatae, alis primoribus margine poftico longioribus, quan margine in. teriore.

423. Angulatae, margine poftico angulis prominentibus circumfcripto. 
424. Rotundatae, margine poftico angulis orbo.

425. Falcatae, margine pofico finu obtufo. 426. Incurvatac, margine antico curvo, (arcu extrorfum facto.)

427. Rhombeac, forma rhombi.

8) MARGINE.

428. Integrae, indivifae, omnique finu defitutae.

429. Fiffae l. digitatne divifae finubus linearibus marginibus restis.

430. Caudatae, una alterave ferratura elongata in procentum.

431. Bicandatal, proseffubus duobus caudatine (430).

432. Subcaudatac procentu vix a ferratura di. finģuendo.

43. Excandatae, nullo procertu elongatae.

434. Dintatas, margine acuminibus patentibus remotis.

435. Dentato - caudatae, dertibus caudisque mixtis.

436. Evolac, finuatae, finubus minimis ab. tifis lacinisque iraequalibas.

437. Dentato-erofac, dentibus inter finus interjętis.

438. Crenstae, margine incifuris neutram extremitatem refpicientibus fedo.

439. Serratae, margine omnibus incifuris extremitatem refpicientibus.

440. Repandae, margine flexuofo, tamen plano.

44I. Ciliatae, margine fetis parallelis longitudinaliter digentis.

442. Denticulatae, dentibus diftingtis minutis. 
443. Integerrimae, margine lineari, nec minime fecto.

P) SU PEREICIE.

444. Nudae, nuilis pilis, fetis, vel fquamis tectae.

4+5. Denudatae, paite tantum aliqua alarum fquamis vacua, at opaca.

446. Hyalinae, denudatae totae, transparentes $\mathcal{f}$. diaphanse.

447. Imbricatae fquamis, tectae fquamulis imbricatim politis.

448. Nervofae, vafis fimplicifimis a bafi ad apicem extenfis.

449. Radiatae, quorum vafa ut radii e com. muni centro divergunt.

450. Reticulatae, quorum vafa, reticulatim venofa funt.

451. Teffelatae, maculis nigris plerumque ita difpofitis ut pavinentum teffelatum imitentur.

452. Tumidae, meınbranis inter venas elevatis. 455. Puculatae, i. e. merabranis promifcue concavis et depreffis.

454. Nitidiflimae, fquanis glabritie maxime fplendente.

455. Tomentofae, villis intertextis nec difcernendis obtectae.

456. Barbatae, parte aliqua alterutrius paginae pilis fafciculatis obfitae.

f) NOTIS ET COLOKE.

457. Coloratae, infeciae colore quodam.

458. Concolores, utrisque paginis ejusdem coloris.

459. Verficolores, variis coloribus infeetse. 
460. PU N C T U m eft mseula minima fubrotunda, colore a reliqua ala diffineta. 46 1 . Punctatae, alae punctis notatae. 462. Irroratae, alae punetis minutiffmis f. atumis fparfim notatae.

463: Callofum punztum, elevatum rigidiufculum.

464. Ramofum punetum, divifum in par. tes diftantes.

465. Ocellare punctum, orbiculare, in me. dio diverficolor.

466. Sesquialtevum punctum, ex duobus diffinctis contiguis conflatum.

467. Geminum, punta duo vicina, at difcreta.

468. M A CULA, pars alae puncto major indeterminatae figurae, colore a reliquis differenti notara.

45.9. Maculatae, alae maculis notatae.

470. Ovata, macula dianetro longitudinali excedente transverfalem, bafi fea gmento circuli circumfcripta, apice anguftiore.

47 I. Deltoidea, fere triangularis.

472. Rhombea, figura rhombi.

473. Reniformis, fubrotunda bafi finu exfculpto, absque angulis poficicis.

474. Anmularis, orbicularis, medio cun reliqua ala concolore.

475. Subannularis, non prorfus annulam efficiens.

476. Sagittata, triangularis, angulis pofticis acutis finu divifis.

477. Falcata, fubulata, curvata.

478. Linearis, aequali ubique latitudise. 
479. Flexuofa, horfun vorfum dire?ta.

480. Sexfida futuris, divifa finubus fex lincaribus, venofis elevatis.

481. Palmata, divifa ultra dimidium in 10 . bos fubrequales.

482. Radiata, divifa finubus angulofis ex uno centro diffufis.

483. Teffolata, macula aiio colore tefelatim notata.

484. SIIGMi eft macula in alis prioribus ad anaftomofin vaforum prope mar. ginem anticum.

495. Simplex, unicum. 485. Duplex, Stigma grminum.

487. Reniforme, fubrotundum, bafi finu exfculpto, absque angulis pofticis.

488. L I TURa eft macula colore una parte diluticre, altera intenfiore.

489. LU N U LA eft macula falcata utrimqque fubulata.

490. CICATRIX eft macula elevata rigidiufcula.

49I. FENESTRA eft macula denudata, hyalina, diaphana.

492. Feneffratae alae, una pluribusve feneftris ( $49 \mathrm{r}$. ) ornatae.

493. OCELLUS eft macula orbiculata, medio puncto diverficolore, quod vocatur Pupilla.

494. Ocellatac alae, uno pluribusve ocellis notatae.

495. Obliteratus ocellus, vix diftinguen pupilla.

496. Carcus, ocellus inter alios pofitus, pupiila deftitutus. 
497. Bipupillatus, pupilla gemina.

498. Tripupillatus, pupilla tergemina.

499. Didymies, ocellis duobus contiguis. 500. Sesquialter 1. fesquiocellus, ocellus major, includens alium minorem.

5or. Pupilla hafata, macula pupillari fagittata $(4,6$.) angulis poiticis finu divifis ad latera prominentibus.

502. Lunatus, lunula ocelli femicinfus,

5॰3. Nictitans, lunula ocelli, et annulo alio aliaque lunula pupillari femiclaufius.

504. Feneftratzs, pupilla hyslina, diaphana, 505. Dioptratus, pupilla feneftrata, lineo. la transverfim divifa.

506. L I N E A eft coloris diverfi a reliqua ala, longitudinaliter extenfa, aeçuáli fed tenui latitudine.

507. Nebulofae alue funt notatae lineolis auruptis fparfis, variae latitudinis, numerofifimis.

508. Undulatre alae funt notîtac lineis continuis fubparallelis in undarum morem flexuofis.

509. Characteres funt lineae varie flexuo. fac inftar characterum f. feripturae.

5IO. STRI A eft linea longitudinalis lation plaga extenfa.

5II. INSTIta eft fria, fubaequabilis latitudinis.

512. VITTa eft fria, margine fle:uofo feu finubus exfculpto.

513. STKIGA eft transverfalis tenuifima ca. pilli inftar.

5r4. Recta, reßa extenfa.

515. Arcusata, in arcum flexa. 
516. Obliqua, alain non transverím fed oblique tranfiens.

517. Undata, finubus flexuofis obtufis.

5:8. Flexuofa, horfun vorfum reeta linea aćts.

519. Rcyanda, finubus flexuofis acutis. 520. Anaftomofans, decurrens fecundum vafa nervofa, gorumque anaftomofin.

521 . Interrupta, non una ferie continue ex. tenfa, led fupra infrave continuata.

522. F A S C I A elt friga latiori plaga extenfa.

523. Recta; brevifima via extenfa.

524. Aruzata, in arcum flexa.

525. Obfoleta, vix a reliqua alae parte difinguenda.

526. Communis, per alam priorem et po. Ateriorem extenfa.

527. Dimidiata, per dimidium alae tantum excurrens.

528. Abbreviata, ad unum marginem tan. tum extenfa, nec dimidium attingens.

529. Interrupta, non una ferie continue extenfa, verum infra fuprave continuata.

530. Ex maculis; i. e. maculis difcretis ita difpofitis, ut fafciam depingant in ala.

531. Articulata, eft fafcia ex maculis contiguis ficta.

332. Sesquialtero, includens fnfciam alteram dimidio minorem, (vel occupanș tertiam partem alae).

533. Sesquitertia, occupans guartam par. ten alae. 
534. Terminalis, vicina apici et margini poftico.

535. Marginalis, in ipfo margine decurrens.

536. Hyalina, denudata, diaphana.

$53 \%$ V Е N A E funt vafn per alam diffufa.

538. Venae nigrae, colore nigro pittse.

539. Dilatatae, ex utraque parte, ultra valis colorc extenfo.

d) 540. Alae Gymnopterae funt alae membranaceae, hyalinae, fquamis deftitutae.

54I. Reticulatae, quorum vafa reticulatim funt venofa. (Neuropteris.)

542. Extenfal, non fibi inviceun impofitae.

543. Planae, extenfae, horizontales.

544. Evectae, quiefcenres, ad fe invicem accedentes.

545. Incumbintes, quae quiefcentes dorfun sbdominis horizontaliter tegunt.

546. Deflexae, incumbentes $(545$.$) ad latera$ nutantes.

547. Plicatae, quae quiefcentes funt flexae in plicas acutas, volatu explicandas.

548. Nervofae, nervis pro alarum magnitudine fortioribus interftinctae (Hymenopteris et Dipteris.)

549. Plicatiles, quae quiefcentes, in plicas volatu explicandas funt flexae."

550. Planae, quae plicari nequeunt.

551. Tumidae, membranis inter nervos elevatis.

552. Lanceolatae, oblongae, ab utraque extremitate attenuatae.

553. Incumbertes ( 545 ).

554. Stigma eft macula marginalis ad anafto. mofes nervorum. 
555. Patentes funt horizontales, nec conniventes, nec incumbentes.

556. Unguiculatae, dente feu ungue membranaceo ad coftam leu marginem exteriorem inftructae.

557. Subulatae, lineares, apice attenuatae.

e) 558. HALTERES funt capitula pedunculata, pone alas thoraci affixa. (in Dipteris.)

559. Cum fquamula, fub fquama membranacea fornicatn halteres affixae.

560. Nudae, fine ulla fquamula infertae.

3. 56r. PEDES funt organa motus articulata pro ambulando, peffori affixa in plerisque, in aliis pectori abdominique.

562. Totrapoda Infecta. funt ea quae fex quidem habent pedes, at anticos minores, debiles, nec ad ambulondum idoneos (Papiliones quidain).

563. Hexapoda, pleraque, pedibus fex.

564. Octapuda, pedibus octo. (Acari, Phalangia, Scorpii, Arancae, Cancri.)

565. Polyyoda, pedibus plurimis (Scolopendrae et $F_{u l i}$ )

556. Curforii, ad currendum apti (plerisque).

567. Saltatorii, femoribus crafioribus, ad faliendum aptis.

568. Natatorii, compreffi, bifariam ciliati, ancipites, ad natandum apti.

569. Mutici, absque unguibus vel fpinis.

5\%०. Spinofi, acuminibus fubulatis rigidis pungentibus.

57r. Chelyferi, apice incrafiato, ungue laterali mobili. ( M A N U S.)

572. Pectorales feu unguiculati, (in Larvis Lepidopterorum et Tenthredinum) pectori affixi ac 
unguibus inftructi, rudimenta pedum fu. turorum.

573. Temporarii (in Larvis fupradictis) nulla ru. . dimenta pedum includentes.

574. Caudales feu fubcaudales, temporarii caudae Iarvarum affixi:

575. Intcrmedii, temporarii inter pectorales et caudales medii, (in Larvis).

576. Annulati, alternatim annulis diverficoloribus cinati.

Peduin partes Fesnora, Tibiae, Tarfi, Ungues, Trochanteres, Patellae.

a) 577. FEM OR A, partes pedum Trunco proximae ac Thoraci affixae.

578. Simplicia, proportionata, nec crafitie notabili. 579. Crafidima, incraflata, magna fubglobofa. 580. Clavata, incrafiata apice.

$58 \mathrm{r}$. Arcuata, inflexa in arcum.

582. Dentata, margine uno, pluribusve acuminibus patentibus remotis.

583. Spinola, acuminibus fubulatis rigidis pun: gentibus.

5\$4. Mutica, nec dentata, nec fpinofa.

585. Membranacea, fubntantia folii.

586. Serrata, margine ommibus incifuris refpi* cientibus extremitatem.

587. Bajis, femorum pars Thoraci proxima.

588. Apex, femorum pars Tibiis proxima.

589. Ciliata, margine fetis parallelis, longitudi. naliter digeftis.

b) 590. TRO H ANTERES funt corpufcula oblonga, mobilia, bafi Femoruin latereli. ter affixa, prope thoracem (in Carabis).

1) 59r. PATEl a E funt corpufcula orbicularia, elevata, mobilia, quibus femora bafi infiftunt (in lchneumonum genere).

d) 592 . 
d) 592. T I В I E, partes pedum inter Femors et Tarfos.

593. Dentatae, margine uno pluribusve acuminibus patentibus remotis.

594. Muticae, nec dentatae, nec fpinofae.

595. Spinofae, acuminibus fubulatis, rigidis pungentibus.

596. Serratae ( 586 )

597. Arcuatae, infexae in-arcum.

598. Longiflmae, longitudine corporis.

599. Genicula, bafis tibiaruin f. pars femoribus proxima.

600. Ciliatae ( 589.$)$

601. Foliaceae, auctae utrimque membrana.

e) 602. TAKSI, parțes pedum inter Tibias et ungues.

603. Articulati, articulis 3. 4. vel 5 .

604. Foliacei, articulis auktis membrana.

605. Simplices, nec figura nec magnitudine enormes.

1) 606. PLA N T E, partes Tarforum inferae.

607. Plantae hemifphcricae orbiculatae, fupra convexse, infra excavatae (in Dytific maribus.)

g) 608. С неLA, pars Pedis extrema, incraffata, digito laterali inobili. ( $\mathrm{MAN}_{\mathrm{N}} \mathrm{U}$.)

ii) 609. UNGUES, corpufculs fubulata, arcuatouncinata, apici tarfi affixa.

6 ro Simplices, unico unco.

$61 \mathrm{r}$. Biunguiculati, unco duplici.

6. 612. CAUDA eft pars, abdomini poftice affixa.

a) MENSURA.

613 Brcvis, corpore brevior. (brachyura.)

6 r 4. Elongata, longitudine co: ? poris.

macrouru.

6I 5. Longifima, corpore longior. 
6।6. Mutica, nulla, vel vix ulla.

b) S r R U C T R A.

617. Articulata, divifa in articulos.

618. Simplex fine articulis.

619. Solitaria, indivila.

620. Bifida, divifa fi u lizeazi, margine recto. 621 . Bicomis, divifa finu lunato, apicibus fubulatis.

622. Furcata, divifa finu rotundato, apicibus porrectis.

623. Forcipata, laminis duabus falcatis, fubu. latis.

624. Chelifera, apice incraflato, ungue laterali mobili.

c) FIGURA.

625. Ovata, diametro transverfali parte ali. quanta longitudinalis, una extremitate anguftiore.

626. Oblonga, diametro transverfaii parte ali. quota Inngitudinalis.

627 . Linearis, aequalis ubique latitudinis.

628 . Semiovalis, ex orbiculato oblonga, dimidiata.

d) A P I C E.

629. Obtufa, intra! fegmentum circuli terminata.

630. Emarginata, terminata crena.

631. Retufa, terminata finu obtufo.

632. Truncata, terminata linea transverfa recta:

633. Acuta, terminata angulo acuto.

634. Mucronata, terminata nucrone exftante.

635. Uncinata, terminata unco reflexo.

636. Pentaplyylla, membranis quinque di. ftinctis.

637. Integra, non divifa vel finuata.

c) $I \mathrm{~N}$. 
e) INSTUMENTO.

638. Ariftata, cauda craffiore, terminata arifta $\Upsilon_{\text {. feta }} \mathrm{C}$. filo tenuiffimo.

639. Filoja, aequabili latitudine, filo cy. lindrico.

640. Setofa, lenfim attenuata, elongata, tenuis.

641. Bifeta, trifeta, pro numero fetarum. 642. Siylata, cylindro terminato feta una pluribusve.

643. (Stylus) bifidus, fetis duabus.

644. (Stylus) bifurcus, divifus finu ro. tundato.

645. Bidentata, margine denticulis cuobus. 646. A:uleata, mucrone elongato pungente, non raro venenoro (Aculcus).

647. Simplex, uno mucrone.

6+8. Compofitus, pluribus mucronibus.

649. Vaginatus, inclufus vagina bivalvi.

650. Exjerius, nudus, nec reconditus.

65 I. Reconditus, femper intra abdomen-re traetus, nec nifi raro promendus.

652. Retractilis, plerumque exfertus, at recondi poteft.

653. Rectus, linea recta extenfus.

6j4. Recurvatus, deorfum flexus, arcu fuperiora fpeetante.

6.55. Spiralis, in fpiram collectus.

656. Flexilis, qui flecti poteft.

657. Rigens, flexionis impatiens.

658. Serratus, incifuris extremitatem ro fuicientibus.

659. Laevis, nbsque ferraturis.

f) SU B S TANTIA.

660. Foliacea, membranae infar expanfa. (Corricula.) 
66 r. Cylindrica, teres, aequabili latitudine. 662. Triquetra, tribus lateribus longitudina. libus caudae fubulatae.

663. Enfiformis 1. enfifera, enceps a bafi ad apicem fenfin attenuata.

664. Subulata, ad bafin linearis, apice at. tenuata.

g) SUPERFICIE.

665. Hir juta, pilis varie obfita.

666. Glaberima, fuperficie maxime lubrica.

h) DI Е С $\mathrm{TIONE}$.

667. Rigida, flexionis impatiens.

668. Inflexa, furfum arcuata verfus apicem.

669 Reflexa, apice antrorfum fpectante.

670. Molilis, motus flexionisque patiens.

671. Recta, non flexa.

672. Roftrata, roftri inftar rigens, porrecta.

d. 673. PECTINES funt corpufcula elongata dentibus numero differentibus altero latere in. Aructa, inter pectus et abdomen Scorpio. nibus aftixa.

B. PARTES IN TERNAE Inferti, funt ere quac fine fectione anatomica obfervari nequeunt: id. eoque hic non confiderandae.

INSECTUM varia nomina acquirit pro certa parte ipfi cum aliis cogeneribus propria ac characteriftica.

674. Scutellatus (Scarabaeus)-qui habet fcu. tellum.

675. Exfcutellatus (Scarabaeus) fcutello carens.

676. Curnutus capite (Scarabaeus) cornu capitis inftructus vel pluribus.

677. Cornutus thorace (Scarabaeus) cornu in thorace, vel pluribus. 
678. Muticus, (Scarabaeus) fine ullo cornu ca. pitis vel thoracis.

679. Punctata, (Coccinella) Coleoptris rubris - Alavisve, punctis maculisve nigris.

680. Guttata, (Coccinella) Coleoptris rubris flavisve, albo maculatis.

681. Puftulata, (Coccinella) Coleoptris nigris, rubro maculatis.

682. Sultatoria (Claryfomela) femoribus craffinimis.

683. Elungata, (Chryfomela) linearis oblonea. 684. Longiroftris, (Curculio) roftro capite longiore.

685. Breviroftris (Curculio) roftro capite breviore.

686. Apterus, (Carmbus, Tenehrio, Meloe) alis deftitutus, non raro elytris coadunatis.

687. Alatus, (Carabus, Tenebrio) alis membra. naceis inftructus.

688. Foliacea, (Cicada) thorace comprefto mem. branaceo.

689. Scutellaris, (Cimex) fcutello longitudine abdominis.

690. Coleoptratus, (Cimex) Elytris fere totis coriaceis.

691. Memlinanaceus (Cimex) corpore depretro, foliaceo.

602. Pectinicornis (Phalaena) antennis pectinatis. 693. Seticornis (Plaalaena) antennis fetofis.

694. Spivilinguis, (Phalaena) lingus in fpiram revoluta.

695. Elinguiis, (Phalaena) lingua adeo parva, ut vix fit confpicus.

696. Seturia, (Mufca) antennis, funplici feta laterali.

697. Pismofa (Mufca) antennis pluma latcrali. 
698. Filatae, (Múfcae) antennis nec fetariis, nec plumofis...

699. Brachyurus, (Cancer) cauda corpore breviore.

700. Macrourus, (Cancer) cauda corpore longiore vel ejusdem longitudinis.

\section{HABITUS.}

\section{A. GENERATIO, in qua obfervanda:}

I. SEXUS, diftinguitur

a. NuMERo.

a) Binatus, Mares et Feminae, nec plures in eo. dem genere.

b) Ternatus, Mares, Feminae et Neutra in Vefpis, Apibus et Formicis,

b. Characteres.

a) EXTERNI.

a) Magnitudo. Feminae plerumque in Infetis majores quam mares; abdomen foetum ovis in Feminis fere femper majus, qquam in maribus.

b) Antennas; quae in mariblis plermmque am. pliores, pennatae, pettinatae, ferratae; qutm in Féninis pennae ve! ferraturae vix fint confpicuae, vel totae anternae vel clavae multo minores.

c) Cornua capitis et thoracis, quae in folis maribus funt obvia, ut in mammalium genere cervino; in Feminis nulla.

d) Alae. Mares Lainpyridis, Cocci, Phalaenarum antiquae, gonoftigmae, defoliariąe, brums. tae et Lichenellse et Ichneumonum quorun. dam alati; Feminae apterse. 
b) NATURALES SEU ESSENTIAES.

a) Genitalia, oblonga tubulofa, hanulis laterali. bus in majculis plerisque; tubus vacinae. formis brevior in feminis; illa connexa cum vafis fpermaticis, hatc cum ovario.

b) Locus.

1) Intra Anum, plerisque.

2) In Araneis, palpi mafculis in Capite; feminis genitalia ad bafin abdominis.

3) Cancris ad infertionem Caudae f. abdominis bafin.

4) Libellulis mafculis in ima parte pectoris, feminis ad. extremitatem abdominis elongati.

c) Numeins.

1) Unum genitale, alterutrius fexus in quovis Infecto.

2) Duo genitalia, in Cancris et Araneis, ficuti in Anphibiis.

II. NUPTIAE.

a. MONOGAMAE, uno mare fufficiente pro fingula Femina.

b. POLYGAMAE, fingulo infeeto unius fexus, pluribus alterius.

a) Monarfenes, uno mare fufficiente pluribus feminis. (in Phalacnis.)

b) Monothelyes, una femina foecundata a pluribus maribus. (in Apibus.)

C. CR YPTOGA MAE, femina a mare foecundata, generante feminas vivas impraegnatas in quintam us. que generationem. (Aphides.)

III. FOETURA.

-a. Vivipara, rara, Onifi, Mufca Hederae, et Aphides prims parte aeftatis: 
b. P UP I PA R A, rara; Hippobofca equina.

c. OVIPARA, communis, plerisque Infeetis.

d. COENOGONA, iisdem snimalibus prims aeftatia prte viviparis, autumno oviparis. (Aphides.)

IV. METAMORPHOSES.

2. 70\%. $\mathrm{OVUM}$, continet famen novi Infecti.

c.) I IG $\mathrm{IRA}$.

102. Globofumi, teres, orbiculare, diametro undique aequali.

103. Hemisphaericum, globo, medio diffesto. !04. Oblongum, dianetro transverfali parte aliquota longitudinalis.

105. Cylindricum, teres, lineare.

'06. Cydariforme, globo utrimque truncato.

०:- Tympaniforme, cylindricum margine utrim. que elevato.

p8. Peticlatum, clavatum, affixum per po. tiolum.

79. Urceolato-coronatum, forma urceoli una extremitate cozonata.

b) S. PER F I C I E.

7 0. Glaberrimum, fuperficic maxime lubrica. 7.x. Sulcatum, lineis profundis excavatis.

72. Reticulatum, venis inftar retis difpofitis.

7 3. Punctatum, adfperfum punctis excavatis. 754. Lacunofo - reticulatum, difco depreffo iu. ter venas reticulatas.

715. Porcatum, lineis longitudinalibus elevatis.

DISPOSITIONE.

7 I 6. Sparja, fine ordine difpofite.

71 7. In quincuncem, per feries aequidiftantes al. ternation.

7 8. Annulata, cingentia ramum inftar annuli, 7 19. Spiralia, cingentia ramuin in formam fpirae. 
d) COLORE.

720. Albida, non plane alba,

721. Badia, colore caftaneae unaturae faturate furca.

722. Spadicea, obfcure purpurea feu intenfe fufca.

723. Ex margaritaceo candida, endore cuin commiffura quadam coeruli coloris et fplendentia.

724. Flava, coloris flavi.

725. Viridia.

726. Coevulea.

727. Rofea, dilute purpurea.

728. Uricoloria, coloris ejusdem undique.

729. Variegata, inaculis afperfa divefiroloribus.

730. Colorem mutantia.

731. Colorem retinentia.

e) Lo c o, inftinctu naturali divinitus mmifo, parentibus deponentibus ova locis atis, ubi pro. genies ftatim alimentum fibi propinn reperit.

a) In aquis et plantis aquaticis, (hi ifci et Ncuroptera fere omnia, Cullices, Tipulae nonnullae, Cancri, Monoculi e enif( $i)$.

b) Intra terram, ad radices planarm, (quaedam Phalaenae, Gryllus Oyotalpa „etc. Siarab. Melolonithi).

c) In plantis.

1) In foliis, inter Epidermides 1 fubftantia parenchyma.

2) In feminibus, (Brucchi, Cultiones).

3) Intra lignum (Cantharides, alacna Cof. fus etc.) -.

4) In gallis, i. e. Excrefcentia frofa orta a punctione folii, corticis etc.-ynipes.)

d) In 
d) In animalibus.

I) Vivis eorumque

a. Pilis Tarandi, (Oeftrus).

b. Cute Boum, (Ocftrus).

c. Naribus et ofje frontis Equorum et ovium (Oeflrus).

d. In inteftino recto Equorum.

e. In Larvis, Pupisque Infetorum (Sple. ces et (chneumones).

2) Mortuis et Cadaveribus. (Silphae, Formicae etc)

3) Recremcontis et partibus animalium.
a. Excrementis, (Mufcae et Scarabaei).
b. Lina, (Tineae).
c. Corio, (Dermefies).

f) DEFENSIONE fé VESTITU, contra ininclementiam aëris, folis, pluviam etc.

a) Nuda, defenfione nulla, (Pialacnae nonnullae).

b) Vernice inducta, glutine oblita indurato.

c) Folliculo fericeo.inclufa, (qnedam Araneae).

d) Pilis a matre derafis obvoluta.

e) In cellis favi, (Apes, Vefpac).

-. f) A parentibus circumfornutur in folliculo.

5) Sub cidavere matris mortuae (Cocci (i. quidam .

g) NUMERO.

a) Quaedam panca ova ponunt.

b) Alia numerofyjomn, una Apis usque ad 40000 uno anno ova ponit.

is b. 73 2. LARvA; (Eruca) eft animalculüm ex ovo exclufum, fuccofum, molle, majus, fterile, tardum, vorax alimento proprio.

a) 33. Apodia, pedibus deftituta.

$$
\text { I } 3 \text { b) } 73 \text {. }
$$


b) 734. Polypoda (in Phalaenis a 6 ad 8 pedes numerantur, Coleopterorum Larva ple. rumque pedibus 6 . Tenthredinum pluribus quaḿ 16. usque ad 22).

c. 735. P u PA, (Nympla, Aurelia, Chryfalis, ) eft animalculum e Larva mutatum, in formam ea ficciorem, duriorem, coarktatam, faepe ore deftitutam.

a) VESTITU.

a) 736. Nuda, fine ullo folliculo pilofo f. fericeo.

b) 737. Folliculata, inclufa folliculo pilofo feu fericeo, vel etiam e foliis, lana, quifquiliis, ligno, terra conglutinato.

(1) M०rv.

a) 738 . Mobilis, quae gaudet motu loco-motivo.

b) 739. Immobilis, quae moveri nequit, affixa.

c) HA ITU ET FIGURA.

a) 740. Completa, onnibus partibus agilis, (Aranea, Acarus, Onifcru).

b) 741. Semicompleta, folis alarum rudimentis (Gryllus, Cicata, Cimex, Libellula, Ephemera.)

c) 742. Incompleta, alis pedibusque immobilis, (Ve/pa, Apis, Formica, Tipula).

d) 743. Obtecta, corticats thorace abdomine-

1) Nuda. que diftincio (Lepidoptera).

2) Folliculata.

e) 7.44. Coarctata intra globum, indiferetis partibus. ( $M u f(c a$, Oefrus.)

d. 745. I $\leftrightarrow \wedge G$ o, eft animalculum $e$ ?ups prodiens, perfectum, declaratum, revolatum, generans, agile, antennis inftruitum: (multa slas eequirunt, pauca sprera).

B. VI. 
B. VICTUS.

\section{GENUS CIBORUM.}

a. PHYTIPHAGA。

a) Rhizonhaga, quae ra dices Plantarum imprimis comedunt. (Scarabaei, Gryllus Gryllotaipa)

b) Phyllophaga, quae foliis Plantsum vistitant. (Yapilionum et. Phalaenarum Largae, item Coccinellarum, Chryfomelarum etc.)

c) Hylophaga, quae arbores penetrant, et lignum rodunt. (Larvae Ciramlycum, quorundan Cntharidum; Siricum, Fhilaenae Coff etc.)

d) Anthophagae, quae flores devorant.

c) Nectarinyzones, quae nectar fiorum fugendै extrahunt. (Apes, Vespae, quaedam Mufine, Papiliones.)

f) Spermophagae, quae femina exedunt (Ptini, Curculiones, Brucchi).

b. Z O О P H G A.

a). Ptomatophaga, quae cadavera et mortua animalia appetunt. (Silphae, Mufcae carnariae.)

b) Zontophaga, quae vivis animalibus vilitant.

a) Sanguinem fugendo, Haematophaga. (Pedicu. li, Pulices. Culices, Conopes, Tabani.)

b) Penetrando cutem, Enoterophaga, et intra cain vivendo. (Oeftri.) Pulex.

c) Nares vel anum intrando. (Oeftri).

c) Coprophaga, quae ftercora animalium pro viłu habent.

d) Ecdytophaga, quae animalium exuviis vietitant, viz. Pilis, Lana, Pennis, Pellibus, Cosio.

c) Pupophaga, quae pupas Infectorum devorant. f) Idiophaga, quae propriae fpeciei non parcunt. 
II. MODUS ET VARIETAS CIBORUM.

a. Pantophaga', quae omnia producta unius naturae regni indifcriminatim devorant. (Locufta migratoria, Termes fatale, Formica omnivora.)

b. Eclećtophaga, quae felecta et patca tantum genera plantaruin vel ciboruin comedunt.

c. Monophaga, quae unicum plantae genus, vel fingu. * lam fpeciem amant.

\section{MORES.}

J. So.crETAS.

a. Solitaria Infecta, quae fingula et fparfa reperiuntur.

b. Gregaria, quae in focietate minore conjunctim a. vivunt.

c. Politica, quae in focietatibus regulatis et majoribus vivunt, ac diriguntur veluti legibus et inftitutis ut in civitate bene ordinata.

Gynazecocrutica, quae in politiis vivunt, quibus praeeft unica Focmina.

11. Mores Peculiakes.

a. Alia retia pandunt pro capiendis dipteris mufcis, et neuropteris. (Araneae.)

b. Alia fubfultim apperunt varia Infecta. (Araneae.)

c. Alia contum in falulo excavant, inque eo latitant ac infêta quae in conum incidunt capiunt, vel eva- dere nitentia fabuli granulis conjectis in coni fundum dejiciunt et fic devorant (Myrmeleon).

d. Alia mufcam 'capiunt vel phalaenam, araneamve, ' ' 'dein occidunt, ac ei ovum concredurt, denique fepeliunt, ut cibum larvae futurae excludendae prieparent (Sthex.)

c. Alia plura ova deponunt intra Larvam vivam Pha. laenae, quae exclufa, Larvulas plures in Larva viventes eamque devorantes exhibet. (Sphex.) 
f. Alia nent fibi fepulcrum intra folliculum fericeum fummo artificio. (Phalaenab.)

g. Alia deponunt ova intra globum fimi, quem pedibus pofticis circumvolvunt. (Scarabaei.).

h. Alia intra teftam vacuam, vitam agunt ut Dioge. nes in dolio, quan quotannis mutant. (Cancri.)

i. Alia intra teftam vivam fe recipiunt, ac eam contra Sepias et alios hofles monent, ne incauta devora. retur: (Cancer.) et quingenta alia mira obfervata et adhuc obfervanda in Infectorum moribus, quae non hic enumeranda.

\section{STA T IO.}

A. HABITATIO, non locus ubi cafu Infectum reperi: tur, fed potius planta vel animal, locusve, in quo et ex quo vivit, ubique conftanter.

I. PERPETUA feu FIXA babitatio infecto propria per omnes ejus Status et Metamorphofes.

a. $A Q \cup A$.

a) Salum.

a. Oceanus, mare altifinum, procul ab omni terra.

b. Mare breve, littoribus inclufum, Balthicum, Mediterraneum, album, Pontus, Cafpium, Perficum, Arabicum, Ochotenfe, Rubrum Americae.

c. Littora arenofa, glareofa, faxofa.

d. Scopuli, Mare et lirevia inter fcopulos i. e. rupes mari cinctas.

e. Lapides littorei, qui jacent in littore aeftu maris tegendi, et recedente mari nudi.

f. Syrtes, loca arenofa, mari cineta et tefta, plus minùsve. 
b) AQUAe Dulges.

a. Lreus, aqua duicis pura, fundo fabili.

b. Flumina aqua dulcis defluens magno volumine.

c. Rivuli, aqua dulcis defluens, parvae molis, fun-

- do faxofo, vel fabulofo, praecipiti.

d Paludes et Stagna, aqua dulcis ftagnans, fundo lutofo, plantis inundatis et aquaticis featens.

b. TERRA.

a) Alpes, feries maximorum montium verticibus nive tectis.

Rupes, loca faxofa montofa.

Cumpi, loca aprica, ficca, alpera, ventofa.

Prata, campi depreffi et convalles herbis laxu. riantes.

b) Syluas, umbrofs, arboribus continue tecta. Arbufta, arborum nemoribus difcretis. Fruticeta, loca confita fruticibus, fentibus.

c) Arva, loca culta, campeftria.

Pagi, loca humanis habitationibus, fparfis confita. Urbes, loca humanis habitationibus continuis tecta.

II. TEMPORARIA habitatio infecto propria tantum tempore quodam mutationis vel metamorphofis. (Sic plerorumque Neuropterorum Larvae et Pupae, ut et Tipularum quarundum et Culicum, in aquis degunt, animalia perfecta volant fupra Terran.)

B. REGIO.

I. CLIMA.

a) Intra Tropicos.

b) Locis temperatis.

c) Intra Circulos Polares:

II. GEOGRAPHICE.

a) Indiae $\left\{\begin{array}{l}\text { continens } \\ \text { Infulae. } \\ \text { b) Africs. }\end{array}\right.$

e) Anie. 


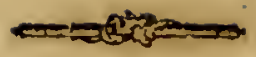
c) America $\stackrel{\text { Septentrionalis. }}{\{}$ Infulae
d) Nova Hollandia.
e) Infulae Maris pacifici.

\section{T E M P US.}

\section{A. GENERATIONIS.}

I. NUPTIARUM ET AMORIS.

a. Anni et tempeftatum, per Stadia florefcentiae, groffificationis, maturitatis, me/fis etc.

b. Vitae Stạdio, femper ultimo, Infeeto perfecto, nunquam Larva vel Pupa generante.

c. Duratio, in copula funt per dies integros, horas, mo. menta paucula.

II. NIDIfICATIONIS, per diem, biduum; (uti Sphex Figulus).

III. EXCLUSIONIS ovorum.

IV. EDUCATIONIS.

a. Lavvae, quamdiu in hoc ftadio permoneat.

b. Pupae, quandiu in fradio fecundo duret.

c. Imago, quamdiu perfectum Infectum virat.

B. VITALIUM ACTIONUM.

I. VICTUS ET CIEI.

a. Ratione ftadii.

a) Larva edente; Pupa non, Imagine rurfus vorace.

b) Larva et Pupa et Imagine edente.

c) Larva edente, fed Pupa et Imagine non.

d) Larva et Pupa edente, Imagine non.

b. Ratione temporis.

a) Alimenta fumunt mane, diu, vefperi, noctu.

b) - - - fole fplendente, tempore vento: fo, nebuloro, pluvio, ante, vel poft pluvism.

c) Alis alimenta fumente Larva, alia Imagise.

d) Las- 


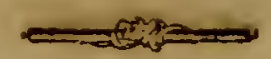

d) Larvis exclufis Onifci et Cọcci devorantibus vivain matrem.

II. SOM NI ET QUI E'TIS.

a. Quamdiu quieti indulgeant?

b. Quando quiefcant et lateant? Quandó curfitent vel circumvolent? Diu? Noctu?

\section{c. MTGRATIONIS.}

I. Lo cus.

a. a quo? (Gryllis migratorius ex Arabia, Blattae).

b. ad quern? (in Stptentrionem et occidentem).

II. TEMPUS, qua primum vifi. (viz. 1670, primum Cimex lectularius in Anglia vifus.)

III. CAUSAE migrationis.

D. DURATIONIS.

I. $A N \mathbb{N} U A$.

II. LONGAEVA.

\section{QUALITAS.}

A. ODOR, nervos olfactorios afficit et in genere fyftema nérvofum.

B. SAPOR, fibras mufculorum afficit, per falia.

C. TACTUS, fibras mufculorum afficit, fuperficie.

D. COLOR eft refexio radioruín fols a fuperficie Infeeti vel partis, variatus pro ratione fúperficiei.

a. PEI N CIPAIIS.

a) Alkus, radiis omnibis fimul reflexis:

b) Niger, radiis omnibus abforptis.:

c) Purpureus, ? ininime refractus. violacius medius inter purpureum

d) Coeruleus. i et coeruleum.

orcen virdis inter coerul, et luteum.

c) Luteus.

f) Ruber, i maxine refractus.

b. Re. 
b. Reliqui colores ex frincipalium intenfione; faturatio"e, expanjane, et commifuris fimplicibus vel duplicibus.

Principalis, Intensus f. Saturatus f. Eypansus f. FIORIDUS, AUStTERUS. DILUTUS.

1) Albus, niveus, candidus, lacteus.

2) Niger, furvus, ater, fuliginofus,

3) Purpureus, hyacinthinus, hyfginus, rofeus.

4) Coeruleus, fapphirinus, cyaneus, coelentis.

5) Luteus, flavus, croceus, fulphureus.

6) Ruber, coccineus, fanguineus, miniatus.

Ex commiffuris inter principales.

(1.2) Cinereus, incanus, plumbeus, lividus.

(3.4) Violaceus, chalybatus, ianthinus, amethyfinus.

(4. 5) Viridis, fmaragdinus, glaucus, prafinus:

(5.6) Aurantius, flammeus, fulvus, gilvus. .

(2.3.5) Fufcus, fpadiceus, badius, ochraceus.

E. MENSURA.

Plerumque a notis Infeßtis defumenda, vel etiami a partibus corporis humani, ut in Botanica viz. lineare, unguiculare, pollicare, palmare Ipithamaeum, dodrantale, pedale Infectum.

\section{USUS.}

\section{A. NATURALIS.}

I. OECONOMIA NATURAE; ejusque POIITIA.

a. In comp fcendis fpeciebus plantarum, et jufta inter eas proportione.

b. In purgañais aguis, ačre, et ter ab omni infectio. ne, confumendo defuruendoque omnia putrida, noxia, mortua.

c. In 
c. In praeparandis minuendisque nimiis terrae vifcidae, argillofae particulis, ut ita inagis aptae fiant ad recipienda femina, earumque incremento inferviendo.

d. In compefcendis ipfis Infectorum Jpecicbus, ne nu-. merofa 'noxia evadant.

e. In cibum cedendo, Mammalibus, Avibus, Pifcibus, Amphibiis et ipfis Infectis.

f. In exequendo judiciali minifterio divinae providen. tiae, in puniendis regnis, provinciis, civitatibus et villis, infligendo mortem inter pecora domeftica, et devorando fata, pafcua, fructus hortorum et arboruin.

II. PROVIDA NUMINIS CURA, in multiplicandis utiliffmis fpeciebus, Apibus inprimis, Bombycibus et aliis.

B. ARTIFICIALIS.

I. CUIINARIS.

a. Cancris penne omnibus cedentibus in cibum gratum, fopidum ac falutarem.

b. Locuffis et Gryllis in cibum cedentibus inter incolas regionum aridaruin, fabulofarum, calidarum, vel recentibus, vel fale conditis Gryllis.

c. Larvis Curculionis Palmae, Cerambycis Cervicor. nis, a Nigritis appetitis. Pupae Phalaenae Mori, ablatis folliculis fericeis, a,Chinenfibus comeftis et fervatis.

Larva Phelaenae Coffi Romanis olim in deliciis erat.

d. Monoculo Polyphemo, in America feptentrionali co. mefo ab hominibus ut cibus bonus, ut et in China.

II. MEDICUS.

a. In genere, plerisque diureticis, ftimulantibus, paucis adfringentibus, raro refolventibus, paucis fpiritu volatili analeptico. 
b. In fpecie.

a) Meloè veficatorius pro veficatoriis, ftimulo et diuretico.

b) Coccus Cadi pro diuretico sdhibetus.

c) Coccus llicis adffringens et roborans.

dj) Formicue praebent ipiritum volatilem, qui folvi ferruin et tincturam pracbet tonican, roborantem, adfringentem.

Formicae quoque aqua ferventi infufae in pars. lyfi in balneis adhibentur, ut analepticum.

Formicue, vino albo Gallico infufae, equos generofos, curfu excellentes reddere feruntur.

c) Lacca, Formicarum vei Vefparum opus in India, tincturam prsebet topican, antifepticam; roborentem, confolidantem.

f) Millepedes, refolventem vim et diureticam habent.

5) Oculi et Chelae Cancrorum pro abforbentibus ufurpantur.

h) Gallae, Cynipis opus in Querco gallifera Afrae, funt ingens ftypticum et adftringens.

i) Munna, ex Fraxino Orno exfudans, punctato a Cicada orni, purgans.

III. OECONOMICUS.

a. Cultura Apum, pro colligendo ex examinibus et alvearibus melle et cers.

b. Cultura Bombycum, pro colligendis ferici filis, opus feininarum et libérorum.

c. Textoria Serici.

d. Tinctoria.

a) Colore ruburo tingunt, Larvae Cocci Cácti, Polonici, et. Quercus llicis, (forte et Ulmi - campeftris, et Uvae Urfi) Acarus tinetorius; folliculi Apnidis Piftaciae, et Gummi Laccae.

b) Lusteo, folliculi Aphidis Piftaciae, et Gallae Cy. sipis in Salice.

c) Gal- 
c) Gallae Cynipis nigro ex Quercu gallifera.

e. Pro Cultura Ficus Caricae, Cynips Pfenes a Graecis cultoribus adhibetur fumma ntilitate, augendo fructus, ut pro 25. ad minimum 230 libras colligant.

f. Gummi Laccae, Refina ex Crotone, laccifero praeparata, per Formicae vel Vefpae fpeciem, pro cera figillatoria paranda adhibetur.

IV. METEOR O L O G I CUS.

a. Conops irritans, pungens ante pluviam.

b. Culices et Tipulae gregariae vefperi in aërem alte evolantes et ludentes, bonam praefagiunt tempeftatem.

c. Apes magna celeritate alvearia repetentes inftantem docent piuviam.

lnventis facile aliquid addcre:

\section{ORDINUM CHARACTERES}

\section{ET GENERA.}

A. COLEOPTERA: Alae fuperiores 2 cruftacese feu Elytra in futuram reftam conniventes, tegentes Alas 2 inembranaceas. Ore maxillofo.

I. ELYTRIS INTEGRIS, tergum omne tegentibus.

a. ANTENNIS Clavatis, verfus apicem incraffatis.

I. Scarataeus. Antennae clava fifili. Tibiae antice dentatae. Tarfus 5 articulis.

2. Lucanus. Antennae clava compreffa, latere latiore pectinato-fifili. Maxillue porrectae, exfertae, dentatae. Tibiae anticae dentatae. Turfus 5 articulis.

3. Dermestes. Antennae clavatae, capitulo perfoliato, tribus extremis articulis craffiori-

bus. 
bus. Thorax convexus, vix marginatus. Caput fub thorace infexum et conditun. Tibiae anticae dentatae. Flytria immargi. nata. Tarfus 5 articulis.

4. HISTER. Antemnae capitulo folido, articulo infimo comprefto decurvato. Caput retra. ctile intra corpus. Os forcipatum. Tibiae anticae dentatae. Elytra abbreviata. Tar. Jus 5 articulis.

5. Cis t e l. A. Antemane extrorfum crafiores, perfoliatae. Thorax conicus, vix marginatus. Caput intra thoracem retractile, alias infleyum. Corpus globofo-cylinåricum, Pedes comprefli, in tactis vel mortuis adprefti, in. tra foveolan abdominis recipiendi. Tarjb 5 articulorum recipiendi intra fulcum tibiae.

6. ВукRнus. Animac clavatae, folidae, fub. compreffae. Tibiae anticae dentatae. Turfus 5 -articulís.

7. Gy g INUS. Antcinae clavatae, rigidae, com. preffae, capite breviores. Oculi 4 , lateraies 2 et inferi 2. Pedes natatorii. Tar articulis.

8. Silpha. Antennae clavatac. Caput prominens. Thorax planiufculus, dillatato mar. ginatus. Tibiae antice dentatae. Tarfiss 5 articulis (in quibusdan fpeciebus poftici Tarfi 4. articulis).

9. Curculio. Antemae fubclavatae, roftro corneo infidentes. Roftrum corneum prominens. Tarfus 4 articulis.

10. A T TEla u S. Antennae apicem verfus craf. fiores. Caput exfertum; inclinatum, poftice IS atte. 
attenuatum. Truncus cylindricus. Tarfus 4 articulis.

I. A T т п I в US. Antennae clavatae. Caput exfertum. Thorax latus, marginatus. Ely. tra lata, brevia. Tarfus 4. articulis.

12. C O C C I E I L A. Antennae fubclavatse, trun catae, palpis cordatis breviores. Caput ex thorace vix prominens. Corpus hemifphaericum. Thorax et Elytra marginata. Abdomen planum. Tarjus 3. articulis.

b. ANTENNIS FILIFORMIBUS, fecundum totam longitudinem aequabili craffitie (I Z 4).

13. Pт I U S. Antennae filiformes, articulis ultimis majoribus, Thorax, fubrotundus, immarginatus, caput recipiens. Tarfus, 5. articulis.

14. $\mathrm{BR}$ U с н U S. Antennae filiformes, fenfim craffiores. Caput fubroftratum. Tarfus 5. articulis.

15. LAMPYRIs. Antennae filiformes, Thorax planus, femiorbiculatus, caput fubtus recipiens et occultans. Abdominis latera plicato-papillofo. Elytra flexilia. Tarfus 5. articulis. Femina aptera plerisque.

16. Cassida. Antemae fubfiliformes, extrorfum craffiores. Thorax clypeatus, planus, marginatus. Caput fubtus recipiens et occultans. Elytra inarginata. Tarfus 4. stticulis.

17. H IS PA. Antennac, fufformes, bafi approximatae inter oculos fitae. (hyperophthal. 
mae.) Thorax et Elytra faepe aculesta. Tarfus 4 articulis.

18. TEN в в IO. Antennae moniliformes, ultimo articulo fubglobofo. Caput exfertum, prominens. Thorax planus, conrexiufcu. lus, Inarginatus. Elytra rigida. Tarfus 5 articulis, vel 5 in primo pare et 4 articulis in reliquis paribus, vel ubique 4 articulis.

19. Ch к Y o m E. A. Antennae moniliformes, extrorfum craffiores. Thorax inarginatus, nec Elytra. Tarfus 5 atticulis primi paris, 4 in reliquis, vel 4 ubique articulis.

20. MELOE. Antennae moniliformes, articulo ultimo ovato. Caput infexum, gibbum. Thorax inaequalis, fubrotundus, immargiratus. Elytra mollia, flexilia. Tarfus 5 articulis primi paris, 4 in reliquis.

21. MOIDEL A. Antcnnae filiformes, ferratae, ariculis trigonis. Caput inflexum. Palpi conpreflo-clavati, oblique truncati. Elytra ve:fus apicem deorfum curva. Epigaftrium ante femora poftica. Tarfus 5 articulis primi paris, 4 in reliquis.

C. ANTEN IS SETACEIS, verfus apicem fenfim atenuatis,

22. C д а м в х. Antennas attenuntae, fub-amphiophthalmse. Thorax lateribus mucronato. allofus. Elytra linearia. Tarfus 4 articulis.

23. Le ITU R. Antennae feraceae. Caput exfertum. Thorax fubrotundus. Elytra atte. nuata. Tarfus 4 articulis.

24. C N т н $\mathrm{A}$ I s. Antennae fetacese. Coiput exfertum. Thorax marginatus, capite bre: $\mathrm{K} 2$ vior. 
vior. Elytra flexilia. Abdomen lateribus plicato-papillofum. Tarfus 5 articulis ubique, vel 5 articulis primi et fecundi paris, 4 ultimi.

25. Elater. Antennae fetaceae, et in crena capitis recondendae. . Sternum terminatuin mucrone, e foranine abdominis refiliente. Thorax verfus bafin elytrorum, lateribus angulo acuto. Tarfus 5 ar. ticulis,

26. C I C I N D E IA. Antennae fetaceae. Maxillae prominentes et dentatae. Oculi prominuli. Thorax rotundato - marginatus. Femora poftica bafi Trochentere infrueta. Tarfi 5 , articulis.

27. Buprés Tis, Antennae fetaceae, longitudine thoracis. Caput dinidium intra thoracem retractum. Elytn et. Corpus verfus anum anguftata. Tar $i$; articulis.

28. CA R A B U s. Antennac fetaeae. Thorax obcordatus, apice truncatus, marginatus. Elytra marginata. Femora Trochantere inftrueta. Targi 5 articulis.

29. Dyticus. Antennae fetaceae (aut clavato. perfoliatae). Pedes poftici, ciliati, natatorii. Tarji 5 articulis.

II. ELYTRIS MUTILATIS, terg vel brevioribus, vel anguftioribus.

30. N E CY d LIs. Antennac fraceae. Elytra mutilata, alis breviora vel inzuftiora. Cauda fimplex. Tarfi 4 articulis.

3I. S т Р н Y IN US. Antenne moniliformes. Elytra dimidiata. Alae ectae, plicatae ac 
fub Elytra retractae. Cauda fimplex, veficulis duabus oblongis exfertis. Tergum infra nudum. Tarfi 5 articulis.

32. Forf 1 C U la. Antennae fetaceae. Elytra dimidiata. Alae tectae. Cauda forcipata. Tarji 3 articulis.

B. HEMIP TERA. Alae hemelytratae fuperiores femicariaceae, margine interiore impofitae. Os Ko. $^{\circ}$ frumque inflexum verfus peetus.

33. B L A t T A. Caput inflexum. Os moxillofum; palpis 4. Antennae fetaceae. Thorax planus, orbiculatus, dilatato; marginatus. Hemely. tra oblonga, coriacea, plana. Pedes curfo. rii. Turfi 4 articulis. Cauda corniculis duobus foliaceis. Femina alis mutilatis.

34. Ma N T Is. Caput inflexum nutans. Os maxilloium, palpis infructum. Antcnuae reta ceas. Stemmata 3. Aluc 4 membranaceae, convolutae; inferiores plicatae. Thorax linearis, elongatus, anguftatus. ledes antici compreff, fubtus ferrato-dentati, armati ungue folitario, et digito fetaceo laterali, articulato: poftici remoti, longiores, laeves, ambulatorii. 'Tarf! 5 articulis.

35. Gry lu s. Caput inflexum. Os maxillofum, palpis 4. Antennae fetacene feu filiformes. Stemmata 3. Alae 4 deflexae, convolutas; inferiores plicatae. Pedes poftici faltatorii, reliqui ambulatorii. Torfis 4 in Tettigoniis et Locuftis, 3 in Acletis. Ungues ubique bini.

36. Fulgora, Caput fronte producta, inani. Antennac hyyoplatialuse, articulis 2, inferiore cylindrico, exteriore globcto, majore 
foramine pertufo. Roftrum infiexum. Alae deflexae, corpore longiores, inferiores cruciatae. Pedes greflorii. Tar $\sqrt{i} 3$ articulis.

37. C I CADA. Rofrum inflexum. Antennae feta. ceáe 2 vel 5 articulorum. Alae 4 membraniceae, deflexae. Stemmata in minoribus 2 , in majoribus 3. Pedes (plerisque) faltatorii. Taifl 3 articulis.

38. Not o ecta. Roftrum inflexum. Antennae thorace breviores, hypophthalinae. Alae 4 cruciato - complicatae, antice coriaceae. Scutellum in quibusdam. Pedes poftici pilofi, natatorii. Tarfi 1 vel 2 articulis.

39. NEPA. Roftrum inflexum. Antennae breviffinse, hypophthalmae. Scutellum in quibus. dam. Alac 4 cruciato - complicatae, antice coriaceae. Pedes antici chelyferi, reliqui 4 ambulatorii. Tarfil I vel 2 articulis.

40. C 1 M EX. Rofirum inflexum. Antennae thordce longiores, 3. 4. vel 5 articulis. Alae 4cruciato-complicatae, fuperioribus antice corinceis. Dorfum planum, Thorace marginato. Pedes curforii. Tarfi 3 articulis.

41. A Р н Is. Roftrum inflexum. Artennae thorace longiores, in feminis 6 vel 7 , in mafculis $10-20$ srticulis. Alae 4 erećrae, aut nullae. Abdomen poftice bicorne. Pedes ambulatorii. Tarjus unico articulo.

42. С HеRMES. Roftrum peftorale, inter pedes primi paris. Antennae thorace longiores. Stemmata 3. Thorax gibbus. Abdomen teiminatum acumine. Alae 4 deflexae. PCdes faltatorii. Tar $\sqrt{b} 2$ articulis. 
43. Coccu 5. Roftrum pectorale inter pedes primi paris. Antennae fetaceae, vel moniliformes, vel perfoliatae. Abdomen apice feto. fum. Alac 2 erectae mafculis, Feminse apterae.

44. TH R I S Roftrum obfoletum, rima longitudinali. Antennae filiformes, longitudine thoracis. Corpus lineare. Abdomine furfuin inflexo. Alae 4. Hemelytris' duriufculis, anguftatis, longitudinalibus, dorfo incumbentibus. Tarfi veficulofi.

C. LEPIDOPTERA. Alis 4 membranaceis et imbricatis fquanis. Os Lingua involuta fpirali. Corpur pilofum.

45. P а P I I O. Antenuae extrorfum crafiores, faepius clavato - capitatac. Oculi prominuli. Alae (fedentis) ereçae, furlumque conniventes, (volatu diurno). Pupa obteEta, nuda.

46. S Р н I N cae. Alae deflexae, pofticae plerumque ini. nores anticis, (volatu gravi matutino feu vefpertino). Corpus tumidum. Caput parvum. Oculi prominuli. Pupa obtecta, folliculata.

47. Phalaena. Antennae fetaceae. Caput parvum. Oculi parvi. Abdomen verfus anum at. tenuaturn et minus tumidum (quam in Sphingihus). Alae (fedentis) faepius deAlexae (volatu nocturno).

D. NEUROPTERA. Alae 4 nudaē, venis reticulatae. Cauda plerumque aliquo fexus adminiculo in: ftructa, inermis. 
48. LI в ELLU LA." Os inaxillofum; maxillis pluribus. Antennae letacene, "thorace breviores. Oculi magni, hemifphaerici, prominuli. Stemmata's verticalia; vel frontalia. Alae planae, extenlae, non tegentes fe invicen. Abdomen elongotum, tenues lineare, fub. cylindricum. Cauda (Maris) hamofo - forcipata. $T_{a r j} 3$ articulis. .,

49. RA P H D I'A. Os maxillis féu dentibus duobus. P'alpi 4. Cäput depreffum obcordatum. "Antennae fetacese, lóngitudine Thoracis elongati, cylindrici. Truncus longitudine reli. qui corporis, cylindricus. Stemmata 3 ver. ticalia: Alae deflexae: Carida (feminae) feto recurva, laxa. Tarji 4 articulis.

50. Pн RYGAía, Os edentuluin? Psilpi 4. Antinnale fetacese, thorace loncriores. Stemma: ta 3. Alac incumbentes vel deflexae, inferioribus plicatis. Cauda vel ariftata fetis 2 truncatis, vel inutica. Tarfus 3 vel 5 ar. ticulis.

51. EPFI F ERA. Os edentulum, absque palpis. Antennee fetaceac, longitudine thoracis. - Sieminata 2 vel 3 maxime hyperophthalma. Corpus elongatum, tenue; verfus caudam attenuatum. Alae erectso, pofticis minimis. Cuneda 2 vel 3 fetis. Tarjus 5 àticulis.

52. H E M E R O в I US. Os prominulum dentibus 2 falcatis. Palpi 4. Antennae letaceac, porrectae, thorace convexo longiores. Stemmat is nulla. Alae defexae, (nec plicatae). Tarjl 5 articulis.

53. PA N OR PA. Os Roftrum elongstum, corneum, cylindricum. Labia 2. Palpi 4. 6arti. culati et 4 articulati. Antennae fetaceae, tho. 
race longiores. Stcmmiata 3. Cauda (maris) chelata. Tarji 5 articulis.

54. MYR MELEON. Os maxillofum, prominens. Dentibus 2. Pailpi 4 elongati. Antemac cla. vatae, compreffae, longitudine thoracis. Stemmata nulla. "Aláe deflexae. Cauda (maris) e filamenitis 2 rectiufculis. $\operatorname{Tar} \hat{i} 5$ articulis.

E. HYMENOPTERA. Alae 4 membranacese; nu. $\mathrm{d} a$, nervis pro alarum magnitudine fortiori. bus interfinctae. Os maxillis 2 validis. Stummata 3. Cauda aculeo armata (in Feminis).

55. APIs. Os maxillis dentatis, atque probuficide infexa, raginis duabus bivalvibus Linguam includentibus. Caput triangulare, fronte plana, flexum. Antennae faepe pe. datae, primo articulo reliquis longiore. Alae planae. Aculeus punctorius recorditus, retractilis, ferratus Feminis et Neutris. Tar.j 5, articulis, primo longitudine Tibiae, compieflo, ciliato, tiansverfim fulcato.

56. F o r M I CA. Os maxillis validis. Antennae pedatae, primo articulo reliquis longiore. Caput fubtriangulare. Stemmata 3. verticalia. Thorax capite angutior. Squamula thoraci ac sbdomini interjecta. Alae Ma. fculis et Feminis: Neutris nullac. Acuicus reconditus, Feminis et Neutris, Tarjus 5 articulis.

57. VESPA. Os maxilits dentatis validis. Lingua membranacea; inflexs, Palpi 2. artieulis 4. Antennae pedatá, articulo primo ad geniculuin usque, reliquis 10 . vel I I, medis craf. K 5 frosibus, 
fioribus, extremitatibus anguftiorilus. Stemmata 3. Oculi lunati. Corpus glabrum. Alae fuperiores plicatae, inferiores minores in ormi fexu. Aculeus punctorius, reconditus Feminis et Neutris; Mafculis nullus. Tarfus 5 Articulis.

Haec 3 genera in Societate vivunt politica, gynaecocratica.

58. CнRYSIs. Os maxillis, palpisque, absque probofcide. Antennae filiformes, Articulo primo reliquis I I longiore. Stemmata 3 . Thorax poftice fubtruncatus latere dente fubípinofo. Abdomen aequale, ovatum, fubtus fornicatum, utrimque fquama laterali. Anus dentatus, aculco exferto. Alac planae. Corpus auratum. Tarfus 5 articulis.

59. S I REX. Os maxillis; Palpis 2 truncetis. Antcnnae filiformes, articulis ultra 24. Stem. mata 3. Thorax in plerisque pilofus. Aldomen oblongum feffile, mucrone corneo, excavato, recondente Aculeum exfertum rigentem, ferratum, vagina bivalvi in. clufum. Alae lanceolatae planae, Tarfus 5 articulis.

60. TENTHREDO. OS maxillis 2. absque probofcide; Labio fuperiore contanter cum pedibus concolore. Stemmuta 3. Palpi 4, exteriores 4 articulis, interiores duobus. Antennne variae. Thorax pone Scutellum granis duobus elevatis, diftantibus. Abdomen oblongum foffile. Aculeo laminis duabus ferratis vix prominentibus. Alae planae, tumidae. Tarji 5 articulis. 


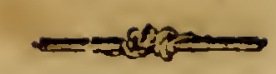

6r. CYN IPS. Os maxillis, absque probofcide. Palpi 2. biarticulati. Antennae vel fetacese, vel clavatae pedataeque. Stemmata 3. Abdomen ovale, lateribus coinpreflum, apice acuminatum. Aculeus fpiralis, faepius reconditus. Alae inferiores breviores. Tarfus 5 articulis.

62. S P н EX. Os maxillis, absque lingua. Antersnae filiformes grcuatae, 10 orticulis, raro trunco longiores. Stemmata 3. Aldomen petiolatum. Aculeus punctorius, reconditus. Alae plano - incumbentes (nec plicatae) in omni fexu. Tarjus 5 articulis.

63. I C H N U MON. Os maxillis 2. absque lingua. Palpi 2. Antennae vibratiles, fetaceae, trun. co longiores, articulis 30 . Stemmata 3 . Truncus latus, arcuatus. Abdomen petiolatum cylindricum, faepe falcatum. Aculeus exfertus feminis, Vagina bivalvi cylindrica. Alae fuperiores longiores. Pedes elengati. Tarfi 5 articulis.

64. MU TI L A. Os maxillofum. Antennae fetaceae vel pedatae. Stemmata 3. Thorax retufus. Corpus pubefcens, Aculeus punctorius reconditus. Alae plerisque nullae. Tarfi 5 articulis.

5. DIPTERAE. Alae duae membranaceae. Halteres clavati, folitarii pone fingulam alam faepe fub Squamula propris.

65. Tipula. Os, capitis inflexi, elongati, Ma. xilla fuperiore fornicata, Palpi 2. incurvi, articulati, capite longiores. Probofcis securvata brevifima. Antennae filiformes, peđinatae, 
natae, vel perfoliatae, vel verticillatae. Stemmata 3. Thorax gibbus. Abdomen lineare, elongatum. Pedes tenues, elongati. Tarf 5 articulis. :

66. CULEX. Os roftro cylindrico fuAtorio, et 5 aculcis fetaceis, omnibus intra vaginam com. muncem, appendices duae in mafeulis longae, in feminis breves, ad latus vaginae. Antequnac rerticillatae (maris), pectinatae (feminae). Stemmata nulla. Thorax gibbus. Alae fquam:s raris te Zae.: Abdomen elongatum, tenue, cylindricum. Pcdes ténues, elongati. Tarji 5 articulis.

67. EMPIs. Os roftro corneo, inflexo, arcuato, bivalvi, thorace longiore, valvulis horizontalibus. Antemae moniliformes, apice fetaceae. Stemmata 3. Corpus pilofum. Truncus gibbus. Alidomen cylindricum. l'edes elongati. Alae ovales. Tarfi 5 articulis.

68. As i lus. Os roftro cornee, recto, porrecto, bivalvi, fafciculo pilorum cincto (bartato). Antennae conicae, acuminatae. Stemmata 3. Thorax gihbus. Abdomen tenue, apice anguftatum. Corpus pilofum. Pedes elongati, ciliati fetis. Tarjus 5 aiticulis cordstis.

69. Con o Ps. Os roftro porresto, geniculato, divi. fo, aculeum-includente. Antennae variae. Stcmmata 3. Tarfi 5 articulis.

70. BOM Е longiffimo, bivalvi (nee geniculato), valvulis horizontalibus, intra quas aculei fetacei. Antennàe articulatae, fetaceze, porrectae. Stemmata 3. Corpus hirfutum. Abdo- 
men fubrotundum, thorace latius. Alae facpe punetato- inculatae, vel ex parte opacae. Pedes clongati, tenues. Tarfus 5. articulis.

7 I, H I Р РО в О S $А$. Os roftro cylindrico, obtufo, bivalvi, nutante. Antcnnae brevifimae, fetaceae. Stemmata nulla. Caput et Truncus compreffa. Abdomen rotundatum, coriaceum. Alae Abdomine longio. res. Tarjus 5 articulis. Ungues plures quam duo.

72. M U S A. Os probofcide carnofa, plicatili, recondenda inter duo labia lateralia, longitudinalia, absque palpis. Antennac variae. Oculi grandes, hemifphaerici. Stemmata 3. Tar. 5 articulis.

73. ТА ваN Us. Os probofcide carnora, porreda, apice labiis duobus terminata, includente roftrum vagina valvis duabus lateralibus, ri: gidis fubulatis, continente 4 aculeos feta. ceos punctorios. Palpi probofcidi laterales. Antennae filatae, lunulatae, fubulatae. Oculi plerisque colorati, punctati vel fafcinti. Stemmata 3. Alis faepe maculatis. Tarfus 5 articulis.

74. OESTRUS. Os nullum, punctis tribus, absque roftro aut probofcide exferta. Antennae fetaceae, infiftentes articulo globofo. Stemmata 3. Corpus pilofum, Tarjus 5 articulis,

9. APTERA. Alae nullse in omni Sexu.

75. L e I s M A. Pedes fex curforii, compreffi, imbricati lquamis. Os Palpis 2 fetaceis, 2 capitatis. Stemmata 2. Cauda fetefa: fetis extenfis. 
Corpus oblongum, fquamis nitidis imbricatum. Abdomen quolibet fegmento, fetis duabus minoribus.

76. P O D U R A. Pedes 6 curforii. Antennae elongatae fetaceae. Oculi 2 ex fexenis vel octonis compofiti. Cauda bifurca, faltatrix, inflexa in fulco fub sbdomine. Corpus oblongum, fquamis imbricatum.

77. Termes. Pedes 6 curforii. Antennae fetaceae. Oculi 2. compofiti. Os maxillis 2. palpis 2.

78. PE D I U LUS, Pedes 6 ambulatorii. Oculi 2. compofiti. Os aculeo exferendo. Antennae filiformes, longitudine thoracis. Abdomen depreffum, fublobatum.

79. Pulex. Pedes 6 faltatorii. Oculi 2 compofiti. Antennae filiformes. breves. Os probofcide fetacea, inflexa, aculeum recondente. Abdo.

- men compreffum, reliquis partibus multo majus.

80. Acarus. Pedes 8. Oculi 2 laterales. Os ro. fro includente aculeum vel fiphonem. $C a$. put prominens anguftatum verlus os. $A n$. temnae Tentacula 2 articulata, pediformia, faepe furcata. Abdomen laepe dilatatum.

81. Phalangium. Pedes 8. in plerisque longiffini, qualibet pedum parte; bafi articulo ininore inftueta. Tarfus articulis numero infinitis. Oculi 2 verticales contigui, 2 , laterales remoti. Antennae pediformes in fronte. Or palpis 2 chelyferis, inflexis. Culput intra Thoracem receptum. Abdomen sotundatum. 
82. A K ANEA. Pedes 8. qualibet pedum parte, bafi articulo minore.' Tarfi apice unguicu. lati. Oculi \& funplices, varie difpofiti. Antennae palpiformes 2 , breves, articulatae, (mafculis) genitalibus capitatae. Os unguibus, flexilibus, falcatis, tubulofis. Caput intra Thoracern receptum. Abdomen ovatum, apice 5 vel 6 papillis textoriis.

83. Sc O R P I O. Pedes 8. cheliferi, articulati. Antcnnae pediformes, cheliferae, frontales. $O c u$. li 8. 2 verticales, 3 utrimque laterales. Os palpis 2 cheliformibus. Caput intra Thoracem. Abdomen oblongum, 7 fegmentis. Cauda elongata, 6 articulis, 5 to longiffimo, 6 to amplifimo, terminato mucrone ar. cuato, tribus foraminulis pertufo. Pectines 2 fubtus, inter Peetus et Abdomen, dentibus $6-3^{2}$.

84. Ca n C e R. Pedes 8. (raro 6 feu Io.) Mantus 2 cheliferae. Oculi 2 compofiti, remoti, pe. dunculati, elongati, mobiles. Antennac elongatae, fetaceae, articulis numerofiftimis. Os palpis 2 dentatis, cheliferis, dentibus praeterea 2 et aliis minoribus palpis. Capat intra Thoracem receptum. Cauda articulata inermis, fub Abdomen inflexa. (Genitalia Maris ad bafin 5 paris pedum, Feminae ad 3 paris.)

85. MONOCULus. Pedes numerofi; natatorii. Oculi 2 compofiti, approximati, teftae inתati. Antennae fetaceae, faepe bi-vel trifurcae. Os dentatum, palpis 2 brevibus ar. ticulatis. Corpus crufta vel tefta tectum. Cauda (plerisque) vel fimplex vel bifurca, fetis pluribus conftans. 
86. On I scus: Pedes 14 . Oculi 2 compofiti, minuti, laterales. Antennae pedatae, fetacese, (raro 4.) Corpus ovale, fcutis tectum. Os palpis 2.

87. SCOLOPENDRa. Pedes numerón, totidem utrimque quot corporis fegmenta. Oculi 2. compofiti. Antennae fetacene. Os palpis 2. articulatis. Corpùs depreffum elongatum.

88. Ju Lus. Pedes numerofi, duplo atrinque plures, quam corporis fegmenta. Oçuli 2 compoliti. Antennae moniliformes. Os palpis 2. articulatis.' Corpus cylindricum. 


\title{
T E R M I N I
}

$\begin{array}{lllllllll}B & O & \text { T } & \text { A } & \text { N } & \text { I } & \text { C } & \text { I }\end{array}$

$S E C U N D U M$ METHODUM

\author{
CELEBERRIMI EQUITIS \\ CAROLI A LINNÉ \\ EX
}

VARIIS EJUS OPERIBUS CONGESTI. 


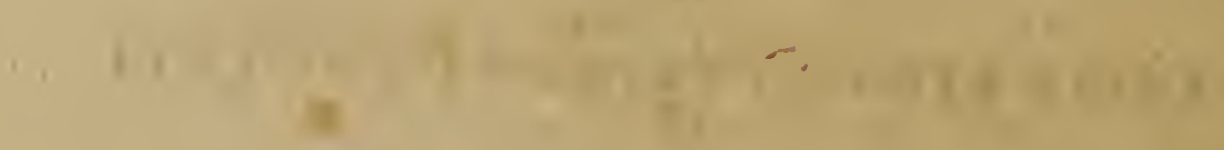

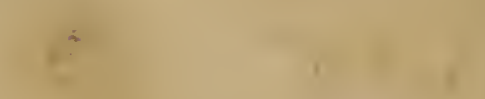




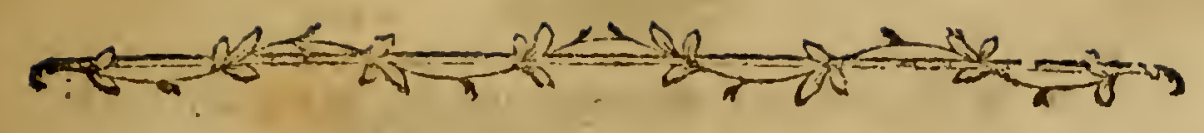

\section{T E R M I N I}

\section{$\begin{array}{llllllll}\text { B } & \mathrm{O} & \mathrm{T} & \mathrm{A} & \mathrm{N} & \overline{\mathrm{I}} & \mathrm{C} & \mathrm{I}\end{array}$}

LINNAEANI.

\section{DELINEATIO PLANTAE.}

\section{THEORIA.}

\section{A. G ENUS. Nomen felectiffimum.}

Charaiter, naturalis, effentialis, artificialis.

Clafis ordoque jyftematis praefantifimi.

Ordo naturalis demonjliandus.

B. SPECIES. Nomen triviale.

Differentia fpecifica demanfrranda : certiffima, breviffima.

Synonyma ex Defcriptione f. Figura felećta; vernacula.

C. CRITICA. Etymologia nominis generici, Specifici.

Inventor cum tempore.

Eruditio Hiltorica, Critica, Antiqua.

\section{DESCRIPTIO.}

A. RADIX, organum nutriens plantam.

a. DURATIONE.

1. Annua, intermoritura intra annums. $\odot \uparrow$

3. Perennis, per plurimos annos regerminans, 4

b. FI G U R A.

a) 4. Fibrofa, tota conftans radiculis fibrofis.

5. Rámojá, in fibras laterales Cubdivifa.

1. 2 6. Fis. 
6. Fuffformis, oblonga, craffa, attenuata.

7. Praemorfa, apice deorfum truncata.

b) 8. Repens, longe excurrens, hinc inde germinans.

9. Articulata, geniculis intercepta.

10. Dentata, moniliformis, ex articulis concatenata.

C) I1. Globofa, fubrotunda ( 158 .) radiculis lateralibus.

12. Tubcrofa, e partibus carnofis, bafi filo connexis.

13. Fafcicularis, e partibus carnofis, bafi feffili. connexis.

14. Palmata, carnofa lobata.

d) 15. Bulbofa, radix bulbo inftrueta.

16. Granulata, particulis carnofis adfperfe.

c. DIRECTIONE.

17. Perpendicularis, reeta defcendens.

18. Horizontalis, fub terra transverfim extenfa.

B. TRUNCUS, organum multiplicans plantam.

a. S P é I E, Caulis, Culmus, Scapus, Stipes.

19. Cassis, truncus elevans folia et fructificationem.

20. Culmus, .... graminibus proprius.

21. Scapus, elevans fruetificationem, nec folia.

22. Stipes, truncus in folia tranfiens.

b, DURATIONE.

23. Herbaceus, etiamnum annuus, (non lignofus.)

24. Sujfruticajus, bafi permanens, ramis quotannis marcefcens.

25. Frutico/us, peresnis, cum caudicibus pluribus.

26. Arboreus, perennis caudice fimplici.

27. Solidus, interne farctus.

28. Inanis, interne medulla fpongiofus.

29. Fiftulufus, interne tubulofus.

c. MENSURA.

a) (Proportio ad folia reliquasque partes.)

b) Craflities ex fimili notiflimo. 


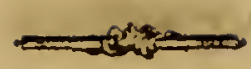

d. DIRECTIONE.

a) 30. Erectus, fere ad perpendiculum fe atto!lens.

3I. Strictus, omnino perpendicularis absque flexura.

32. Rigidus, flexionis impatiens.

33. Laxus, libere in arcum flexibilis.

34. Obliquus, a perpendiculari horizontalive linea difcedens.

35. Adfendiens, arcuatim furfum verfus.

36. Declinatus, arcuation defcendens.

37. Incurvatus, introrfum nutans.

38. Nutans, apice extrorfum 'reflexus.

39. Diffufius, ramulis patentibus ( 133 ).

40. Procumberis, debilis terrae innitens.

4r. Stoloniferus, turiones ad radicem edens.

b) 42. Sarmentofus, filiformis geniculis radicantibus.

43. Repens, terrae incumbens radiculasque agens.

44. Radicans, altis fe affigens radiculis lateralibus.

c) 45. Geniculatus, internodiis interceptus.

46. Flexuo/us, a genuma ad gemman horfum vor- furm aglus.

47. Sca dens, slta petens, aliis funtinendus.

48. Volubilis, fpiraliter adfcendens per alia corpora.

Dextrorfum a dextra od finiftram, contra motum folis vulgo.

Siniftrorfum a finifra ad dextran fecundum folem vulgo.

e. FI GUR A .

a) 49. Teres, angुulis deftitutus.

50. Semiteres, hine planus, inde teretiufeulus.

-5 I. ComprefJus; duobus lateribus oppofitis planis.

52. Anceps, angulis duobus oppofitis acutiufculis.

53. Angulatus, pluribus quam duobus angulis cavis longitudinalitcr excavatus. $3 \cdot$ oangulatus. Acutangulus, obtufangulus a figura angulorum.

L 3

b) 54 . 
b) $54.3-6$ gonus, angulis $3-6$ prominen. tibus longitudinalibus.

55. $3-5$ queter, lateribus $3-5$ exacte planis.

f. VESTITU.

5 ́. Nudus, oppofitus 5 fequentibus $(57-61)$.

57. Aphyllus, foliis dertitutus.

58. Foliatus, foliis inftruatus.

59. Vagiratus, foliorum vaginis cinctus.

60. Sqliamofus, fquanis adfperfus.

6 r. Imbricatus, tectus, ut nudus non appareat.

g. SURERFICIE.

d) 62. Suberofus, cortice exteriore molliore, fed elaftico indutus.

63. Rimofus, cortice exteriore fiffuras fponte agens.

64 Tunicatus, membrdnis vefitus.

b) 65. Laevis, fuperficie aequali.

66 Striatus, lineis tenuifhmis excavatis infcriptus. -

67. Sulcatus, lineis profundis exaratus.

c) 68. Glaber, fuperficie lubrica (215).

69. Scaber, punctis eminentibus rigiliufculis exafperatus (242).

70. Muricatus, punctis fubulatis afperfus.

7 I. Tomentofus, villis intertextis, nec difcernendis obductus (237).

72. Villofus, teetus pilis mollibus (235).

73. Hifpidus, fetis rigidis alperfus (243).

74. Aculeatus, fquamis (380.) armatus (244).

75. Spinofus, fpinis (386.) armatus.

76. Urens, ftimulis (399.) adfperfus.

d) 77. Stipulatus, fipulis (292.) notatus.

78. Membranaceus, complanatus more folii.

79: Bulbifcrus, bulbos gerens.

h. COMPOSITIONE.

a) 80. Enodis, continuus absqae articulis. . 
81. Simpliciflimus, ramis vix ullis.

82. Simplex, continua ferie verfus apicen' extenfus.

b) 83. Artieulatus, internodiis geniculatus.

84. Prolifer, ex apicis centro tantum emittens ramos.

85. Dichotomus, bifariam femper divifus.

86. Brachiatus, ramis decufation oppofitis.

c) 87. Subramofus, ramis paucinimis lateralibus.

88. Ramofus, ramis pluribns lateralibus.

89. Ramofifimus, ramis multis absque ordine $\mathrm{clm}$ mulatus,

d) 90. Virgatus, ramufculis debilibus inxequalibus.

91. Paniculatus, ramis várie fubdivifiss.

92. Faftigiatus, ramis aequalis altitudinis.

e) 93. Patens, ad angulum acutum ramis infertis.

94. Divaricatus, ramis ad angulun obtufum difcedentibus.

RAMI, partes Caulis.

2. STRUCTURA Caulis.

- - - Frondis.

b. 95. Altemi, per gradus circa truncum exorti (I 4 ). 96. Diftichi, duo latera trunci refpicientes, licet undique inferti (I I 5).

9\%. Sparji, absque certo ordine conftituti (ir 7 ).

98. Conferti, plurimi totum fere occultantes truncum (I 1 8).

99. Oppofiti, per paria decufatim collocati (126). 700. Verticillati, plures truncum ad genicula circumdantes.

c. ror, Erecti, fere ad perpendiculum fe extollentes. 102. Coarćtati, verfus fummitatein sere incumbentes.

103. Divergentes, a trunco ad angulum rectum divergentes, . 
ro4. Divaricati, ad angulum obtufum a trunco difcedentes.

105. Deflexi, in arcum deorfum declinati. 106. Reflexi, perpendiculariter dependentes. 107. Retroflexi, horfum vorfum divaricati. 108. Fulcrati, Fulcris (290) inftructi.

d. Altitudine caulis: longis.

$$
\begin{aligned}
& \text { brevibus. } \\
& \text { patentibus. }
\end{aligned}
$$

C. FOLIA, organa motus et refpirationis plantac.

1) DETERMINATIONE, folia notain acquirunt aliunde, quam a propria fructura.

2. L o c o, quo adneêuntur plantae. 109. Seminale, quod àntea cotyledon fuit; et primum eft in planta.

I10. Radicale, radici infidens.

III. Caulinum, cauli infertum.

112. Ramezim, ramo infidens.

1 3. Axillare, (Subalare) fub rami bafi infertum.

114. Flarale, flori proximum. NB. Numerus notetur; unicum, duo, tria, pauca, plurima.

b. S I TU.

a) II5. Alterna, per gradus circa ramum exorta.

II6 Difficha, duo latera rami refpicientia, licet undique inferta.

11\%. Bifaria, ad latera rami oppofita tantum enata.

118. Sparfa, absque certo ordine confituta,

119. Conferta, plurima totum fere occultantia ramum vel caulem.

120. Imbricata, qua dimidiam partem invicen tegentia. 
12 I. Fafeiculata, plura ex eodem puncto prod. euntia.

122. Bina, terna, quaterna, quina, fena etc. de numero ad genicula ramorum.

123. Confluentia, ad bafin inter fe cohaerentia.

124. Approximata, ad fe invicem proxime ac. cedentia.

125. Remota, fpatio a fe invicem diftanria.

b) 126. Oppofita, per paria decufiatim collocata.

127. Decufjata, its oppofite difpofita, ut folia, apice infpecto, quatuor ordines referant.

128. Stellata, plura quam duo folia caulem nmbientia: terna, quaterna, quina etc.

c. DIRECTIONE.

a) 129. Erectum, fere ad perpendiculum conAtitutum.

30. Strictum, omnino perpendiculare absque flexura.

31. Rigidum, flexionis inpatiens.

132. Adpreffum, difco cauli approximatum.

133. Patens, ad anguluın acuium cauli infidens,

134. Horizontale, ad angulum rectum a caule difcedens.

I35. Afjurgens, arcuatim erectum; primum declinatum, dein apice erectum.

I36. Inflexum, furfum arcuatum verfus apicem.

137. Reclinatum, deorfum flexum, ut arcus fit bafi inferior; apice afcendente.

138. Recurvatum, deorfun flexum, ut arcus fuperiora fpecret.

139. Revolutum, in firam recurvatum.

1 40. Dependens, terrom recta fpectans.

b) 141 . Obliquum, bafi coelum, apice horizontem fpectans. 
142. Adverfum, paginam fuperiorem meridici feu foli (non coelo) obvertens.

143. Verticale, disverfum, ut regio bafis angu. ftior evadat regione apicis.

144. Refupinatum, pagina fuperiore inferiore, et inferiore contra fuperiore facta.

c) 145. Submerflum, intra aquae fuperficicin abs. conditum.

146. Natnns, fuperficiei aquae incumbens.

147: Radicasus, radices agens.

d. INSERTIONE.

a) 143. Petiolatum, petiolo (29 r.) ad" bafin inferto.

149. Peliatum, petiolo difco folii inferto.

b) 150. Seffile, immediate cauli (absque petiolo) infidens.

151. Adnatum, pagina fuperiore bafi rami adnexum.

I 52. Coadunata, plura inter fe connata.

I 53. Decurvens, bafi folii deorfum per caulem extenfa.

154. Amplexicaule, bafi caulem ambiente.

155. Perfoliuturi, bafi transverfe cingente (nec antice dehifcente) caulem.

I56. Connuta, oppolitorum paribus, bafi utrimque coadunatis.

157. Vaginizns, bafi formante tubum, caulem veltiente.

II) STRUCTURA.

a. FIGUKA.

a) 158. Subrotundum, figura orbiculatae (159.) proxima.

59. Orbiculatum, peripheria circinata, (dia: meter longitudinalis aequalis transverfali). 


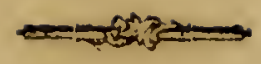

160. Ovatum, cujus diameter longitudinalis fuperat transverfaleni, bafi fegmento circuli circumfcripta, apice anguftiore.

I6r. Ovale, ex orbiculato oblonguin, utraque extremitate rotundata aequali.

b) 162. Oblongum, diamerro longitudinali aliquoties fuperante transverfalem.

163. Parabolicum, verfus apicem fenfin angur ftius rotundatum.

164. Cunciforme, fenfim verfus bafin anguftatum. 165. Spatulatum, fubrotundum (158.) bafi an. guftiore lineari (169).

c) 166. Rotundatum, angulis orbum.

167. Lanceolatum, oblongum ab utraque ex. tremitate attenuatum.

168. Ellipticum, lanceolatum latitudine ovati folii.

169. Lineare, aequali ubique latitudine.

I 70. Acerofum, lineare (I69.) perfiftens (274).

b. ANGULIs.

17 1. Integrum, indivifum, omnique finu de. ftitutum,

17.2. Triangulare, Quidrangulare etc. a nune. ro angúlorum.

173. Deltoideum, rhombeum (174.) ex quatror angulis, e quibus loterales minus a bafi diftant, quan reliqui.

174. Rhombeum, forma rhombi.

175. Trapeziforme, forma trapezii.

c. SIN UBUS.

a) 176. Cordatum, fubovatum, bafi finu exfculpto, absque angulis pofticis.

177. Reniforme, fubrotundum, bafi finu exfculpto, absque angulis pofticis. 
178. Lunatum, fubrotundum, bafi finu divifum, angulis pofticis acutis.

179. Sagiltatum, triangulare, angulis pofticis acutis finu divifis.

1 80. Haftatum, fagitatum (1 79.) angulis pofticis finu divisis ad latera prominentibus. I 81. Runciraturn, pinnatifiduin (189.) ita, ut lobi antice convexi, poftice fint trans. verfi, e. gr. Leontodon.

182. Panduriforme, oblongum, lateribus inferne coaretatis.

b) 193. Fiffum, divifun finubus linearibus, maroinibus rectis.

1 84. Lobatum, ad dimidium divifum in partes diAtantes. Bilobum, Trilobum, Quadrilubum. I\$5. Bifidum, Trifidum pro numero fifura. rum (I 83 ).

186. Partitum, ad bafin fere divifum. Tripartitum.

187. Palmatum, divifum ultra dimidiuin in 10 . bos fubaequales.

188. Lyratum, transverfim divifum in lacinias, quarum inferiores minores remotiores.

189. Pinnatifidum, transverfim divifum in lacinias horizontales oblongas.

190. Sinuatum, a lateribus finubus dilatatis.

19r. Laciniatum, varie et indeterminate in partes le̊ium.

192. Squarrofum, divifum in lacinias elevatas, nec plano parallelas.

d. MarGINE.

a) I 93. Integerrimum, ipfo margine lineari, nee minimum fecto.

194. Crenatum, margine incifuris, neutram extremitatem refpicientibus, fecto.

195. Serratum, margine omnibus incifuris refpicientibus extremitatem. 
196. Ciliatum, margine fetis parallelis longitudinaliter digeftis.

197. Dentatum, margine acuminibus patentibus remotis.

198. Spincolum, margine acuminibus fubulatis rigidis pungentibus.

199. Cartilagineum, margine fuboffeo.

b) 200. Repandum, margine flexuofo, tamen plano. 201. Lacerum, margine varie divifum, feginentis difformibus.

202. Erofum, finuatum (190.) finubusque minimis obtufis laciniisque inaequalibus.

203.'Daedaleum, una flexuofum, lacerumque (20r).

c. APICE.

a) 204. Obtufum, intra fegmentum circuli terminatum.

205. Emarginatum, terminatum crena.

206. Retufim, terminatum finu obtufo.

207. Praemorfum, terminatum obtufe incifuris inaequalibus.

208. Truncatum, terminatum linea transverfali.

b) 20g. Acutum, terminatum angulo acuto.

210. Acuminatum, terminatum apice fubulato $(270)$.

2Ir. Cuspidatum, terminatum apice fetaceo.

21 2. Mucronatum, terminatum mucrone exftante.

2I 3. Cirrhofum, cirrho (293.) terminatum.

f. SUPERFICIE.

a) Pagina fuperior vulgo coelum,

- inferior terram fpectat.

2 I 4. Nudum, fetis et pilis deftitutum.

215. Glabrum, fuperficie lubrica. 
216. Nitidum, glabritie lucente.

217. Lucidum, quafi illuminatum.

2 8 . Coloratum, alio colore quam viridi.

b) 219 . Nervo fum, vafis fimplicifimis a bafi ad apicém. 220. Trinerve. tribus nervis in bafi folii con. currentibus.

22 I. Triplinerve, nervofum tribus nervis fupra bafin concurrentibus.

222. Trinervatum, nervofum tribus nervis pone bajin folii concurrentibus.

223. Enerve, nervolo (190-222.) oppofitum. 224. Lineatum, nervis depreffis.

- 225. Striatum, lineis parallelis leniter excavatum. 226. Sulcatum, lineis profundis excavatum.

c) 227 . Venofum, vafis multifariam divifis.

2,28. Rugofum, rugis refertum.

229. Bullatum, ex rugoro (228.) venis contractis, ab altera parte concavis.

230. Lacunofum, difco deprefro, inter venas interjectas.

$23 \mathrm{r}$. Avene, f. avenium venofo (227.) oppofitum. d) 232. Punctatum, adiperfum punstis excavatis.

233. Papillofum, tectum punetis carnofis.

234. Papulofum, tectun punctis veficularibus.

235. Vifiidum, oblinitum tenaci humore.

c) 236. Villofum, tectum pilis mollibus.

237. Tomentofism, villis intertextis nec difeer. nendis obduatum.

238. Sericeum, tectum pilis adpreffis mollifinis. 239. Lanatum, indutum quifi tela araneae, (pilis fponte curvatis).

240. Barbatum, pilis paralletis obfitum.

241. Pilofum, pilis diftinctis elongatis tectum.

242. Scabrum, punatis eminentibus rigidiufculis exafperatum. 
243. Hifpidum, fetis rigidis adfperfum:

244. Aculeatum, fqusmis (386.) armatum,

245. Sirigofum, aculeis lanceolatis (167.) rjgidis $(32)$.

g. EXPANSIONE.

246. Pianum, fuperficie aequali.

247. Canaliculatum, fupra fulco profundo longirudinaliter excavatum.

248. Concavum, margine difco arktiore, ut de. primatur difcus.

249. Convexum, margine difco aretiore, ut elevetur difcus.

250. Cucullatum, lateribus ad bafin conniventibus, apice vero dilataris.

$25 \mathrm{I}$. Plicatum, difco plicis acutis alternatim flexo. 252. Undatum, difio plicis obtufis alternatim flexo. 253. Crifpum, margine luxuriante, ut difcus evadat lengior fua rachi,

h. SUESTANTIA.

a) 54. Membranaceum, fubftantia propria folii.

25.5. Scariofum, fubftantia ficca arida tactu fonora.

256. Gibbum, utraque fuperficie convexa, mediante copiofiore pulpa.

257. Teres, fere cylindricum.

258. Depreffum, pulpofum (263.) difco magis quam lateribus complanato.

259. Compreffum, pulpofum, lateribus magis, quam difco complanatis.

26c. Carinatum, parte prona difci prominente longitudinaliter.

b) 23 1. Compactum, fubftantis folidn conftans. 262. Tubulofum, interne concavum vel inane. 263. Pulpofum, materia tenaci farctum. 264. Carnofum, interne pulpa folidiufcula refertum.

$$
\text { 6) } 265
$$


c) 265. Triquetrum', 3 lateribus longitudinalibus in folio fubulato $(690)$.

266. Anceps, duobus angulis prominentibus longitudinalibus? difco convexiore.

267. Lingulatum, lineare ( 168. ) carnofum (264.) fubtus convexum (249).

268. Eńfiforme, anceps (266.) \& bafi ad apicem fenfim attenuatum.

269. Subulatum, ad bafin lineare, verfus apicem attenuatum.

270. Acinaciforme, compreffum (259.) carno. fum (264.) altero margine convexo angufto, altero rectiore craffiore.

2 7. Dolatriforme, compreflum, (259.) fub. rotundum ( 158.$)$ extrorfum gibbum (256.) acie acuta inferne teretiufcula.

i. MENSURA.

Brevifjima.

Longif/sma refpectu ad caulem articulosve.

$k$, DURATIONE.

272. Deciduum, peraêta unica aeftate cafurum.

273. Caducum, brevi decidens, nec per integrain aeftatem permanens.

274. Perfiftens, peracta aeftate non cafurum.

275. Perenne, per aliquot annos virens.

276. Sempervirens, per omnia tempora anni virens.

III) COMPOSITIONE.

a. Compositum, petiolo (29r.) plura quam unum proferenie folia.

277. Articulatum, folio ex apice folii excrefcente. 278. Conjugatum, pinnatum (282.) tantum binis foliolis lateralibus.

279. Digitatum, petiolo fimpliol apice adne. Etente foliola. 


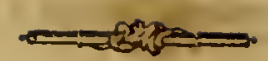

280. Binatum, digitatum (279.) foliolis duo. bus terminatum; Ternatum, Quinatum etc

281. Pedatum, petiolo bifido, latere tantum in. teriore adnectente foliola plura.

282. Pinnatum, petiolo fimplici lateribus ad. nectente foliola plura.

283. Bijugum, (Trijugum, Quadrijuguin) etc. pinnatum, fed foliolis tantuin quatuor.

Cum impari pinnaturn, foliolo unico (in. pari) teruinatum.

Abrupte pinnatum, nec cirrho, nec foliolo terminatum.

Cirrhofum, cirrho (293.) terminatum. Foliolis oppofitis (126).

Alternis (114).

Interruptis, foliolis alternis minoribus.

Decurfivis, foliolis petiolo decurrenti. bus (153).

b. DECOMPOSITA.

284. Bigeminum, petiolo dichotomo (84.) apice adnectente foliola plura.

285. Biternatum, duplicato ternatum ( 280$)$.

286. Bipinatum, duplicato pinnatum (2\$2).

c. SUPRADECOMPOSITA.

287 . Tergeminum, triplicato geminatum.

288. Triternatum, triplicato ternatum.

289. Tripinnatum, triplicato pinnatum.

D. 290. F $\mathrm{U}$ LCRA, adninicula plantae pro commodiore fuftentatione.

29r. Petiolus, fulcrum fuftinens foliu:n,

292. Stipula, fquama bafi petiolorm enafien. tium adfans.

293. Cirrlus, vinculum filiforme fpirale, quo - planta alii corposi alligatur. 
294. Pubes, hirfuties omnis in planta.

295. Arma, mucrones arcertes animalia, ne lae. dant plantam.

296. Bractea, folium florale (I 12. ) facie a caeteris foliis recedens.

297. Pedunculus, fulcrum fuftinens fruetifica; tionem.

I. PETIOLUS.

a. FIGURA.

298. Linearis ( 169 ).

299. Alatus, lateribus dilatatus.

300 . Clavatus, verfus apicem incraffatus.

301 . Membranaceus, complanatus.

302. Teres (257).

303. Semiteres $(50)$.

304. Triqueter (55).

305. Canaliculatus (247).

b. MAGNITUDINE.

306. Brevifimus, qua magnam partem non attingens longitudinem folii.

307. Brevis nondum longitudinem folii ad. tingens.

308. Mediocris longitudine folii.

309. Longus, fuperans longitudinem folii.

310. Longi $\sqrt{\text { timus, }}$ aliquoties fuperans longitudinem folii.

c. INSERTIONE.

311. Infertuss, perpendiculariter ramo infidens.

312. Adnatus (151).

313. Decurrens (153).

14.' Amplexicaulis (154).

3r5. Appendiculatus, ramentis foliaceis ad bafin.

d. DIRECTIONE.

316. Erectus, $(129)$. 
317. Patens (133).

318. Afjurgens (135).

319. Recurvatus $(138)$.

e. SUPERFICIE.

320. Glaber ( 2 I 5).

32 I. Aculeatus (244).

322 . Nudus (2 I 4).

323. Articulatus (83).

324. Spinefiens, indurefcens et pungens.

11. STIPULAE.

a. 325. Geminae, duae et duse per paria.

326 . Solitariae, fimplices tparfae.

327. Null.ae, fi abfunt.

b 328 . Laterales, lateribus infertae.

329. Extrafoliaceae, infra foliun collocatae.

330. Intrafoliacere, fupra folium collocatae.

331. Oppofitifuliae, in latere folii oppofito col. locatae.

c. 332. Caducae (273).

333. Deciduae (272).

334. Perjiftentcs, poft defoliationem reftantes.

335. Spinefcentes $(324)$.

d. 336 . Seffiles $(\mathbf{I} 50)$.

337. Adnatae (15i).

338. Decurentes ( 153 ).

339. Vaginantes (157).

e. 310. Subulatae (269).

34 r. Lanceolutac (167).

342. Sagittatae (179).

3+3. Lunatae (178).

f. $34+$ Ereitne (129).

$3+5$. Fatentes (133).

346. Reflerae (106). 
g. 347 . Integerrimac (193).

348 . Scruatce (195).

349. Ciliatae (196).

350: Dentatae (197).

35 1. FifJae (183).

11. 35 2. Breviffimae, qua magnam partem non ad. tingentes longitudinem petioli.

353. Mediocres, longitudine petioli.

354. Longae, fuperantes longitudinem petioli.

III. CIRRHUS.

a. 355. Axillaris (I 3 ).

356. Foliaris, folio ínfidens.

357. Petiolaris, petiolo (291.) infidens.

358. Peduncularis, pedunculo (297.) infidens.

b. 359. Simplex, indivifus.

360. Trifidus, in tres partes divifus. 361. Multifidus, multoties divifus.

c. 362. Convolutus, in annulos contortus. 363. Revolutus, fpira dinidio itinere retorta.

IV. PUBES.

a. 364. I'ili, dustus excretorii plantae fetacei. 365. Laza, pili curvi denfi. 366. Barba; pili paralleli. 367 . Tomentum, vilii intertexti vix confpicui. 368. Strigae, pili rigidiufculi planiufculi.

b. 369. Setae, pili rigidiufculi teretiufculi.

373. Simplices, continuo extenfae longitudidinaliter.

371. Humofae, animalibus facile adhaerentes.

372. Ramojae, fubdivifae quafi in ramulos.

373. Plumofae, villofae compofitae.

374. Stellatae, deculation difpofitae. 


\section{$18 \mathrm{I}$}

c. 375. Hami, mucrones acuminati curvati. 376. Glochides, mucrones apice retrorfum multidentati.

d. 377. Glandula, papilla humorem excernens. 373. Utriculus, vafculum liquore. fecreto rev pletum.

379. Foliaceae, foliis infertae.

380. P'ctiolares (356).

$38 \mathrm{r}$. Peciunculares (358).

382. Stipulares, ftipulis $(292$.$) infertae.$

383. Culycinae, calyci (5 4.7.) infertae.

e. 384: Vifcrfitas, qualitas hamoris tenacis.

385. Glutinofitas, quaiitas humoris lubrici.

\section{ARMA.}

A. 386. Aculci, mucrones pungentes plantae cortici tontum affixi.

387. Recti, fiexuris deftituti.

388. Incurvi, introrfum flexi.

389. Recurvi, extrorfum reflexi.

b. 390. Furca, aculcis divifis in plures.

391. Bifidae et Triffdae, a numero divifionis.

c. 392. Spina, mucro e ligno plantae protrufus.

393. Terminalis, ad apicem plantae pofita.

394. Axillaris ( 113$)$.

395. Calycina, calyci $(527$.$) infidens.$

396. Foliaris (355).

397. Simplex (370).

398. Divija, apice partita.

d. 399. Stimuli, mucrones puneturas inflammato. rias efficientes, unde pruriginofae eva. dunt partes.

400. Pungentes.

40I. Urentes. 
VI. BRACTE AE, folia.

a. 402. Coluratae (218).

403. Caducac $(2,3)$.

404. Deciduae (272).

405. Perfiftentes (274).

b. Numerus, unae, duae, plures.

c. 406 . Coma, bracteae caulem terminantes magnitudine infignes.

d. Folïis quae propria funt $109-289$. ea quoque ad Bracteas referri poffunt.

VII. PEDUNCULUS.

40\%. Fartialis, (a - e) aliquot flores peaunli communis proferens.

408. Communis, communis piuribus foribus.

409. Pedicellus, proprius fioribus in pedunculo communi (408).

a. I O C O.

410. Radicalis (I 10).

4 I I. Caulinus (III).

412. Rameus (112).

4I3. Petiolaris (357).

414. Cirrhiferus (293).

4 I 5 . Terminalis (393).

416. Axillaris (I 13 ).

417. Oppofitifolius (331).

418. Lateriflorus (328).

419. Suprafoliaceus, in fuperficie folii collocatus.

420. Intrafoliaceus (330).

42I. Extrafoliaceus (329),

b. S I $\mathrm{Y}$ U.

422. Alteruus ( 1 I 5 ).

423. Sparjus (1 18 ).

424. Oppofitus ( 126 ).

425. Verticillatus ( 100$)$.

c. Nu. 
C. NU MERO.

426. Soliturius $(326)$.

427. Geminatus (284).

428. Umbellula fefilis, plures peduneuli ex codém centro ambitu aequali prodeuntes.

d. DIRECTIONE.

$$
\text { 420. Adprefjlis (132). }
$$

430. Erectus (129).

$43 \mathrm{r}$. Patens (133).

432. Cesmuls, apice terram fpectans.

433. Reflepinatus (147).

434. Declinatus (36).

435+ Nistans (38):

436. Fiaccidus, debilis, ut a proprio foris pon-

, - dere dependeat.

437. Adficudens (35).

438. Pendulus, laxus, ut cum folio deorfum tendat.

439. Strictus (3 I).

440. Flexucfus, a flore ad florom fiexus.

441. Ketrofratus, vi quari ad dependentian redsêtus.

e. Meisuira.

442. Brevis (307).

443. Brevifimis $(306)$.

44. $1.0 n g u s$ (309).

445. Longifinius (310).

f. FLORUM NUMERO, unifiorus, biflorus, trifionus, multiflorus.

g. STRU CTURA.

446. Tëres (49).

447. Triqueter ( 55$)$.

448. Tetragonus (54).

449. Filiformis, acquabili ubique crantite. 
450. Attcnuatus, verfus apicem craffitiem perdens fenfinn.

45 I. Clavatus $(300)$.

452. Incrafjatus,-apice fenfim majorem molem acquirens.

453. Squamofus (60).

454. Nudus (214).

455. Foliatus ( 58$)$.

456. Bracteatus, bracteis (296.) inftufus.

457. Geni:ulatus (45).

458. Articulatus (83).

E. INFLORESCENTIA, eft modis, quo'fores pedunculo piantae anneetuntur: graduali modificatione fcandit:

459. Spadix, receptaculum PALMAE enstum intra fpatham in ramülos fructificantes divifum $(1037)$.

460. Cyma, receptaculum ex centro eodem univerfali, partialibus vero vagis, elongatum in pedunculos faftigiatos $(1033)$.

461. Umbella, receptaculum ex eodem centro, elongatum in pedunculos filiformes pro-

- portionatos (922).

462. Aggregatus flos, receptaculo dilatato, flo. fculis fubpedunculatis $(642)$.

463. Compofitus. Flos receptaculo dilatata integro, Flofculis feffilibus (920).

464. Spica, flores feffiles alterni in pedunculo communi fimplici (490).

465. Amentum, ex receptaculo ( $9 \mathrm{r}_{\text {. }}$ ) communi palenceo gemmaceo $(563)$.

466. Strobilus, ex Amento factus, fquamis induratis (987).

467. Corymbus, ex fpica (490.) factus, dum finguli, flores pedunculis propriis in-

ftruan. 
fruuntur, fitu elevato proportionali ( 1505 ).

468. Racemus, pedunculo Ramis lateralibus inftructo ( 5 I I).

469. Panicula, fores fparfi, in pedunculis diverfe divifis $(523)$.

47c. Thyrfus, panicula $(523$.$) coartata in for-$ main ovatam ( 508 ).

47 I. Fajciculus, colligens fores erectos, paralle. los, faftigiatos, approximatos (48\%).

472. Capitulum, floribus pluribus in globum congeftis (483).

473. Verticillus, foribus pluribus caulem annulatim ambientibus $(+83)$.

474. Lateriflora, floribus pluribus eidem, lateri caulis affixis.

FLORES.

a. Terminales (393).

b. Laterales (428).

c. Sparfir ( 1 I 7 ).

d. Seffles (150).

e. Pedunculati, pedunculis infrueti (297.) 477).

f. Unicus, planta nonnifi unum florem proferente.

g. Solitarius (326).

h. Terni (122).

i. Copiofi, plures, numero indeterminato, in apice cujuslibet rami, vel ad genicula ramoruin.

k. Evecti (30).

1. Cernui (432).

m. Nutantes (38).

n. Refupinati (1 44).

o. Verticales (143).

p. Horizontales (134).

1) 475. VERTICILLUS, (473).

a. 476. Sefflis, absque pedicillis manifertis. 
477. Pedicnculatus, pedunculis flores elevantibus.

b. 478 . Nudus (479.480.). oppofitus.

479. Involucyatus, involucro $(570$.$) infruetus.$ 480. Bracticatus (456).

c. 481. Confortus, pedunculis approximatis. 482. Difuans, pedunculis remotis.

II) 483. CAP TTULUM $(722)$.

a. 484. Subrotundum, fere globofum (485).

485. Globollum, ab onni parte rotundum.

486. Dismidiatum, ab altera parte rotundum, ab altera plarium.

b. $48 \%$. Foliofum, foliis intermixtis foribus. 4.88. Nucum, foliis et fetis dentitutum. …n 489. Fafciculus ( $47 \mathrm{I})$.

III) 490. SPICA $(464)$.

a. 491. Simplex, continua indivifa,

492. Compofita; pluribus fpicillis pedunculo inficentibus:

493. Glomerata, fpicillis varie congefta.

b. 494. Ovanta (160).

495. Ventivicofa, a lateribus gibba, (256).

496. Cylindrica, teretiufcula.

497. Interrupta, fpicis minoribus alternis diftantibus.

c. 498. Imbricata (1 19 ).

499. Articulata (83).

550. Ramofa, varie dirifa.

50:. Linearis $\left(169^{\circ}\right)$.

502. Ciliata (196).

5०3. Foliacen, folis intertingta.

504 . Comofa, terminata foliolis.

IV) 505. CORYMBUS (467).

506. Simplex, dum finguli flores pedunculis pro. priis in?ruuntur. 


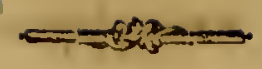

507. Compofitus, dum finguli flores pedicellis elevanrur, pedunculis communibus infidentibus.

V) 508. THYRSUS $(470)$.

509. Nudus, oppofitus $(510)$.

5 ro. Foliatus, (58.) foliis veftitus.

VI) 5 I1. RACEMUS, (468).

a. 512. Simplex, indivilus.

513. Compofitus, divilus in plures.

b. 514. Unilateralis, flores omnes ad alterum latus inferti.

515. Secundus, flores omnes ad alterum latus flexi.

516. Pedatus ( $\approx 81)$.

517. Gonjugatus $(278)$.

c. 5 18. Erectus (129).

5 19. Laxus (33).

520. Dependens (140):

d. 521 . Nudus (488).

522. Foliatus ( 38 ).

VII) 523. PANICUIA, (469).

Trunci Aructura, (pag. $164-167$.

F. 524. FRUCTIFI $\dot{C} A T I O$, vegetabilium pars tem. poraria generationi dicata.

525. Simplex, paucis foribis conftans.

526. Compofita, pluribus fofculis confuentibus.

I) 52\%. CALYX, Cortex plantae in fruetificatione praefens.

a. 528. PERIANTHIUM, calyx "fructificationi contiguus.

529. Fructificationis famina germenque includens.

530. Floris . ftamina absque germide continens. 
531. Fructus, Germen absque ftaminibus continens.

b. 532: P R OPRIUM, quemlibet florem refpiciens.

a. PARTIBUS.

533. Mrnoplyyllum, unico folio abfolutum.

537. Pulyphyltum, pluribus foliis conftans.

Dipliyilum, Triphyllum, Tetraphyllum.

b. I, ACINIIS.

535. 2 - 5 fidum (185).

$536.2-5$ partitum (186).

537. Integrum ( $17 \mathrm{I}$ ).

c. FIGU RA.

538. Tubuilofum (262).

539. Patens (r33).

540. Reflexum, partibus retrorfum fiexis.

$54 \mathrm{I}$. Inflatum, inftar veficae cavuin.

542. Globofum, ad globi figuram accedens.

5+3. Clavatum (300).

544. Erectum, (1 29).

d. PROPORTIONE.

$5+5$. Abbreviatum, longitudinem tnbi non ad. tingéns.

546. Longum (309).

547. Longitudine tubi, Corollae.

e. AP ICE.

548. Obtufum (204):

54.9. Acutzm (2 10).

550. Spinofum (75).

$55 \mathrm{I}$. Aculeatum (244).

552. Acuminatum (2 10).

553. Unico denticulo truncatum.

f. AEQUAL ITATE.

554. Aequale, Laciniis ejusdem magnitudinis et altitudinis.

555. Inaequale, Laciniis qubusdam minoribus. 
556. Alternis brevioribus.

55?. Lubuatum, Lsciniis irregularibus in duo labia hiantibus.

g. MARGINE.

558. Integerrimum (193).

559. Serratum (195).

560. Ciliatum (196).

h. SUPERFICIE Foliorum ( $214-253$.)

i. S ITU, ratione Germinis.

561. Superum, cui Germen fub receptaculo.

562. Inferum, cui germen fupra receptaculum.

k. DURATIO NE.

563. Cadlcum, ad primam explicationem foris decidens.

564. Decialuum, uns cum corolla decidens.

565. Perfigtens, non nifi maturo fruetu cafurum.

c. COMMUNE, plures flores congregatos continens. 566. Imbricatum, fquamis variis fuperimpofitis. 567. Squarrofum, fquamis undique divaricatis. 568. Turbinatum, obverle conicum.

569. Calyculatum, calyce quafi alio minore ca. lyce ad bafin cineto.

d. 570. IN V O L U C R U M, calyx a flore remotus.

a. 571 . Univerfale, umbellae univerfali fubjęum.

572. Partiale, umbellae partiali fubiectum.

573. Proprium, cuilibet fori lubjętum.

b. 574. Monophyllum.

575. Polyphyilum, et quidem pro numero fo. liorum, diphyllum, triphyllum etc.

e. 576. GLUMA, calyxi graminis, valvis ample. xantibus.

a. 577. Unifura, unicum forem ampleatens. 578. Bi-Multifiora, plures flores inciudens. 
6. 579. Univalvis, unica conftans fquamạ. 580. Bivalvis, duabus conftans fquamis.

531 . Multivalvis, pluribus quan duabus fquamis.

c. 582. Colorata (218).

583. Glabia ( 2 is).

584. Hifirida (243).

f. 585 . A R I S T $A$, mucro fubulatus glumae infidens.

a. 586. Mutica, mucro apice fubulato deftitutus.

587. Terminalis, apici glumna affixa.

588. Dorfalis, lateri exteriori grlumae impofita.'

6. 589 . Recta, perpendiculariter exiens.

590. Tortilis, flexa funis inftar.

591. Geiniculata (75).

592. Recurvata, $(138)$.

g. 593. A M EN TUM (465).

59 4. Squtamofum.

595. Nudum.

h. 596. S Р А т н A, Calyx longitudinaliter ruptus.

597. Univalvis, uno latere dehifcens.

598. Dimidiata, latere tantum inferiore fru. Eificationem obveftiens.

599. Bivalvis, duobus lateribus dehifens.

i. 600. Calyptra, Calyx Musci, cucullatus antherae fuperimpofitus.

$60 \mathrm{I}$. Rccha, undique aequalis.

602. Obliqua, ad aliquod latus inflexa.

k. 603. Vo IVA, Calyx FuxG I membranaceus,

604. Approximata, ad capitulum accedens. 605. Remotifima, a capitulo fpatio recedens.

II) 606. COROLLA, Iaber plantae in fore pracfens. a. 607. PETAIUM, pars corollae in plures divita. a. PARTES.

608. Tulus, Corollae monopetalae pars inferior. 
609. Unguis, Corollae polypetalae pars inferior receptaculo affixa.

610. Limbus, Corollae monopetalae pars fupe. rior dilatata.

611. Lamina, Curollae polypetalae pars fupe. rior patula.

b. PETALA.

612. Monopetala.

6I3. Di - Polypetala.

c. LA C I I AE, praecipue in Monopetalis, raro in Polypetalis. $2-5$ lainiuta.

d. AEQUA I I T $\triangle$ T E.

6 I 4. Aequalis, partibus corollae, figura, mazni. tudine et proportione aequalibus.

615. Regularis, aequalis figura, magnitudine et proportione partium.

616. Irregularis, Limbi partibus figura, magnitudine et proportione partium diverfa.

6I?. Inaequalis, partibus non magnitudine fed proportione refpondentibus.

e. FIGURA.

6 I 8. Globoja, globum referens $(5+2)$.

6I9. Campanuslata, ventricofa (495.) sbsque tubo.

620. Infundibuliformis, Conica, tubo impofita. 621. Hypocrateriformis, plana, tubo impolita. 622. Rotata, plana, nulli tubo inpofita. 623. Cyathiformis, tubo fuperne parum diatato. 624. Urceolata, fubglobofa, gibba, apice aperta. 625. Ringens, irregularis in duo Labia hians. - 626. Galea Ringenitis, Labium fuperius. Lsbium (fimpliciter) pro labio inferiore floris ringentis non raro finitur. 
627. Faux, hiatus inter laciniss corollae, ubi rubus terminatur. (in monopetalis.)

628. Claufa, Fauce, fquarnulis conniventibus uosvexis in fornicem, obturata, f. fornicata.

629. Coarctata, anguftior tubo.

630. Coronata, prominentiis $f_{0}$ tuberculis ca arêsta.

631. Nuda, aequalis vel amplior tubo f. pervia.

632. Rictus, eft hiatus inter duo labia.

633. Pevjonata, ringens $(625)$ fed inter labia palato claufa.

634. Cruciata, petalis quatuor aequalibus patens.

635. Concava $(248)$.

636. Patens $(133)$ ad angulum acutum Laminis unguibus infiftentitius.

637. Papilionacea, irregularis, petalo inferiore cymbifnrmi (carina) fuperiore adfcendente (Vexillum), lateribus folitariis (Alae).

638. Rofacea, petalis concavis annulatim difpofitis.

639. Undulata (253).

640 . Plicata (251).

64i. Revoluta (139).

642 . Torta, flexa in alterum latus,

$f$. MARGINE.

643. Crenata (194).

647. Serrata (19,5).

645. Ciliata (196).

g. SUPERFICIE.

6.46. Villofa $(235)$.

647. Tomentofa (237).

678. Sericea (238).

649. Pilofia (2a1.) etc. etc. Criffata, Imber.

bis, Burbata, (240).

h. P R 0 - 
h. PROPOKTIONE.

6:5. Loni ifma, calyce aliquaties longior.

651. Breviffima, longitudineın calycis non ad. tingens.

i. Si T U.

652. Supera $(56 \mathrm{I})$.

653. Infera $(562)$.

$k$ DURATIONE.

654. Caduca, perfiftens tantum ad explicationem floris, et tum decidens.

655 Decidua, cum floris cafu defluens.

65 f. Perjittens, permanens usque ad maturitat in ficctus.

657. Muriefcens, perfiftens, at contabefccns.

l. COMPOSITIONE.

658. Comprfita, pluribus conftans flofculis intra commune perianthium, fupra receptacu. lum corrmune.

659. Ligulata, corollulis flofculorum omnibus planis veríus exterius latus.

660. Tubuloja, corollulis flolculorum omnibus tubulofis fubaequalibus.

661. Rudivita, corollulis difci tubulofis, ambitus vero ligulatis difformibus.

m. COLORE.

Albu, purpureo, vinlaceo, cyanco, viridi, luteo, aurantio, coccineo, nigro, fufco, et eorum fpeciebus: (candido, ochroleuco); (hy/gino, hyacinthino); (ianthino, amethitino); (caeruleo, fupphivino); (glauco, prajins); (favo, croce.); (fulvo, flumeo); rubro, miniaio); (arro. fulicinojo); (Jpadicen, ochraceo); et ex eorum commixtione ortae COMM!SSU. R A E. Ex athoer purpurco refeo. Ex viridi et purpureo olivaceo ete.

h. 662 . 
b. 662. NECTARIUM, pars mellifera fori propria. a. 663. Proprium, a petalis et ceteris partibus diftineta.

664. Calcaratum, in tubum incurvum apice clauium definens.

655. Singularc, ftructura a reliquis foris parii. bus aliena.

666. Coronans, formans coronam foliaceam in corolla

6. 667. Petalinum, Petalis infertum.

668. Calycinum, Calyci infertum.

669. Stamineum, vel Antheris vel Filamentis in. fertum.

670. Piftillaceum, Germini infertum.

67 I. Receptaculaceum, Receptaculo infertum.

III) 672. STAMEN, Vifcus pro Pollinis praeparatione.

a. 673. FI I A I E T U M, pars elevans adnetensque Antheram (organuın mafculum genitale).

a. Numero, ab I - Ið0o, unde Claffes Sy. ftematis.

b. FIGURA.

67 +. Capillave, tenuiffima craftitie capilli.

675. Nlarum, para!lela, fuperficie acquabili $(246)$.

676. Cuneiforme (164).

677 . Spirale, linea fpirali adfceudens.

678. Subulatum (269).

679. Emarginatum (205).

680 Reflexum (106).

681. Laciniatum ( 191 ) laciniis 2. 3. 9.

682. Dentatum (197) denticulis.

683. Mutilatum, rudimento tantum filamenti.

68 . Caftratuin, anthcran! nullam vel fierilem clevans. 


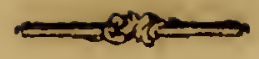

c. INS BRTIO N F.

685. Calyci oppofita, i. $\epsilon$. foliolis $r$. fegrnentis calycis.

686. - - alterna.

687. Corollae inferta (Corcllina).

688. Calyci inferta (Calycina).

689. Receptaculo inferta (Receptaculacea).

690. Nectario inferta (Nestarina).,

691. Stylo injerta (Gynandra).

d. PROPORTIONE.

6y2. Aequalia, eandem fervantia lorigitudinem.

693. Inaequalia, aliquot majoribus vel minoribus.

694. Connata, in unum corpus coslita.

695. Longiffma, corollam longitudine excedentes.

696. Brevifima, corolla multo breviora.

697. Longitudine Corollae, corollam longitudine exaequantes.

698. Longitudine Calycis.

e. SUPERFICIE et STRUCTURA.

699. Hirfutum f. Villojum (2 36), Pilofum (241). 700. Nectariferum (662), Membranaceum (301).

f. DIRECTIONE.

701. Ericlum (129).

702. Patens (133), Patentiufculum:

703. Arcustum, in arcum fiexum cum caeteris.

704. Connivens, apice approximante caeteris.

705. Reflexum (106).

706. Declinatum (36).

707. Inflexum (136).

7c8. Flarcidium (436).

709. Afjurgens (135).

7 10. Adjecridens (35).

711. Recurvum (138) (389).

7 12. Incurvum (3\%) (388). etc. 
b. 7 I 3. A N I E RA, pars floris gravida polline, quod inatura dimittit.

a. NU M E O, relatione ad filamenta.

714. Unica in fingulo filamento, Simplex.

- in tribus.

- in quinque.

7 15. Duae in fingulo filamento.

716. Tres in fingulo filamento.

717. Quinque in fingulo filamento.

- in tribus.

b. FIGURA.

7 I 8. Oblonga ( 162 ).

719. Globoja (485).

720. Sigittata (179).

721. Angulata (53), Quadrangula.

722. Cornuta, forma Cornuum, bicornis.

723. Linearis (169).

724. Acuta (209), Acutiufcula.

725. Cordata (176).

726. Ovata (160).

727 . Haftats (180).

728. Biloba (184).

729. Reniformis (177).

730. Bifida (185).

731. Ripartita (186).

732. livtingda (166).

733. Aviffatit, apice in ariftam definens.

734. In fetam definens.

735. Rofisata, delinens in roftrum filiforme.

736. Truncata (208).

737. Obtuja (204).

738 . Emarginuta $(205)$.

739. Acuminata (210).

740. Furat $(300)$, divifa apice divergente, 
c. DIRECTIONE.

741. Erecta (30).

742. Rigida (131).

743. Patens (133).

744. Afurgens (1 35).

745. Inflexa $(136)$.

746. Nistans (38).

747. Declinata (.6).

748. Pendula (438).

749. Incuma (388).

750. Connizens (?०4).

75 r. Spiraliter contorta.

d. INSERTIONE.

752. Sefjilis. (150).

753. Verfatilis, incumbens, fed non rigida.

754. Adnata (I51).

755. Diftinctae, non inter fe cohaerentes.

756. Connatae, in unum plures concretae.

757. Cylinaraceae in cylindrum $f$ tubum aequa. lem coalitae.

758. Tubulatae, in tubum coalitae.

759. Concatenatae, in annulum.

760. Cohaerentes bafi, apice etc. Contingentes.

761. Incumbens, medio Filamento impolita. Lateralis, toto latere conncxa filanento.

c. SUBSTANTA.

762. Membranacea (254).

763. Depreffa (258), lirifuta (236).

764. Comprefja (25\%).

765. Convexa (249).

766. Plana (246).

767. Sulcata (226.) transverfim, longitudinaliter.

768. Subulata (269).

769. Bilamellata, menbranacea geminatim.

f. MEN. 
f. MENSURA.

770. Filamentis brevior f. longior.

77. Coralla brevior $\Upsilon$ longior.

772 . Longitudine corollae, filamenti etc.

773. Aequalcs, ejusdem cum caeteris magnitudinis.

774. Inaequalis, diverfae magnitudinis.

775. Longiffina, multo longior quam filamenta 7:6. Brevs/fima, multo brevior filamentis.

g. LoCUs.

777. Tecta, Squamula fornicis in afperifoliis velata.

7.8. Inclusa, intra faucem fita.

779. Nuda, non tecta, nec inclufa.

j2. LOCUII et APERTURA.

780. Unilocularis, Bilocularis, etc. $(908)$.

781 . Bivalvis (580).

782. Didjma, Capfula duobus nodis extus gibba (9 10).

783. Sterilis, nullo polline foeta.

784. Deflorata, polline exploío ante evolutio: nem fioris.

785. Foecunda, polline foeta.

786. Apice, Latere, Dehilcens.'

i. S I Tus, in Filamentis apice, latere, bafi ; in Co. rolla, Nectario, Piftillo, receptaculo.

787. Pollen, puivis floris, humore rumpendus, atemosque elafticos ejaculans. (genitura plantarum) Globus echinatus, perforatus, didymus, rotatus, dentatus; angulatus, reniformis. Philyra convoluta.

IV) 788. PISTILLUM, Vifcus fructui adhaerens, pro pollinis receptione, (organum genitale foemineum). 
a. 799. GER MEN, rudimentum fructus immatưri in flore.

a. NUMERO, I - 5 plura.

b. FIGUR $\Lambda$.

790. Subrotundum (1 58).

791. Ovatum (160).

792. Oblongum (162).

793. Turbinatum (568).

794. Conicum, forma coni.

795. Lineare ( 169$)$.

796. Cordatum (176), obcordatum.

797. Globofum (485).

798. Fiffum (183), Bifidum, 3fidum, 4fidum (185).

799. Partitum ( I 86), 3partituin, 4partitum etc. 800. Angulatum (53), Tetragonum (54). 801. Didymum, capfula 2 bus nodis cxtus gib.

ba (910).

802. Compreffum (259).

803. Acutum (209).

804: Rofriatum (735).

805. Subulatum (269).

c. SUPERFICIE.

8o6. Scabrum (242).

807. Villofim (236).

808. Imbricatum (61).

d. L o c o.

809. Superum, corolla inclufun.

810. Inferum, infra corollam politum.

c. INSERTIONE.

SIr. Seffile (1 50).

812. Pedicellatum, pedicello infiftens.

813. Sctac infidens.

$$
\mathrm{N}_{4} \quad \text { f. MEN. }
$$


f. MENSURA.

8:4. Minimum, ratione corollae.

815. Longitudine ftaminum, calycis, Neetarii.

b. 816. S тYLUS, pars piftilli elevans Stigma a Gurmine.

a. NUMERO, - 12 plures, uride Òrdines Syftematis. -

b. PROPORTIONE.

817. Longsfin:us, refpectu faminum (310).

818 Bveviffimis (306).

819. Longitudine faminum.

820 Craijitie Ptaninum.

82 I. Crafjus, tenusis refpectu ftaminum.

c. D I $V I \subseteq I O N E$.

822. Simplex, Bifidus, Trifidus, 4 fidus, sfi-

$$
\text { dus ( } 185) \text {. }
$$

823. Dichotomus (85), 4partitus (186).

d FIGURA.

824. Cylindricus f. teres (49) et tubulofus.

825." Filiformis (449).

826. Capillaris (674).

827. Apice incrafjuto $(452)$.

828. Subulatus (269).

829. Alutus (299).

830. Tetragonus $(5+4)$.

- 831. Enfiformis (268).

832. Pubefcens. pube tectus.

833. Villojiss $(236)$.

e. SITU et D, TRECTIONE ftaminum ( $70 \mathrm{I}$ - 7 (2).

1) Erectus, patens, arcuatus, connivens, reflexus, declinatus, inflexus, fluccidus, affurgens, adficendens, recurvus, incurvus, Spiralis etc.

2) In 
2) In apice germinis.

Supra infraque Germen.

Ad latus germinis, in lcofandris polyzynae.

f. DURATIONE.

83 .4. Peryiftens, ad maturitatem fruetus permanens.

835. Deciduus, poft efflorefcentiam cafurus.

c. 836. S r IG MA, fummitas piftilli madida humore.

a. Nu MEko. Unicum, Duo, Tria, Quatuor,

Quinque etc.

b. DIVISION E.

837. Simplex (82).

838. Fiffum (183), Bifidum, Trifidum, multifidum (185).

839. Partitum (186), 2 - 6 partitum.

870. Lobatum (184), Bilobum etc.

c. FIGURA.

84r. Capitatum, forma ad globuin accedente.

842. Globofum (485).

843. Conium (794).

844. Ovatum (160).

845. Obtufum (204).

846. Truncatum (208).

847. Oblique depreffum ( 258$)$.

848. Emarginatum (205).

849. Planzim (246).

850. Reniforme (177).

85 1. Orbiculatum (159).

852. Peltatum (149).

8:3. Coroniforme (666).

854. Cruciforme, difpofitum in formam crucis.

855. Stellatum (128). (.374).

856. Uncinatum, apice unco inftruetum.

857. Canaliculatum $(247)$.

858. Concavum (248). 


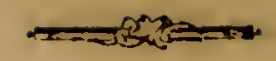

859. Umbilicatum, concavam orbiculatum.

860. Plicatusn ( 251 ).

861. Raciatum, radiis ftriarum a centro divergentibus notatum.

862. Angulatum (53).

863. Stricitum (225).

864. Plurrojum (373).

865. Pubejicns, - pube tectum.

866. Filiforme (449).

867. Capillare (674).

868. Convolutum (362).

869. Revolutum (363).

8;0. Flexum finiftrorfum,

871. Barbatum (365). (240). Imberbe, oppo. fitum illi.

d. MENSURA.

872. Longitudine Styli.

e. EXPANSIONE.

873. Fimbriato - Crifpum (253).

87 4. Foliaceum (379).

875. Cucullaturn (250).'

f. DURATIONE.

876. Perfifens, ad maturitatem fructus permanens, et augendus.

877. Marcefcens, perfiftens, at tabefcens.

V) 878. PERICARFIUM, Vifcus plantae gravidum feminibus, quae matura dimittit.

a. 879. CA PSULA, pericarpiun cavum determinate dehifcens.

a. FIG URA.

880. Turbinata (568).

88 r. Inflata (541).

882. Globofa (485).

883. Didyma (910). 
884. Scrotiformis, capfula duobus nodis elevate. 88.5. Cylindracea, forma cylindri.

886. Columnaris, cylindracea capitata.

887. Ovata (160).

888. Sulrotunda (i 58).

889. Oblonga (162).

890. Obcordata (1 ?6).

891. Obtufa (204).

892. Acuminata ( 210$)$,

893 Ventricoja, oblonga multum convexa.

894. Comprefja (259).

895. Membranacea (254).

896. Triquetra, Tetragona etc. ( 54 et 55$)$. 897. Trifulca, 4 fulcu etc. (226).

898. Triloba, 4 loba etc. ( 184 ).

849. Coronata, apice foliolis in coronam digeftis. 900. Articulata, geniculis coarctatis intercepta. 901. Coriacea, Aruetura Corii inftar. 902. Carnofa, - Carnis 903. Lignofa, - L Ligni -

6. 904. Valvula, paries, quo tegitur fruktus externe, et pro valvularum numero Caplulse funt 2valves, 3 values, twalves etc.

c. 905. Loculamentum, concameratio cava pro feminum loco.

Pro loculamentorum numero Capfulae fune 2 loculares, 3 loculares, 4 locitlares etc.

d. 906. Diffepimcntum, paries, quo frubtus interne diftinguitur in concamerationes plures.

c. 907. Bicapfularis, a numero capfularum. 908. Bilocularis, a numero Loculamentorum.

909. Tricocca, Capfula tribus nodis protuberans, intusque in 3 loculamenta divifa.

910. Didyma, Capfula 2 nodis extus gibba. 
b. 9II. S I L I Q UA, Yericarpium 2 valve' aftigans fe. mina fecundum utramque futuram.

a. FI G U R A.

9 I2. Compreffa, lateribus oppofitis proxime ad fe invicem accedentibus.

9.3. Torulofa, prominentiis hinc inda gibbis.

914. Articulata, geniculis.coaretatis intercepta.

b. DISSEPI MENTU M.

9 I5. Parallelum, latitudine, et diametro transverfali ad valvulas accedens.

9I6. Transver/um anguftius, valvulae coarctatae evadunt coniavae.'

c. A I IC.E.

917. Silicula, fubrotunda, apice ftylo inftruata, facpitis Iongitudine filiculae.

9 I 8. Siliqua (fenfu frrictiore) longifima, vix ullo Stylo notabili praedita.

c. 919. LEGUMEN, pericarpium bivalve affigens femina fecundum futuram alteram tantum.

a. FIGUKA.

920. Subrotundum (158).

921. Ovatum (160).

922. Oblongum (162).

923 . Lineare ( 169$)$.

924. Rhomberm ( 174 ).

92.5. Rhomboidale, forma rhomboidis.

926. Linulatum ( 178 ).

9) 2\%. Muticum, fine apice.

92 s. Obufum (204).

929. Lcurninatum (2 I0).

930. Spina mucronatum (212).

93 1. Venofo-reticulatum $(227)$, venis in reticulum digentis.

932. Venofo - varico Jum, venis formantibus varices. 


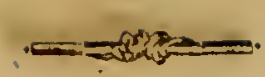

933. Striatum (225).

9.34. Villofum (236).

935. Tuberculatum, te

936. Scabrum (242).

937. I'lanum $(246)$.

938. Mesnbranaceum (25).

939. Foliaceum (254).

940. Diaphanum, transmittens radios lucis.

941. Coriaceum (901).

942. Gibbum (256).

943. Teres (49), Toretiuffulusm.

944. Cylindraceum (885).

945. Alatum (299).

946. Angulis membranaceis.

94\%. Compreffium (51).

948. Nodofum, rodis elevatum.

949. Inflatum $(5+r)$.

950. Turgidum, infiatum, fed non inftar vefrcae cavum.

95 I. Torofum, unde moniliforme prominentiis in lineám digeftis yibbam.

952. Farctum, pianum fubftantia pulyora feu carnofa.

953. Pulpofiun, pulpa plenum.

254. Carnofum, carnola lubftantia fasum.

955. Lignofum, fubftantia Ligni.

956. Subulatum (269).

957. Fulcatum, comprefum fubulatun curvatum.

958. Sefile (150).

959. Pedicellaitum (409), Pedicello elevatum.

960. Rectum, absque flexura.

961. Strictum (130).

962. Rigidum (131).

963. Ad/cendens (35), spice adfcendente.

964. Incurvatum (37).

965. Arcuatum, in 2rcuin flexum. 


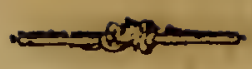

966. Inflexum $(136)$.

967. Reflexum (106).

968. Revolutum (139).

b. MENSURA.

969. Longifimum (refpeeir ad corollam).

970. Longum.

97. Maxinum.

972. Minimum.

973. Latiffrnum?.

c. STR U C T URA.

97 4. Articulatum (9 I 4).

9?5. Uniloculare, Biloculare (908).

976. Loculis intus longitudinaliter digefitis.

977. Eualve, nulla valva initruetum.

978. Bivalve (580).

979. Ifthmis interceptum, in varia Loculauenta interne transverfin diftinctum.

d. 980. FOLl ICULus, pericarpium univalve; altero latere longitudinaliter dehifcens, nec futurae femina affigens, (antea Conceptacultum) Maxime CoNTORTAE hoc habent pericarpium.

e. 98I. DRUPA, pericarpium farctum evalve, continens nucem.

992. Succulcuta, humorem continens.

983. Sitca, praecedenti oppofita.

f. 984. POMUN, pericarpium farctum evalve continens Capfulam.

A. FIGURA, oblongum, ovatum, fubrotundum, jutgglobofum.

b. Loculamenta, 3 - ylocularis, multilocularis. 
g. 985. BA C A , pericarpium farctum evalve, femina cacteroquin nuda continens.

a. 986. Nidulantia, femina, per pulpam fparfa.

6. Mono/perma, Difperma etc. pro numero feminum:

h. 987. Stro bIIUS, pericarpium ex Amento

(593.) factum, iquamis induratis.

a. FIGURA Strobili defcribcnda.

b. - - Squamarum defuricenda.

VI) 988. SEMEN, rudimention novae plantae.

a. NUM ERO. Unicum, 2 - I2: plura, plirima.

b. FI GURA:

Subroinudum, ovatuin, oblongum, fcobiforme, filiforme, turininutum, clcvatuin, angulatum, cylindraceum, triquctrum, accrofusis, teres, ellipticum, lunulatum, corcistum, reniforme, orficulatum, globofum, arilintum, planum, livic rotundatum inde planum, hine rotundatum inde angulatusn, compre/lum, gibum, arsgulis membranaceis, acumilisinim, obtufium, rofratum, erectum, marginio'ss membransscis, cmarginatum, caudatum, iarimutum, jiamatum.

c. L o C U L S, biloculare, tri. multiloculare:

d. SUPERFICIE.

Nitidum, glabrum, fcabrum, - rugofum, fricitum, filiatum, hivtum, viliofum, hifpidum, lanatum f. lana tectum, tunicatum.

e. SU B STA T IA.

Fungofum, fucculestum, carongum, fulcaseum, covisceum, baccatum, cartilizincum, oflerin.

989. Hilum, cicatrix externa feminis ab ejus. dem affixione in frustu. 
990. Corculum, primordium novae plantae in femine.

99 I. Plumulla, pars corculi fquamofa adfcendens. 992. Roftellum, pars corculi funpie'x defcendens.

993. Corcna, Calyculus fupra adhaerens, quo volitat.

994. Pappus, corona pennacea pilofave volitans. 995. Stipitatus, filo elevante et adnectente pappum et femen.

995. Capillaris, pilis indivifis.

997. Plumofus, pilis pennatis conftans.

99\%. Caudu, femen terminatum filo.

939. Himus, pubes quo animalibus adhseret. 1000. Calyculus, tegmentum feminis proprium. Iо0 $\mathrm{r}$. Nux, femen tekum epidermide oflea.

a. Iro numero Loculamentorum, unilocularis, bilocularis.

b. i202. Nucleus, femen inclufum nuce.

10013. Arillus, tunica propria exterior feminis fponte fecedens.

1004. Ala, membrana affixa femini, qua volitante diffeminatur.

1005. Propago, Semen Mufici decorticatum.

VIl) 1006. RECEPTACULUM, bafis qua partes fructificationis connectuntur.

1007. Frucifficationis, pro Flore et Fruetu commune.

voo. Filuris bafis, ubi floris partes absque gerinine adfiguntur.

I009. Fructus bafis, pro fruetu, semota a fioris receptaculo.

a. IO:O. PROPRIU M, partes unius tantum fruziticationis continens.

1011. COMMUNE, plures fores eorumque fru. ctus continens.

a. 1012. 


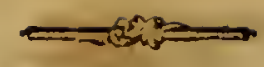

a. I о 2. Punctatum, punetis excavatis adfperfum.

1013 . Piloum (24I).

1014 . Paleaceum, lamellis innatis diftinguens flofculos.

Iôr. Nudum, nec punctatum, pilofum, paleacelumve. :

b. 1016. Planum $(246)$.

1 17 . Convexum (249).

1018 . Conicum, teres verfus apicem attenuatum. 1019. Subulatum $(269)$.

b. 1020. COM P OS I US FL OS, receptaculo dilatato integro, Flofculis feffilibus.

c. 102 I. AgGREGATUS FLos, receptaculo di- latato, flofculis fubpetiolatis.

d. I 0.22 . UM E ELLA, receptaculum ex, eodem centro elongatum in pedunculos filiformes proportionatos.

a. 1023. Simplex, pedunculis omnibus ex uno eodemque receptaculo ortis.

1024 . Compofita, omnibus pedunculis apice um. bellulas gerentibus.

1025.Univerfalis, ex pluribus fimplicibus facta compofita.

1026. Partialis f. umbellula, pars univerfalis. (Ergo compojita ex univerjali, partialique).

I027. Prolifera, umbella plusquam decompolita.

b. 1028. Concava (248).

1029 . Faftigiata (92).

1030. Cunvexa (249).

1 3 г. Erecta (129), (30).

1032. Nutans (38).

e. I033. CумA, Receptaculum ex centro eodem univerfali, pa:tielibus vero vagis, elongatum in peduncuios fantigiatos, 


\section{Bracteata $(480)$}

1035. Nudum, bracteis deftitutum (214).

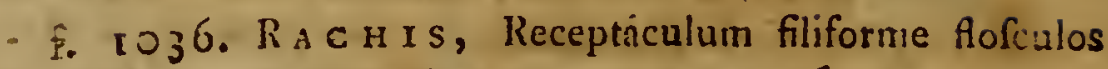
, longitudinaliter adnectens in fpicam.

3. 103\%. SPADIX, Receptaculum Palmae enatum intra fpadicem, in ramulos fructificantes divifum.
a. 1038 . Uniforus.
1039. Multiflarus.
b. 1040. Simplex.
1041. Ramojus.

\section{HABITUS.}

A. GEMMATIO, eft: Plantae compéndium fupra radicem; ańtequam evolvitur, $\int$. Hybermacushim.

I. 1042. BULBUS, hybernaculum plentae e rudimento foliorum praeteritorum.

1043. Solidus, carnofus intus indivifus.

1044. Tunicatus bulbus, tunica extra tunicam.

1045. Squamatus, fquamis imbricatus.

1046. Caulinus, cauli infidens ( 799 ).

II. 1047. GEMMA, hybernaculum plantae ex rudimen: tis foliorum futurorum.

2. ORIGINE
a. Pet:olaris feu fquamis,
b. Stipularis.
c. Corticalis feu foliis conftans.

b. CONTENTO
a. Foliaris, includens folia tantum.
b. Floralis, includens flores tantum.
c. Communis, includens folia et flores.

B. 1048. VER NATIO, foliorum difpofitio intra genmam, 104\%. Conduplicata, foliorum lateribus paraliele appro. ximatis. 
1050. Convoluta, cuculli in modum fpirali.

105I. Involuta, lateribus verfus paginam fuperiorem utrimque fpiraliter contortis.

1052. Revoluta, lateribus verfus paginain interiorem utrimque fpiraliter contortis.

1053. Imbricata, decufratim foliolis fibi invicem incum. bentibus.

1054. Equitans, marginibus conniventia fitu oppofito, ut alterum inclućat alterum.

1055. Obvoluta, pagina fuperiore lateribus approxinatis, ita ut alterum latus diftinguat alterum folium.

1056. Plicata, in plicas varias plicato folio.

1057. Circinalis, in fpirain transverfalem coarctato folio, ut apex centrum obtineat.

C. AESTIVATIO.

Convoluta.

- Imbricata.

Conduplicata.

Valvata.

Inaequivalvis.

D. TORSIO eft flexio partium verfus alterum latus.

a. Conformis. Difformis.

b. Dextra.

Sinif!ra.

Reciproca.

c. Refupinata, corollae labio fuperiors terram, inferio. re caelum fpectante.

Circinalis.

E. VARIÁTIO eft mutatio plantse a cauffa accidentali Climate, Solo, Colore, Ventis, Culturn.

Cororis.

Floris, rubri in album, caerulei in album, lutei in albuin, albi in purpureum, caernlei in tutcum, subri in caeruleum. 
Foliorum, variegatorum maculis albis.

Seminum, nigri in album.

Radicis, violacei in variegatun, etc.

MAGNITUIINIS.

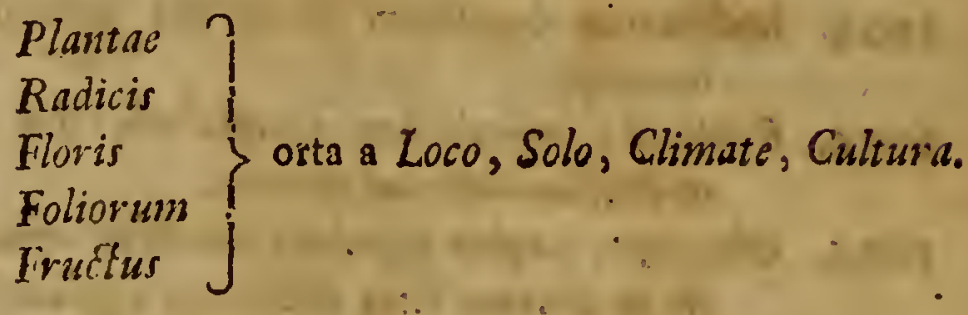

PUBESCENTIAE。

Pilorum.

Tomenti.

Setarum.

Glindularum.

Aculeorum.

Spinarum.

AETATIS.

Foliorum.

Caulis.

Corticis.

2. EXTER $\mathrm{X}$.
Gaulis. $\left\{\begin{array}{r}\text { Plicata, dum ramuli ita intertexuntur, ut fiat } \\ \text { nidus inftar Plicae Polonicae. } \\ \text { Fafciata, connatis pluribus caulibus in unum } \\ \text { latum, compreffum, fafciatum. }\end{array}\right.$ Folio- $\left\{\begin{array}{r}\text { Latifolia, dum ex plantis laciniatis et tenui- } \\ \text { foliis plura foliola et laciniae connafcuntur. } \\ \text { rum. }\end{array}\right.$ et foliola angurta.

Fulcro. $\{$ Mutica, dum Spinae, Pubes et Aculei caulem rum. $\{$ vel alias partes mutilas relinquunt. 


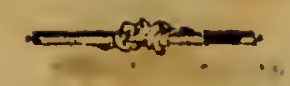

b. INTERNA.

fa. Mutilata flore, non promente corollain, fed . tamen perficiente fructum et femina.

Grandiflora, dum corollae ad infuetan excrefcuni magnitudinem.

6. Multiplicata, dum corolla duplici, triplici, qquedruplıci ferie petalorum eft aucta falvis 1 ta. minibus.

Plena, dum petala adeo atgentur, ut ftamina excludantur, vel ftamina in petala excrefcunt.

Prolifera, flore intra forem (faepe plenum, enaicente.

Frondofa, cum proliferi proles fit foliofa.

Crifluta.

c. Viripara, germinis rudimento excrefcente in folia.

Bulligera, germinis rudimento in bulbum excrefcente.

F. SPONSALIA

Mas, Flos qui Antheras folas continet.

Femina, Fos qui Stiguata fola incladit.

Hermaphrodinus, Flos qui fimul Antheras et Stigmata continet.

Androgyna, planta quae mares et feminas fimul habet. Vionoecia.

G. SEMINATIO, Difperfio feminum poft maturitatem, fapra tellurem.

Haec peragitur, vi ä̈ris ventis procellofis, aquia fluchibus et aeftu maris, decurfu fluminum, motu lacu. ftris aquae, torrentibus a pluvia fatis; praeterea animalia plurima femina difpergunt. Seminatio vero juvatur

a. SEMIN IS Cazida lanata. 
Ala membranacea.

Pappo plumoro et piloro.

Ut fic femina facilius volitare poffent, Volumine at non pondere aucto.

Homulo, acuminato curvato. Glutine vifcofo femen affigente.

Curvatione.

Ut fic femina aninalibus adhaereant et aliis locis difpergantur.

b. PER I C A R P I I

Baccatione, quae ob pulpam juvant feminationem.

Inflationse, quod ideo volumine levius factum volitat. Vifcufitate, affigente idem animalibus.

Elaficitate, qua longe propelluntur explofa feminar

H. PLACENTATIO eft difpofitio cotyledonum fub ipfa Germinatione Seminis.

2. DIC OTYIED ONES funt Plantae, quarum Semina binos cotyledones habent.

Cotyledon eft Corpus laterale feminis bibulum, cad duium.

b. ACOTYLEDONES, ubi nulli exftant cotyledo. nes. Huc et mpnocotyledones pertinent, quod non fint ejusdem cum cotyledonibus naturae, quippe non perfiftunt intra Semen.

Propagineae, Mufcorum.

Perforatae, Graminum.

Unilatcrales, Palmarum.

Reductae, Cepae.

C. POLYCOTYLEDONES. 
A. CLIMA.

\section{4.' S T A T IO.}

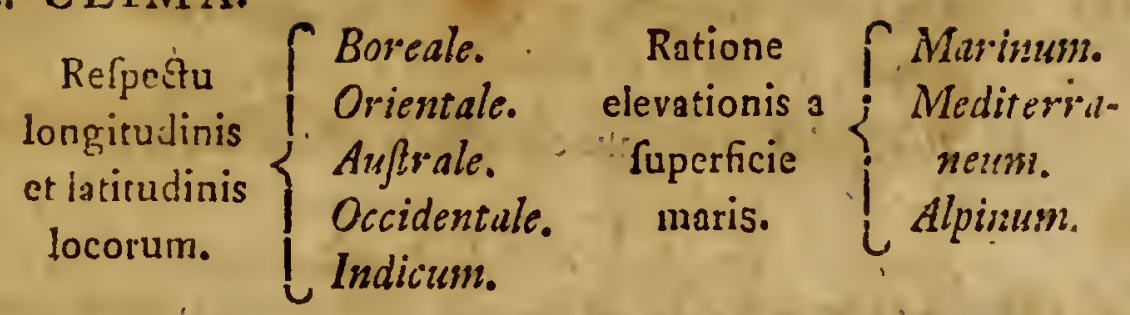

B. SOLUM.

a. Lacuftre, fundo confiftente et aqua dulci pura.

Littorale, arena fale impraegnata.

Maritimum, fundo operto aqua falfa.

Salfum, terra argillacea fale impraegnata.

h. Paluftre, humo lutofa laxa et aqua quieta plens aeftate ficca.

Inundatum, locis hyeme aqua repletis, aeftate putrida exficcandis, imbribus interdum fuffufum.

Uliginofusm, locis fpongiofis, aqua putrida repletis. Caejpitofum, paluftre, humo mixta Sphagno, tecta tuberibus, cincta aqua limofa, profunda.

c. Nemorofum, ad radices montium, lucis humo fpongiofa tectis, unbrofis, humidis, ventis minime expofitis.

Sylvaticum, umbrofum, terra fabulof fterili.

d. Pratenfe, campis depreffis et convallibus herbis lu. xuriantibus.

Campeftre, locis apricis, ficcis, afperis, ventofis. Montunum, locis elevstis, fabulofis, aridis, fterilibus, aqua carentibus.

e. Arvenfe, agris terra fubacta, ct requiets. Cultum, terra fubseta, mista fertilifima. Ruderale, juxta domos, habitacula, vias et plateas.

C. TERRA.

a. Humus, ex particulis Vegetabilium et Animalium putrefactis orta, daedala.

04

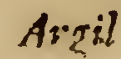


Argilla, ex terra bafí alüminis, plaftica.

Creta, ex mollufcis et vermibus, abforbens.

Arena, ex aqua et acido fpati, dura. '.

b. Parafitica, particulis collectis in arboribus, rupibus etc.

\section{TEMPUS.}

A. GERMINATIO eft tempus quo femina terrae man-

a. Diurum.

b. Menfitim.

c. Innuza.

d. Biennis.

B. FRONDESCENTIA eft tempus, quo fingulae fpecies plantarum prima folia explicant, vel fundunt.

a. VERNATIO, tempus explicationis folioruın.

Praecox.

Aequalis.

Serotina.

b. A UTUMNatro, tempus quo folia plantis de. fluunt.

Praecox.

Lenta.

Cunctins.

C. CALENDARIUM.

a. GER MINATION IS tempus, vernum, quo femina terrae mandata, in cotyledones protrudun-, tur, in quolibet peculiari Climate.

Frondefcentiae tempus, quo fingulae fpecies plantarum folia explicant.

Florejcentiae tempus, quo fingulae fpecies plantarum $\because$ flores emitrunt.

b. GROSSIFICATIONIS tempus, aefivum, quo poft florefcentiam germen excrefrit in groffum. Maturationis, tempus quó fructus crefcere definit, et maturefcere incipit. 
Mefis tempus, quo fruetus plane maturus colligi poteft.

c. EYSOLATIONIS tempus, autumnale, quo plan. tae ex folo in foluin facillime transplantari poffunt.

Defoliationis tempus, autumnale, quo plantae folia dijiciunt.

Congelationis tempus, autzmmale in horenlibus et antarcticis, quo primum aqua congelat.

d. BRUMAE eft tempus hyemsle, quo plantae omnes perennes et biennes ob frigus in hybernacula fefe recipiunt.

Glaciei, tempus hyemis adultae et vigentis.

Regclutionis tempus, quo fole redeunte a tropis frigus mitigatur et flumina regelantur.

\section{HOROLOGIUM.}

a. VIGIL I AE, determinatae horae diei, quibus plan. tae flores quotidie aperiuntur, expanduntur et clauduntur.

Meteoricae funt florum, giui minus adcurate obfervant horam explicationis; fed prius vel ferius aperiuntur pro ratione Umbrae, Aëris humidi vel ficci, preffione atmofphaerae majore aut minore. Tropicae, florum aperientium fefe inane et claudentiuin ante Vefperam, hora explicationis et reclufronis, prout dies vel incrementa vel decrementa capit.

Aequinoctiales, florum qui aperiuntur et recluduntur certa et conftanti diei hora, nec turbantur diei incremento vel decremento.

b. HORAE.

Apertionis. Reclufionis.
05
E. SO= 
E. SOMNUS eff ftatus plantarum, quo folia vel flores contrahuntur, praefertion nožtu.

Connivens.

Includerzs.

Circumsepiens.

Muniens.

- Conduplicans.

Involvens.

Divergens.

Dependens.

Invertens.

Imbricans.

F. DURATIO.

a. PI $\wedge$ NTAE

Caducae.

Senfiles.

Perpetuae.

b. FIORES

Ephiemeri.

Tridui.

Menftrui,

c. FRUCTUS

Prsecoces.

Serotini.

Annui.

\section{QUALITAS.}

A. ODOR rervos olfactorios afficit.

Ambrofiacus, Fragrans, Spirans, Aromaticus, Orgafticus. Hircofus, Nidorofus, Teter, Naufeofus, Virofus.

B. SAPOR fibrillas Linguae afficit. Aquofus, Acidus, Pingruis, Dulcis, Mucofus. Siccus, Amarus, Stypticus, Acris, Salfus.

$$
\therefore \quad \text { C. CO. }
$$


c. COLOR eft refexio radiorum folis a fuperficie plantac vel partis, variatus pro ratione fuperficiei.

a. Albus, radiis omnibus fimul reflexis.

b. Niger, radiis omnibus abforptis.

c. Purpureus, ? maxime refractus.

Violaceus, medius inter purpureum et caeruleum ex eorum mixtione.

d. Caeruleus,

e. Luteus,

Viridis, inter caeruleum et luteum.

Aurantius, medius inter luteum et rubrum.

f. Ruber, $f$ minime refractus.

Reliqui omnes colores orti cx 6 principalium commifjuris, eorumque intcrifione, faturatione, expanfione.

Princifalis. Intensus Saturatus Expansus f. Eloridus. $f$, austerus. f. Dilutus.

I) Albus, niveus, candidus, lacteus.

2) Niger, furvus, ater, fuliginofus.

3) Purpureus, hyacinthinus, hy/ginus, rofeus.

4) Coeruleus, fapplivinus, cyaneus, coeleftis.

5) Luteus, flavus, croceus, fulphureus.

6) Ruber, coccineus, fanguineus, miniatus.

Colores ex commiffuris inter principales.

(3. 4.) Violaceus, chalybatus, ianthinus, amethyftinus.

(4. 5.) Viridis, fmaragdinus, glaucus, prafinus.

(5.6.) Aurantius, flammeus, fulvus, gilvus:

(1 et 2.) Cinereus, incanus, plumbeus, lividus.

(2.3.5.) Fuffus, Spadiceus, badius, ochraceus.

Plures enumeraffe fupervacaneum; facile inveniendis vocabulis compofitis pro plerisque coloribus.

D. TA: 
D. TACTUS.

Humidus Tomentofus, Succofus, Carnofis, Vifcidus, Aridus, Lucidus, Scariofus, Memiranaceus, Scaber.

E. MENSURA.

1058. Linearis; longitudine lúnulae, ab unguis radice verlus unguem (non in pollice.)

1059. Ungiticularis, longitudine unguis. I 060 . Pollicaris, longitudine extimi articuli pollicis. iobr. Palmaris, longitudine manus transverfae. 1062. Spithamaeus, fpatium inter apicem Pollicis et Indicis extenfun.

1063. Dodrantalis, Spstium inter apicem pollicis et digiti minimi extenfi.

1064. Pedalis, a flexura cubiti ad bafin pollicis. 1065. Orgyalis, longitudine hominis.

\section{U S U S.}

A. NATURALIS.

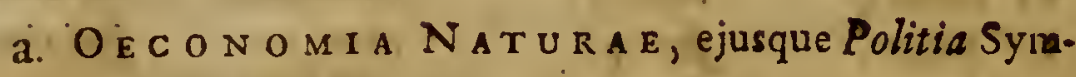
pathia vel Antipathia.

b. PA N Mammalium phytiphagorum domefticorum.

c. PAN D ORA, Infectorum.

B. ARTIFICIALIS.

a. CULINARIS: Radices, Olera, Fruetus.

b. OFFICINAIIS:

a. Simplicia, praeparata.

b. Pretium, Locus.

c. MED ICU S: Vires, Ufas. 
d. OECONOMICUS.

a. Inftrumentalis.

b. Paftoralis.

c. Tinctoria.

d. Culturae.

I. Cerealia.

2. Macellum:

3. Officinalis.

4. Arboretuin. Frutetur.

5. Pomona.

6. Pafcia.

\section{CLASSIUM CHARACTERES.}

I. Monandria, Stomen "I.?

2. Diandria, Stamina 2.

3. Triandria

4. Tetrandria - 4 .

5. Pcntandria -. 5. Aequalia omnia; in Hore

6. Hexandria - 6. . hermephrodito.

7. Heptandria - 7 .

8. Octandria - 8.

9. Enneandria - 9 .

10. Decandria - Io:

1. Dodecandria, ftamina $12-19$. in flore hermaphro. dito.

12. Leofandria, ftamina 20 communiter, faepe plura, (non receptaculo), calycis lateri interno adnata. 
13. Polyandria, ftamina 20 - 1000 , receptaculo infer$t a$ in eodern cum piftllo flore.

14. Didynamia, ftamina 4, quorum duo proxima longiora, in flore hermaphrodito Ringente.

15. Tetradynamia, ftamina 6 , quorum 4 longiora, 2 autem oppofita breviora, in flore hermaphro. dito cruciato, pericarpio filiquofo vel filicu. lofo, nectario faepe filamentis brevioribus infidente.

16. Monadelphia, ftamina filamentis in unum corpus coa. - lita, in fore pentapetalo at cohaerente filamen. tis coalitis, Receptaculo faepe columnari, feminibus reniformibus.

17. Diadelphia, ftamina 10 filamentis in duo corpora coslita, (fiimplici et novem) in flore Papilionaceo, Pericarpio Legumineo.

8. Polyadelphia, ftamina filamentis in tria vel plura corpora coalita.

19. Syngenefia, ftamina antheris (raro filamentis) in cylindrum coslitis, in floribus compofitis, flofculis aut tubulofis, aut ligulatis, sut radiatis, et in quibusdam fimplicibus; Floribus hermaphroditis cum mafculis aut femineis in eadem planta pofitis.

2. Polygamia aequalis, conftat ex multis flofculis ftaminibus et piftillis inftrustis, horum Flores funt Flofculofi.

I. Scmiflofculofi, i. e. ligulati.

2. Capitati.

3. Difcoidei. 


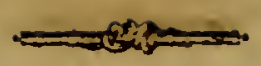

b. Polygamia fpurin, flofculis hermsphroditis difcum occupantibus, margine cincto flofculis femineis, at Ataminibus deficientibus.

a. Polygamia fuperflua, fofculis Difci hermaphroditis figinatibus infruetis et femina pro. ferentibus; fioribus quoque femineis radii feminiferis.

1. Difcoidei.

2. Semiflofoulogis.

3. Radiati.

6. Polygamia fruftranea, flofculis difci hermaphroditis Atigmatibus inftructis et feminiferis; flofculis vero radii fine ftigmate, et ideo fine femine.

c. Polygamia neceffaria, flofculis difci hermaphroditis defectu ftiginatis non feminiferis; - flofculis femineis radii perfecte feminiferis.

d. Polygamia-Jegregata, calycibus floriferis pluribus, communi calyce in unum florem aggregatis.

c. Monogamia, flofculo hermaphrodito fyngenefifta fimplici.

20. Gysandria, ftamina piftillis (non receptaculo) in fident.

21. Mokeecia, Flores mafculi et feminei in eadem planta, fed in diverfis floribus. 
22. Dioecia, Flores mafculi in diverfa planta a femineis pronafcuntur.

23. Polygamia, Flores hermaphroditi et inafculi aut feminei, in eadem fpecie.

I. Monoecia, in eadem planta.

2. Dioecia, in diverfis plantis, - cum mafculis vel femineis.

3. Trioccia, Mafculi in diverfa planta; Feminei in diverfa; Hermaphroditi quoque in diverfa.

24. Cryptogamia, Flores intra fructum, vel fingulari modo occultati; vel oculis nudis partibus -genitalibus nunquam fere difcernendis, ut in Filicibus, $\mathrm{Mu}$ i. fcis, Algis et Fungis.

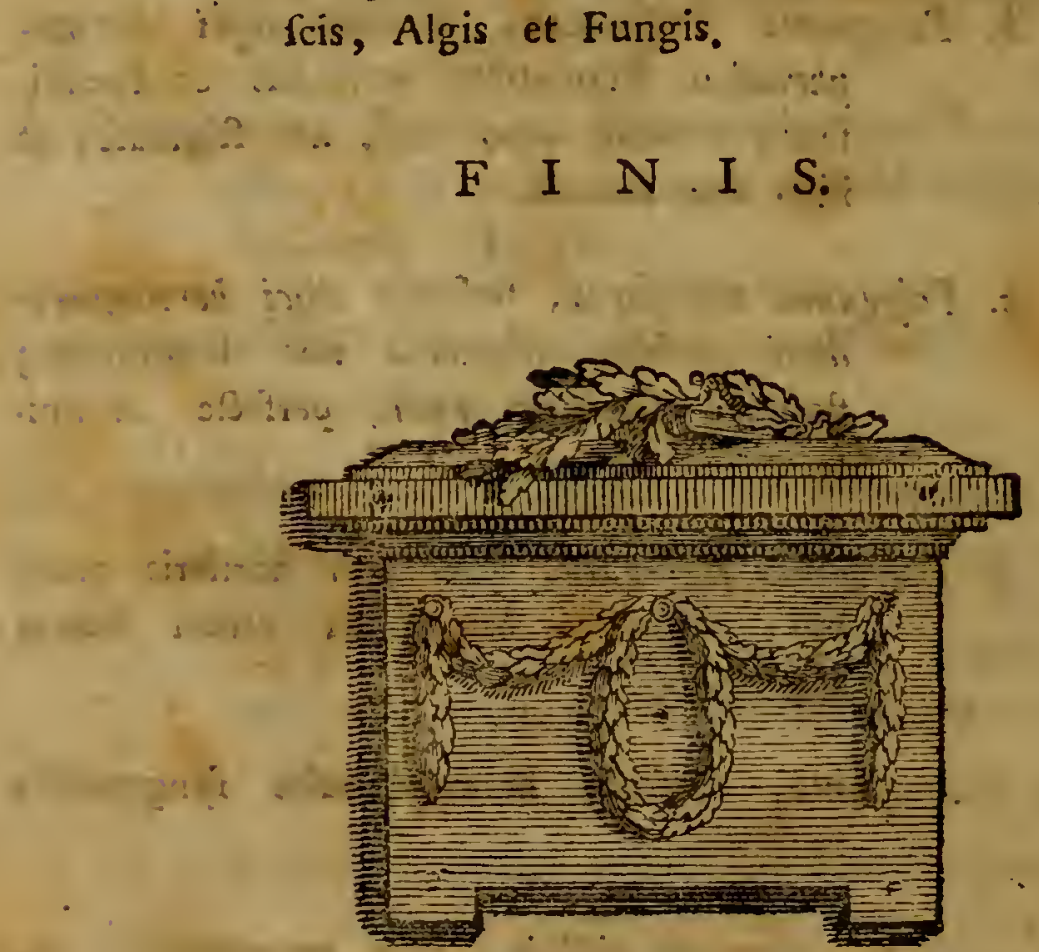


